\title{
A microphysics guide to cirrus - Part 2: Climatologies of clouds and humidity from observations
}

\author{
Martina Krämer ${ }^{1,2}$, Christian Rolf ${ }^{1}$, Nicole Spelten ${ }^{1}$, Armin Afchine ${ }^{1}$, David Fahey ${ }^{3}$, Eric Jensen ${ }^{4}$, Sergey Khaykin ${ }^{5}$, \\ Thomas Kuhn $^{6}$, Paul Lawson ${ }^{7}$, Alexey Lykov ${ }^{8}$, Laura L. Pan ${ }^{4}$, Martin Riese ${ }^{1}$, Andrew Rollins ${ }^{3}$, Fred Stroh ${ }^{1}$, \\ Troy Thornberry ${ }^{3,9}$, Veronika Wolf ${ }^{6, a}$, Sarah Woods ${ }^{7}$, Peter Spichtinger ${ }^{2}$, Johannes Quaas ${ }^{10}$, and Odran Sourdeval ${ }^{11}$ \\ ${ }^{1}$ Institute for Energy and Climate Research (IEK-7), Research Center Jülich, Jülich, Germany \\ ${ }^{2}$ Institute for Atmospheric Physics (IPA), Johannes Gutenberg University, Mainz, Germany \\ ${ }^{3}$ NOAA Chemical Sciences Laboratory (CSL), Boulder, USA \\ ${ }^{4}$ NCAR, Atmospheric Chemistry Observations and Modeling Laboratory, Boulder, USA \\ ${ }^{5}$ LATMOS/IPSL, UVSQ, Sorbonne Université, CNRS, Guyancourt, France \\ ${ }^{6}$ Luleå University of Technology, Division of Space Technology, Kiruna, Sweden \\ ${ }^{7}$ SPEC Inc., Boulder, CO, USA \\ ${ }^{8}$ Central Aerological Observatory (CAO), Department of Upper Atmospheric Layers Physics, Moscow, Russia \\ ${ }^{9}$ CIRES, University of Colorado Boulder, Boulder, USA \\ ${ }^{10}$ Leipzig Institute for Meteorology (LIM), Universität Leipzig, Leipzig, Germany \\ ${ }^{11}$ Univ. Lille, CNRS, UMR 8518 - LOA - Laboratoire d'Optique Atmosphérique, 59000 Lille, France \\ anow at: Brandenburg Univ. of Technology (BTU), Atmospheric Processes, Cottbus, Germany
}

Correspondence: Martina Krämer (m.kraemer@fz-juelich.de)

Received: 16 January 2020 - Discussion started: 27 January 2020

Revised: 27 August 2020 - Accepted: 27 August 2020 - Published: 2 November 2020

\begin{abstract}
This study presents airborne in situ and satellite remote sensing climatologies of cirrus clouds and humidity. The climatologies serve as a guide to the properties of cirrus clouds, with the new in situ database providing detailed insights into boreal midlatitudes and the tropics, while the satellite-borne data set offers a global overview.

To this end, an extensive, quality-checked data archive, the Cirrus Guide II in situ database, is created from airborne in situ measurements during 150 flights in 24 campaigns. The archive contains meteorological parameters, ice water content (IWC), ice crystal number concentration $\left(N_{\text {ice }}\right)$, ice crystal mean mass radius $\left(R_{\text {ice }}\right)$, relative humidity with respect to ice $\left(\mathrm{RH}_{\mathrm{ice}}\right)$, and water vapor mixing ratio $\left(\mathrm{H}_{2} \mathrm{O}\right)$ for each of the flights. Depending on the parameter, the database has been extended by about a factor of 5-10 compared to earlier studies.

As one result of our investigation, we show that the medians of $N_{\text {ice }}, R_{\text {ice}}$, and $\mathrm{RH}_{\text {ice }}$ have distinct patterns in the IWC- $T$ parameter space. Lookup tables of these variables as functions of IWC and $T$ can be used to improve global model
\end{abstract}

cirrus representation and remote sensing retrieval methods. Another outcome of our investigation is that across all latitudes, the thicker liquid-origin cirrus predominate at lower altitudes, while at higher altitudes the thinner in situ-origin cirrus prevail. Further, examination of the radiative characteristics of in situ-origin and liquid-origin cirrus shows that the in situ-origin cirrus only slightly warm the atmosphere, while liquid-origin cirrus have a strong cooling effect.

An important step in completing the Cirrus Guide II is the provision of the global cirrus $N_{\text {ice }}$ climatology, derived by means of the retrieval algorithm DARDAR-Nice from 10 years of cirrus remote sensing observations from satellite. The in situ measurement database has been used to evaluate and improve the satellite observations. We found that the global median $N_{\text {ice }}$ from satellite observations is almost 2 times higher than the in situ median and increases slightly with decreasing temperature. $N_{\text {ice }}$ medians of the most frequently occurring cirrus sorted by geographical regions are highest in the tropics, followed by austral and boreal midlatitudes, Antarctica, and the Arctic. Since the satellite clima- 
tologies enclose the entire spatial and temporal $N_{\text {ice }}$ occurrence, we could deduce that half of the cirrus are located in the lowest, warmest (224-242 K) cirrus layer and contain a significant amount of liquid-origin cirrus.

A specific highlight of the study is the in situ observations of cirrus and humidity in the Asian monsoon anticyclone and the comparison to the surrounding tropics. In the convectively very active Asian monsoon, peak values of $N_{\text {ice }}$ and IWC of $30 \mathrm{~cm}^{-3}$ and $1000 \mathrm{ppmv}$ are detected around the cold point tropopause (CPT). Above the CPT, ice particles that are convectively injected can locally add a significant amount of water available for exchange with the stratosphere. We found IWCs of up to 8 ppmv in the Asian monsoon in comparison to only 2 ppmv in the surrounding tropics. Also, the highest $\mathrm{RH}_{\text {ice }}$ values (120\%-150\%) inside of clouds and in clear sky are observed around and above the CPT. We attribute this to the high $\mathrm{H}_{2} \mathrm{O}$ mixing ratios (typically 3-5 ppmv) observed in the Asian monsoon compared to 1.5 to 3 ppmv found in the tropics. Above the CPT, supersaturations of $10 \%-20 \%$ are observed in regions of weak convective activity and up to about $50 \%$ in the Asian monsoon. This implies that the water available for transport into the stratosphere might be higher than the expected saturation value.

\section{Introduction}

In part 1 of the study (Krämer et al., 2016), a detailed guide to cirrus cloud formation and evolution is provided, compiled from extensive model simulations covering the broad range of atmospheric conditions and portrayed in the same way as field measurements in the ice water content-temperature (IWC- $T$ ) parameter space. The study was motivated by the continuing lack of understanding of the microphysical and radiative properties of cirrus clouds, which remains one of the greatest uncertainties in predicting the Earth's climate (IPCC, 2013). An important result is the classification of two types of cirrus clouds that differ in formation mechanisms and microphysical properties: relatively thin cirrus that form in situ below $-38^{\circ} \mathrm{C}$ (in situ-origin cirrus) and thicker cirrus originating from freezing in liquid clouds (liquid-origin cirrus) that are uplifted from warmer layers farther below.

Since then, a number of studies have been published that shed further light on the exploration of the high ice clouds. For example, some new studies, mostly based on aircraft or lidar observations, provide overviews and climatologies of cirrus cloud properties (Kienast-Sjögren et al., 2016; Petzold et al., 2017; Heymsfield et al., 2017a,b; Woods et al., 2018; Lawson et al., 2019) while others present a more specific view (Urbanek et al., 2017; Urbanek et al., 2018). Overviews of the properties of cirrus derived from global satellite remote sensing observations were also recently enhanced to include ice crystal number concentrations (Sourdeval et al., 2018a; Gryspeerdt et al., 2018; Mitchell et al., 2018). Sev- eral studies make use of the concept of in situ-origin and liquid-origin cirrus, e.g., Wernli et al. (2016) investigating the occurrence of in situ-origin and liquid-origin cirrus over the North Atlantic by analyzing ERA-Interim data; Gasparini and Lohmann (2016) simulating, amongst other things, the global distribution of liquid-origin cirrus; and Gasparini et al. (2018) presenting climatologies of in situorigin and liquid-origin cirrus as seen by the CALIPSO satellite and the ECHAM-HAM global climate model. Wolf et al. (2018) studied the microphysical properties of Arctic in situorigin and liquid-origin cirrus from balloon-borne observations, and Wolf et al. (2019) provide a cirrus parametrization demonstrating the dependence on the origin of the clouds.

The wealth of earlier (see e.g., references in Krämer et al., 2016) and new studies have provided insights into formation processes, life cycles, and appearance of cirrus. Nevertheless, there are still gaps that need to be filled, on the one hand in the understanding of ice processes and on the other in the representation of cirrus clouds in climate prediction models. Accomplishing these tasks requires large and high-quality observational databases that can serve, for example, to evaluate global models or other data sets and be used to derive parameterizations for improved representation of different types of cirrus clouds in models (see e.g., Wolf et al., 2019). In addition, such databases allow detailed studies of special types of cirrus that are still poorly understood, e.g., cirrus in fast updrafts as orographic cirrus or cirrus at the top of strong convection.

In this study, we approach these requirements as follows: we first compile a data archive of airborne in situ observations which is extended with respect to earlier versions (Schiller et al., 2008; Krämer et al., 2009; Luebke et al., 2013; Krämer et al., 2016) in terms of the size of the data set that contains all parameters needed for the desired studies, i.e., meteorological parameters, ice water content (IWC), number concentration of ice crystals $\left(N_{\text {ice }}\right)$, ice crystal mean mass radius $\left(R_{\text {ice }}^{1}\right)$, relative humidity with respect to ice $\left(\mathrm{RH}_{\mathrm{ice}}\right)$, and water vapor mixing ratio $\left(\mathrm{H}_{2} \mathrm{O}\right)$. Although airborne in situ measurements best represent detailed microphysical properties of cirrus and their environment, they are always snapshots of specific situations that are also limited by the possibilities of the flight patterns and thus not suitable to derive spatial geographical or seasonal views of cirrus clouds. For this purpose, a globally complete data set of remote sensing observations from satellite observations is the better option. Hence, as a next step of the study we use in situ climatologies to evaluate cirrus $N_{\text {ice }}$ from satellite observations and, based on this, derive a global climatology of cirrus $N_{\text {ice. }}$. From the portrayal of the two Cirrus Guide II data sets emerging from this study together with some more detailed analyses, we show that the combined evaluation of airborne in situ and satellite remote sensing observations enhances the

\footnotetext{
${ }^{1}$ Mean mass radius $R_{\text {ice }}=\left(\frac{3 \cdot \text { IWC }}{4 \pi \rho \cdot N_{\text {ice }}}\right)^{1 / 3}$ with $\rho=0.92 \mathrm{~g} \mathrm{~cm}^{-3}$.
} 
insights into cirrus properties. The in situ observations are best suitable for the investigation of specific, smaller-scale phenomena and for the evaluation of satellite observations or model simulations. Satellite-borne observations, on the other hand, allow a view of the larger-scale and seasonal properties.

The article is structured as follows: the Cirrus Guide II in situ databases and the methods used are described in Sect. 2 and Appendix A. As an overview, in Sect. 3 we portray the in situ cirrus cloud and humidity database with respect to altitude for the latitudes covered by the observations. The usefulness of the data set is shown by discussing the characteristics and occurrences of in situ-origin and liquid-origin cirrus. Section 4 first presents cirrus and humidity climatologies of the extended Cirrus Guide II in situ database in terms of temperature in comparison to the earlier studies mentioned above. Further, characteristic properties of midlatitude and tropical climatologies are presented.

In Sect. 5 we show another example of a specific analysis extracted from the Cirrus Guide II in situ database: the data set includes recent unique measurements in the tropical tropopause layer (TTL) region of the Asian monsoon anticyclone, where cirrus clouds and humidity are of special interest and observations are rare. The topic is briefly introduced before the special observations in the Asian monsoon are presented and compared with the conditions found in the surrounding tropical regions.

The last part of the study (Sect. 6) is the step to global climatology of cirrus $N_{\text {ice }}$ from satellite remote sensing observations. For this purpose, the Cirrus Guide II in situ database is used to evaluate remote sensing cirrus observations. Based on this, a global $N_{\text {ice }}$ climatology is derived, and first analyses of the global and also regional $N_{\text {ice }}$ are presented.

\section{Databases}

\subsection{In situ data set}

The observations presented here include the ice water content IWC, the ice crystal number concentration $N_{\text {ice }}$, the mean mass radius $R_{\text {ice }}$, the in-cloud and clear-sky $\mathrm{RH}_{\text {ice }}$, and clearsky water vapor volume mixing ratio $\mathrm{H}_{2} \mathrm{O}$. The complete in situ data set comprises 24 field campaigns: the 17 experiments shown in part 1 of this study (Krämer et al., 2016; the campaigns were performed between 1999 and 2014 over Europe, Africa, Seychelles, Brazil, Australia, USA, and Costa Rica), extended by inclusion of the field campaigns SPARTICUS 2010 and START 2008 over the central USA, LTU 2012-2018 over Kiruna, CONTRAST and ATTREX in 2014 and POSIDON 2016 over the tropical Pacific, and StratoClim 2017 out of Nepal.

A map of flights during the various campaigns (extended map of Cirrus Guide: Part 1) is shown in Fig. 1. In Appendix A, a summary of the field campaigns and deployed instrumentation is given in Table A1; Table A2 lists all campaigns and the measured parameters. Also, a discussion of new data evaluation methods, data quality, and data coverage is presented. An overview of each campaign is given in the Supplement. Twenty campaigns are chosen to be included in the climatologies; four campaigns (marked in Table A2), where the data volume is very low (START 2008, LTU 2012 2018 ) or very massive (SPARTICUS in 2010, CONTRAST 2014), so that their contribution to frequency occurrences is either negligible or dominant, are shown in the overview of measurements only (Supplement).

The climatologies are advanced in several aspects in comparison to the compilations of IWC by Schiller et al. (2008), Luebke et al. (2013), and Krämer et al. (2016) and $N_{\text {ice }}, R_{\text {ice }}$, and $\mathrm{RH}_{\text {ice }}$ by Krämer et al. (2009).

- The number of flights and total time in cirrus increased from 104 flights for $94 \mathrm{~h}$ (Krämer et al., 2016) to a total of 150 flights for $168 \mathrm{~h}$. The database disproportionally has extended by about a factor of 5-10 depending on the specific parameter.

- For IWC, a new data analysis method has been developed that increases the observed data volume (Appendix A2.1).

- For $N_{\text {ice }}$, observations from advanced and extended instrumentation have been added to the database; further, a new correction of the occurrence frequencies is applied (Appendix A2.2).

- The geographical spread of the observations has broadened, so that a portrayal of cirrus and humidity with respect to the midlatitude and tropical geographical regions, and also with respect to latitude and altitude, seems worthwhile.

- As in the earlier climatologies, all data underwent strict quality control.

\subsection{Satellite data set}

DARDAR-Nice provides observation-based estimates of $N_{\text {ice }}$ obtained from CALIPSO and CloudSat measurements (Sourdeval et al., 2018a). This unique approach uses the sensitivity of lidar and radar measurements to small and large particles, respectively, to constrain two parameters of a particle size distribution (PSD) parametrization, and $N_{\text {ice }}$ is subsequently estimated by direct integration of the size distribution from a minimum threshold size. For this study, we use the threshold diameter of $5 \mu \mathrm{m}$. DARDAR-Nice uses the parametrization by Delanoë et al. (2005), in which two normalization parameters (a slope parameter $N_{0}^{\star}$ and the volume-weighted diameter $D_{\mathrm{m}}$ ) are used to predict the shape of a PSD. Sourdeval et al. (2018a) have demonstrated that the method of Delanoë et al. (2005) is capable of predicting 


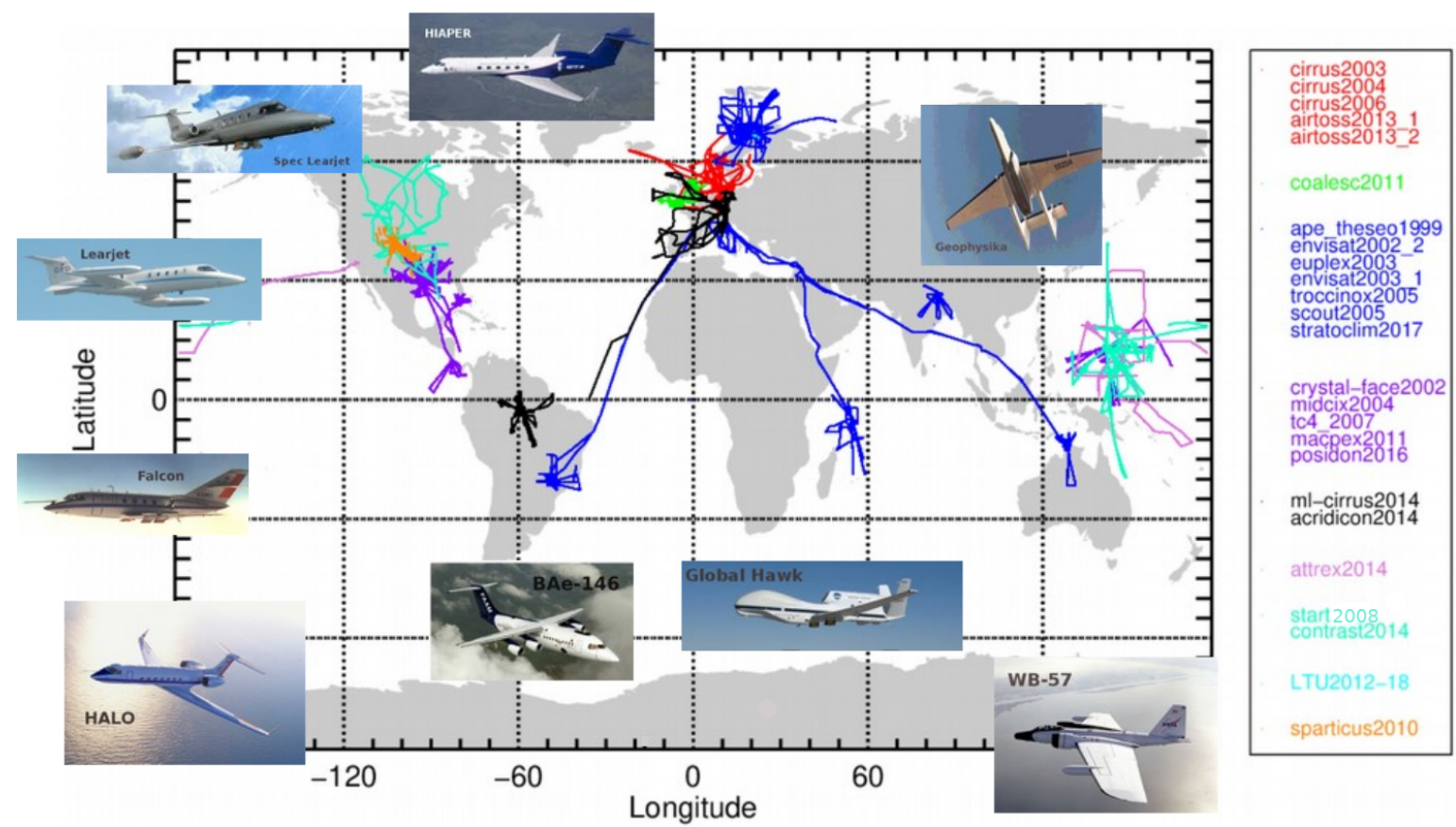

Figure 1. Aircraft flight paths during the 24 campaigns listed in Table A2. A total of 185 flights, $192 \mathrm{~h} \mathrm{IWC} \mathrm{measurements,} 90 \mathrm{~h} N_{\text {ice }}, 84 \mathrm{~h}$ $R_{\text {ice }}, 116$ and $331 \mathrm{~h} \mathrm{RH}_{\text {ice }}$ in- and outside cirrus (campaign names: red - GfD Learjet, green - BAe 146, blue - Geophysica, purple - WB-57, black - HALO, light purple - Global Hawk, cyan - GV HIAPER, orange - Spec Learjet). In comparison: Schiller et al. (2008) and Krämer et al. (2009) - 52 flights, $27 \mathrm{~h}$ IWC measurements, $8.5 \mathrm{~h} N_{\text {ice }}, 8.5 \mathrm{~h} R_{\text {ice }}, 10$ and $16 \mathrm{~h} \mathrm{RH}_{\text {ice }}$ in- and outside cirrus.

$N_{\text {ice }}$ from recent in situ campaigns, by comparing its prediction based on in situ $N_{0}^{\star}$ and $D_{\mathrm{m}}$ measurements to the actual in situ $N_{\text {ice }}$ measurements. Good agreement was found, although it was noted that the inability of the modified gamma distribution to match the frequently bimodal shape of the measured PSDs could lead to an overestimation of $N_{\text {ice }}$ in DARDAR-Nice. This problem typically occurs at temperatures above $-50{ }^{\circ} \mathrm{C}$ and is expected to be cloud-type dependent. Nevertheless, Sourdeval et al. (2018a) showed that the satellite $N_{\text {ice }}$ remains in reasonable agreement with the in situ $N_{\text {ice }}$ (within a factor of 2) from $T=-30^{\circ} \mathrm{C}$ down to $-90^{\circ} \mathrm{C}$, which should cover the entire cirrus temperature range in this study.

This evaluation of DARDAR-Nice is here repeated on the basis of five in situ campaigns archived in the Cirrus Guide II in situ database: COALESC2011, ACRIDICON2014, ATTREX2014, MLCIRRUS2014, STRATOCLIM2017. Based on the agreement between DARDAR-Nice and the in situ observations, a global $N_{\text {ice }}$ climatology is derived from 10 years of satellite observations. Regional $N_{\text {ice }}$ climatologies for the Arctic $\left(90-67.7^{\circ} \mathrm{N}\right)$, northern midlatitudes $\left(67.7-23.3^{\circ} \mathrm{N}\right)$, tropics $\left(23.3^{\circ} \mathrm{N}-23.3^{\circ} \mathrm{S}\right)$, southern midlatitudes $\left(23.3-67.7^{\circ} \mathrm{S}\right)$, and Antarctica $\left(67.7-90^{\circ} \mathrm{S}\right)$ are analyzed in more detail. The results are presented in Sect.6.

\section{Vertical distribution of cirrus and humidity from in situ observations}

As an introduction, atmospheric temperature profiles in the Arctic, at midlatitudes, and in the tropics are shown in Fig. 2, (left panel, adopted from Schiller et al., 2008). Vertical profiles inside of cirrus clouds are shown for 28 flights, using blueish colors for Arctic, greenish for midlatitude, and reddish for tropical observations. It can be seen that in the tropics, with the strongest warming of the Earth's surface by the sun, the air is much warmer at upper-tropospheric altitudes than at midlatitudes or in the Arctic. The coldest atmospheric temperatures are found at the points where the slopes of the temperature profile reverses: the cold point tropopause (CPT). This is the region where the transition from the troposphere to stratosphere occurs. Above the CPT, in the stratosphere, almost no cirrus clouds are observed because it is too dry for ice formation (Smith et al., 2001; Schiller et al., 2009). The relations between temperature and altitude and the potential temperature $\Theta$ are shown in Fig. 2 middle and right panels for the different geographical regions. $\Theta$ is often used in upper-troposphere and lower-stratosphere (UT-LS) research, since it allows a clear assignment of air parcels to the associated atmospheric layer, in contrast to the temperature, whose course reverses above the CPT. The ranges of the tropical tropopause layer (TTL) and the tropical CPT are marked by magenta lines (after Fueglistaler et al., 2009). 

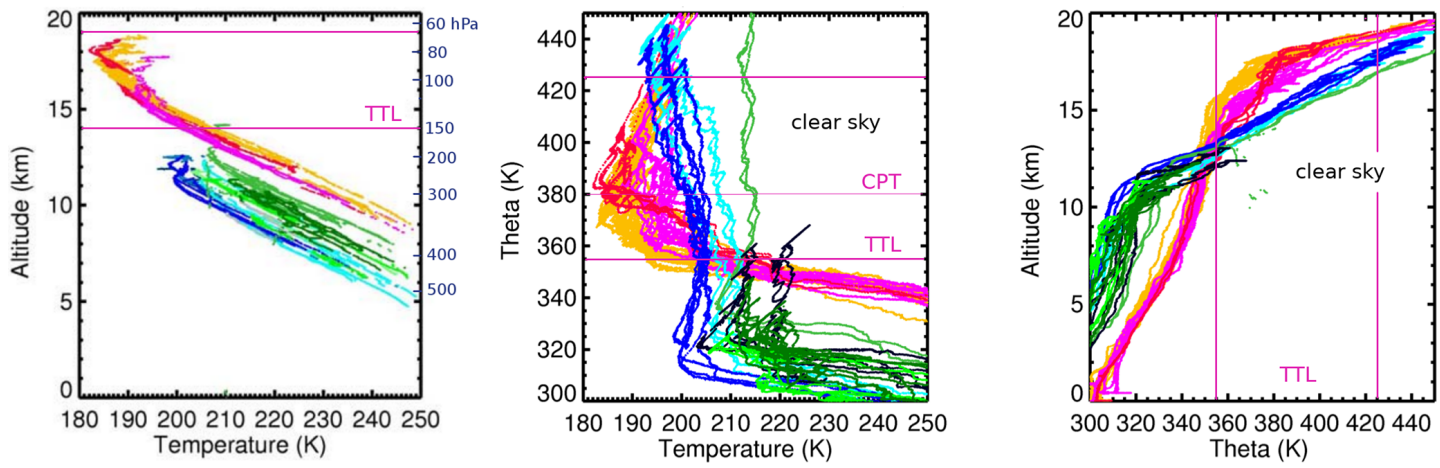

Figure 2. Left panel: temperature vs. altitude inside of cirrus clouds (adopted from Schiller et al., 2008). Middle panel: temperature vs. potential temperature $\Theta$. Right panel: clear-sky $\Theta$ vs. altitude. Plotted are 28 flights from the database, with blueish colors for Arctic, greenish colors for midlatitude, and reddish colors for tropical observations. Magenta lines: range of the TTL (tropical tropopause layer) and tropical CPT (cold point tropopause) (after Fueglistaler et al., 2009).

\subsection{Latitude-altitude distributions}

As a first application of the Cirrus Guide II data set the distribution of cirrus clouds and humidity is shown with respect to latitude and altitude in Fig. 3. Plotted are IWC (color coded by volume mixing ratio), $N_{\text {ice }}$ (color coded by concentration), $R_{\text {ice }}$ (color coded by size), in-cloud and clearsky humidity (color coded by $\mathrm{RH}_{\mathrm{ice}}$ ), and $\mathrm{H}_{2} \mathrm{O}$ (color coded by volume mixing ratio). The color codes range from yellow to blue with increasing amount of the respective parameter; note that the data points are plotted in the order of the colors from yellow to blue. The data were collected in the latitude range from about $70^{\circ}$ north to around $20^{\circ}$ south; i.e., the northern midlatitudes and the tropics are covered by the observations. The altitude range is between about 5 and $20 \mathrm{~km}$. The times of data sampling are displayed in the respective panels; a more detailed description of the database is given in Sect. 4. The way the data are presented here as individual points was chosen because the entire range of measurements is visible. Although data overlap occurs in this type of display, it is possible to identify cirrus types and microphysical processes, especially based on extreme values. As additional overview information, we have created latitude-altitude intervals ( $500 \mathrm{~m}$ altitude, $0.5^{\circ}$ latitude) and calculated the 25 th, 50th (median), and 75th percentiles for all variables. These additional altitude-latitude climatologies are shown in the Supplement (Figs. S1-S3).

Cirrus clouds are found at lower altitudes at midlatitudes and reach higher levels in the tropical region (Fig. 2). Though this structure in the measurements is influenced by the maximum or minimum height the engaged aircraft can reach, it corresponds well with the CALIPSO latitudinal height distribution of cirrus clouds, which is largely caused by the decrease in tropopause height with increasing latitude (Sassen et al., 2008).

\subsection{1 in situ-origin and liquid-origin cirrus}

Krämer et al. (2016), Luebke et al. (2016), and Wernli et al. (2016) describe two different cirrus types: (1) in situ-origin cirrus that form (by heterogeneous or homogeneous ice nucleation on ice-nucleating particles, INPs, or soluble solution aerosol particles) from water vapor directly as ice at $T<$ $235 \mathrm{~K}, \mathrm{RH}_{\mathrm{ice}}>100 \%$, and $\mathrm{RH}_{\mathrm{w}}<100 \%$ and (2) liquidorigin cirrus that evolve (also heterogeneously or homogeneously) from freezing of liquid drops in clouds at $T \gtrsim 235 \mathrm{~K}$ and $\mathrm{RH}_{\mathrm{w}} \sim 100 \%$. $^{2}$ In other words, in situ-origin cirrus are observed at the altitudes where they are formed, whereas liquid-origin cirrus are glaciated liquid clouds from further below which are lifted to the cirrus temperature region where liquid water no longer exists.

Microphysical characteristics. In the new in situ data set, containing advanced measurements and extended by several field campaigns in comparison to the earlier studies, some typical characteristics of the cirrus types and hints to ice nucleation mechanisms are visible. In the following, the cirrus types are briefly introduced using Figs. 3 and 4. The cirrus types and freezing mechanisms are summarized in Table 1.

In situ-origin cirrus can be divided in two subclasses depending on the strength of the updraft: in slow updrafts ${ }^{3}$, in situ-origin cirrus form mostly heterogeneously (Krämer et al., 2016) and are rather optically thin with lower IWCs and few but large ice crystals. We note here that in an atmosphere free of INPs, cirrus clouds forming homogeneously may have similar characteristics to heterogeneously formed cirrus, since only a small number of ice crystals nucleate homogeneously in slow updrafts (see e.g., Spreitzer et al., 2017). Hence, in this regime, the freezing process may not be relevant for determining the cirrus properties. In fast up-

\footnotetext{
${ }^{2}$ For a more detailed description of the freezing mechanisms see Vali et al. (2015), Heymsfield et al. (2017a), and references therein.

${ }^{3}$ Slow updrafts: $\lesssim 10 \mathrm{~cm} \mathrm{~s}^{-1}$ (based on simulations of Kärcher and Lohmann, 2002; Krämer et al., 2016).
} 
(a)

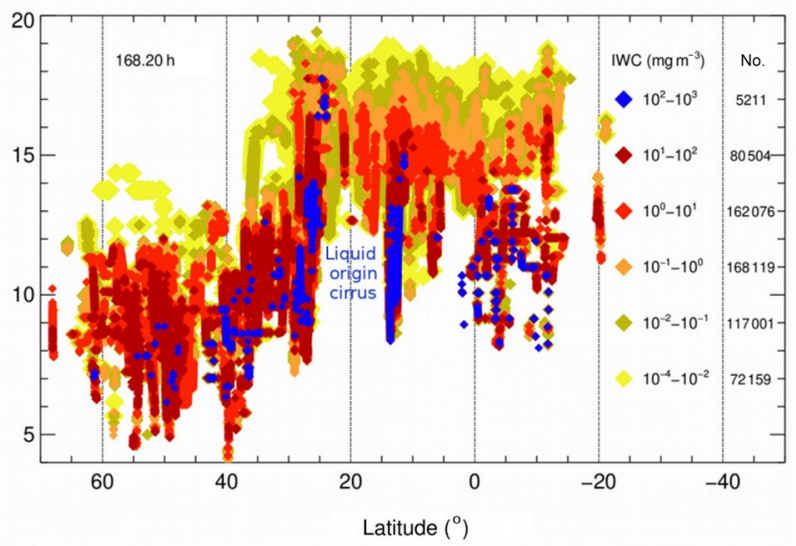

(b)

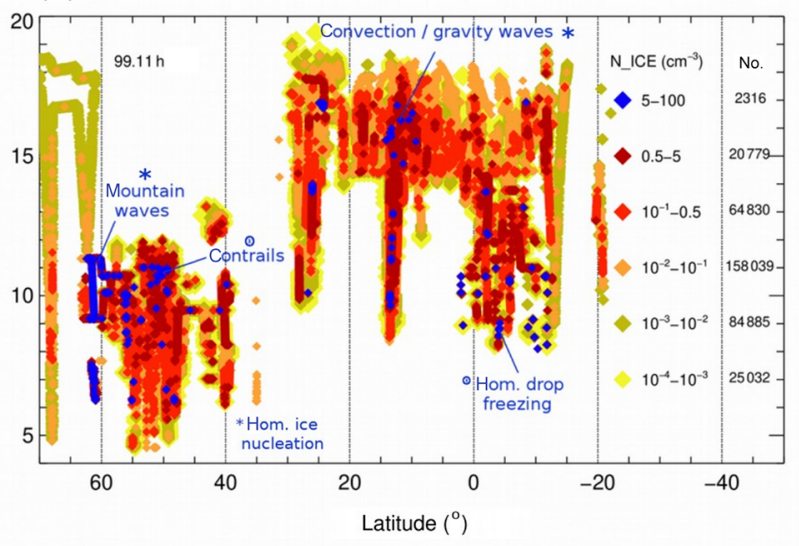

(c)

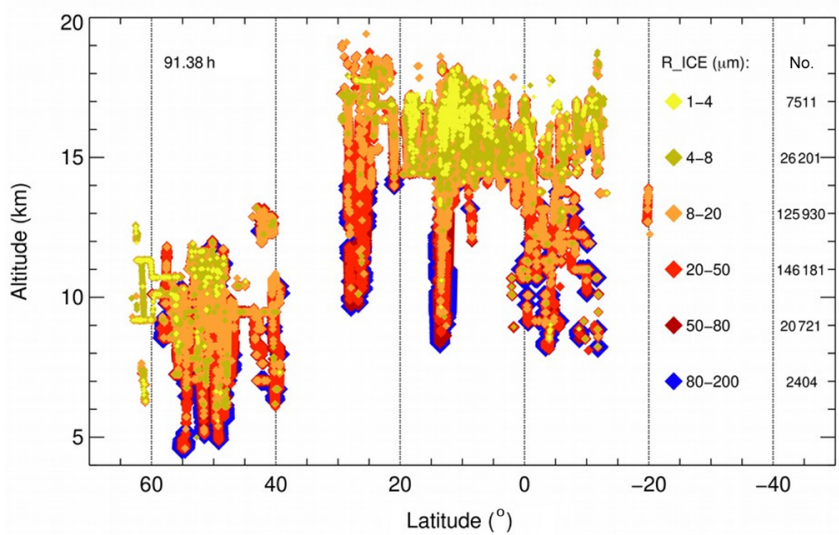

(d)

$\mathrm{RH}_{\text {ice }}$ in-cloud

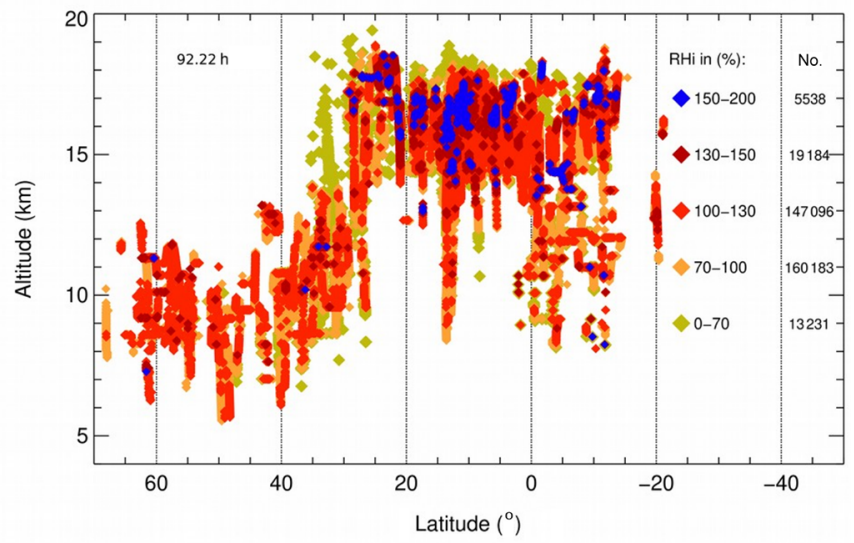

(e)

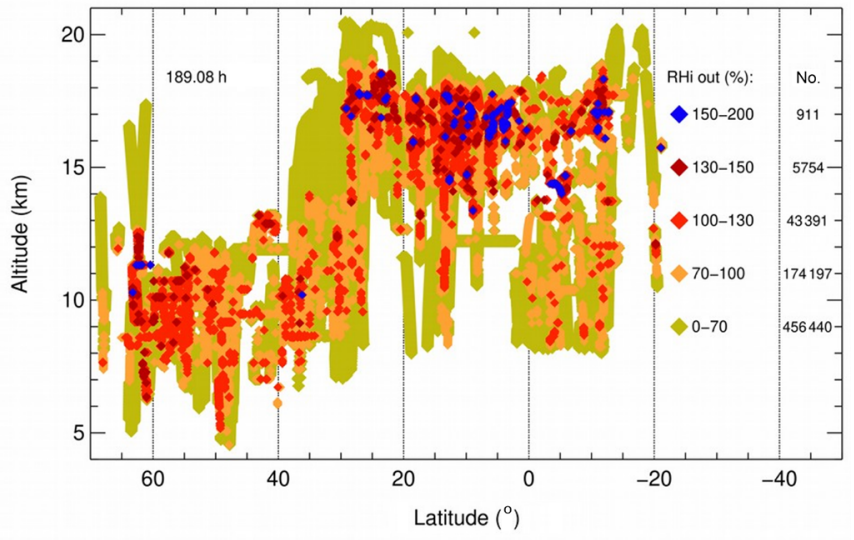

(f)

$\mathrm{H}_{2} \mathrm{O}$ clear sky

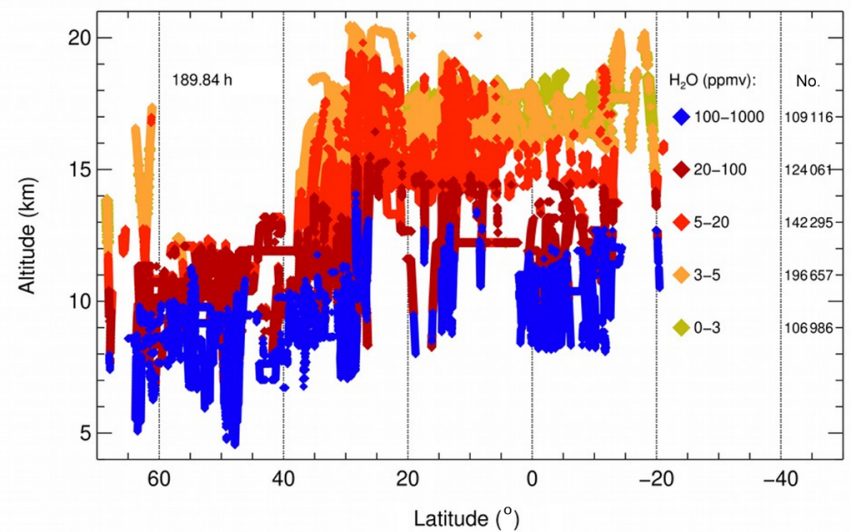

Figure 3. Cirrus cloud distribution with latitude and altitude of (left column, panels a-c) ice water content (IWC, a), ice crystal number $\left(N_{\text {ice}}\right.$, size $>3 \mu \mathrm{m}$ diameter, b), and mean mass radius $\left(R_{\text {ice }}\right.$, calculated from IWC $\left./ N_{\text {ice }}, \mathbf{c}\right)$. (Right column, panels d-f) In-cloud and clearsky relative humidity with respect to ice $\left(\mathrm{RH}_{\text {ice }}, \mathbf{d}, \mathbf{e}\right)$ and clear-sky water vapor volume mixing ratio $\left(\mathrm{H}_{2} \mathrm{O}\right.$, f). The field campaigns are listed in Table A1, and data evaluation methods and detection ranges of the parameters are described in Appendix A. The color codes range from yellow to blue with increasing amount of the respective parameter; for $R_{\text {ice }}$, the color code is reversed to indicate that high and low $N_{\text {ice }}$ values belong to small and large $R_{\text {ice }}$; note that the data points are plotted in the order of the colors from yellow to blue; frequencies of occurrence of the parameters can be seen in Fig. 7. 
Table 1. Typical characteristics of cirrus types in the initial stage.

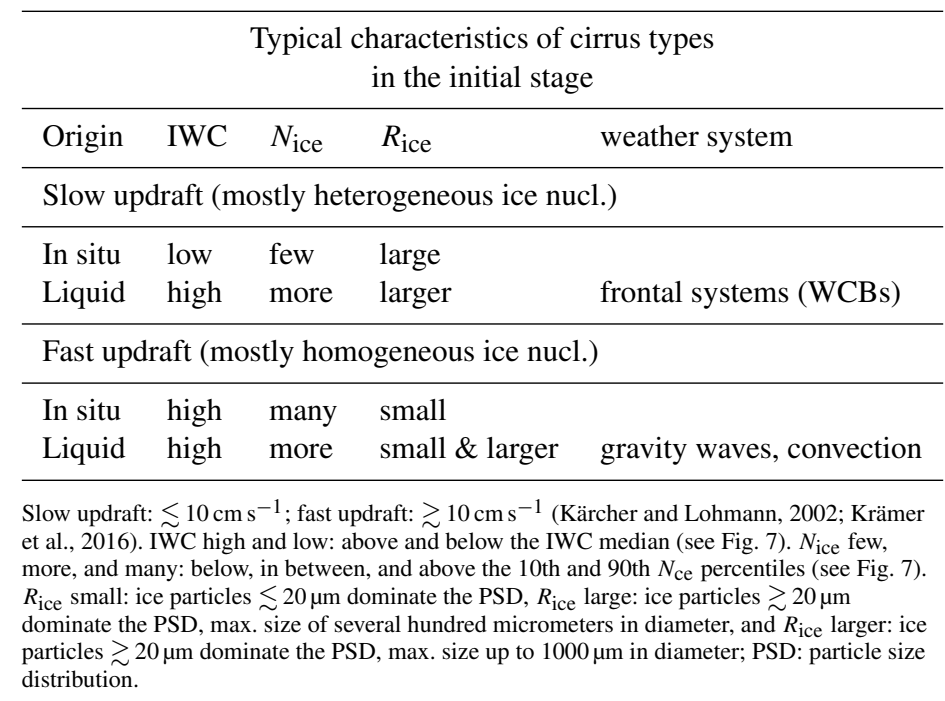

drafts ${ }^{4}$, homogeneous freezing mostly occurs regardless of the presence of INPs, since fast updrafts cause $\mathrm{RH}_{\text {ice }}$ to reach the homogeneous freezing threshold even after heterogeneous freezing. The in situ-origin cirrus that emerge in these situations are optically thicker with higher IWCs and more abundant but smaller ice crystals.

Liquid-origin cirrus stem from lower altitudes, where more water is available, so they generally consist predominantly of thicker cirrus with higher IWC, in slower updrafts together with larger ice crystals that are frozen heterogeneously at $T>235 \mathrm{~K}$. Small supercooled liquid cloud drops, which are much more numerous than heterogeneously formed $N_{\text {ice }}$, do not reach the cirrus cloud altitude (temperature $\lesssim 235 \mathrm{~K}$ ) in the slow updrafts; the clouds completely glaciate before because of the Wegener-Bergeron-Findeisen process, where liquid drops evaporate and ice crystals grow at $\mathrm{RH}_{\mathrm{w}}$ below and $\mathrm{RH}_{\mathrm{ice}}$ above $100 \%$. In fast updrafts, liquid-origin cirrus with very many small $N_{\text {ice }}$ appear. The reason is that here the supercooled liquid cloud drops can reach the altitude (temperature $\sim 235 \mathrm{~K}$ ) where they freeze homogeneously (Costa et al., 2017). This is because the high updrafts keep both $\mathrm{RH}_{\mathrm{w}}$ and $\mathrm{RH}_{\text {ice }}$ above $100 \%$, and thus the Wegener-Bergeron-Findeisen process does not take place (Korolev, 2007).

The meteorological situations where slow updraft in situorigin cirrus frequently occurs (see Krämer et al., 2016) are low- and high-pressure systems (frontal and synoptic cirrus). The warm conveyor belt (WCB) of low-pressure systems can also produce slow-updraft liquid-origin cirrus. Fast-updraft in situ-origin and liquid-origin cirrus occur in gravity waves, often orographically induced, in jet streams, mesoscale convective systems, and anvils.

\footnotetext{
${ }^{4}$ Fast updrafts: $10 \mathrm{~cm} \mathrm{~s}^{-1}-10 \mathrm{~m} \mathrm{~s}^{-1}$ (based on simulations of Kärcher and Lohmann, 2002; Krämer et al., 2016).
}

As outlined in the Cirrus Guide I (Krämer et al., 2016), to a certain extent cirrus types can be identified by their typical characteristics. This applies to the initial stage, after which the clouds lose the signature of the formation process, for example, by sedimentation: as long as an updraft prevails (corresponding to $\mathrm{RH}_{\text {ice }}>100 \%$ ), smaller ice crystals in the size range $\lesssim 20 \mu \mathrm{m}$ grow to larger sizes on a timescale of tens of minutes. The larger ice crystals sediment to lower altitudes, thus removing ice surface from the cloud volume which consequently reduces the depletion of $\mathrm{H}_{2} \mathrm{O}_{\text {gas }}$ $\left(\propto \mathrm{RH}_{\text {ice }}\right.$ ) by water vapor deposition on the ice (for more details see Spichtinger and Cziczo, 2010). The ice crystals that have fallen out of the layer deepen the cirrus extent to lower altitudes (fall streaks can extend the cirrus to several kilometers below the nucleation level; Jensen et al., 2012; Murphy, 2014), while at the same time, large ice crystals from above could sediment into the cloud volume. Altogether, the cirrus evolution is a dynamical process and the cirrus properties change in the course of a cirrus lifetime. At the final cirrus stage, i.e., when the temperature increases, the environment becomes subsaturated $\left(\mathrm{RH}_{\mathrm{ice}}<100 \%\right)$ and ice crystals sublimate, with small crystals disappearing faster than larger ones (timescales of growth and evaporation of ice crystals are shown in Kübbeler et al., 2011, their Fig. 12).

Cirrus types with the most striking features (high IWC and/or $N_{\text {ice }}$ ) are the easiest to identify. They could be liquidorigin or in situ-origin cirrus in fast updrafts or also liquidorigin cirrus in slow updrafts. This will be shown on the basis of Figs. 3 and 4.

In Fig. 4 , the relation between $N_{\text {ice }}, R_{\text {ice, }}$, and IWC is shown for $\sim 87 \mathrm{~h}$ of cirrus cloud observations. It can be nicely seen that in the cases where $N_{\text {ice }}$ is high, the ice crystals are small - because the numerous ice crystals consumed all of the available vapor, thereby suppressing further growth 


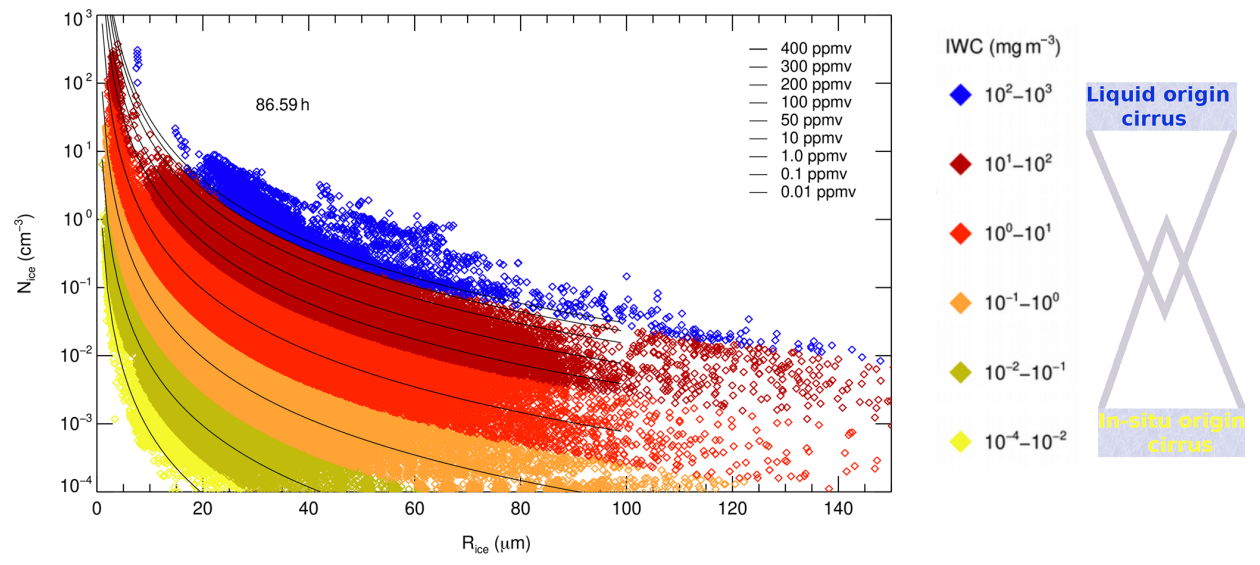

Figure 4. Relation between ice crystal concentration $N_{\text {ice }}$ and mean mass radius $R_{\text {ice }}$, color coded by the ice water content IWC in milligrams per cubic meter, from $\sim 87 \mathrm{~h}$ of cirrus cloud observations $\left(R_{\text {ice }}\right.$ is calculated by dividing IWC by $\left.N_{\text {ice }}\right)$. The thin black lines are isolines of IWC as volume mixing ratio (in the order of the legend). The scheme at the right side illustrates the partitioning of the clouds between "liquid origin" and "in situ origin": the thickest cirrus (blue points) are of liquid origin; the thinnest (yellow points) of in situ origin. As the thickness decreases, the portion of liquid-origin cirrus becomes smaller and smaller while more and more in situ-origin cirrus appear.

- while low $N_{\text {ice }}$ are related to large ice crystals for a given IWC. The IWC (in milligrams per cubic meter) is indicated by the color code and results from the combination of both

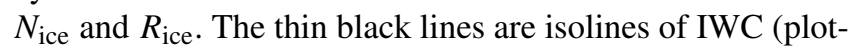
ted as volume mixing ratio, ppmv) that appear in the order shown in the legend. The symbols to the right of the figure indicate the partitioning of the clouds between liquid and in situ origin: the thickest cirrus (blue points) are of liquid origin and the thinnest (yellow points) of in situ origin. As the thickness of the cirrus decreases, the fraction contributed by liquid-origin cirrus becomes smaller and smaller while an increasing fraction is due to in situ-origin cirrus.

Most of the highest IWCs $\left(>10 \mathrm{mg} \mathrm{m}^{-3}\right.$, dark red and blue diamonds in Fig. 3a) are of liquid origin. They appear in the lower parts of the clouds; i.e., they are uplifted from farther below. A good example of this is the field campaign SPARTICUS in 2010, which is separately plotted in Fig. S7 of the Supplement (right panel). About $23 \mathrm{~h}$ of sampling in mostly liquid-origin clouds was performed over the central USA. The clouds were observed in the temperature range 210-240 K, corresponding to altitudes between 5 and $10 \mathrm{~km}$; i.e., they were rather low cirrus clouds. The IWCs are mostly high (red to blue colors) and, as shown by Muhlbauer et al. (2014), ice particles of greater than a thousand micrometers in diameter were frequently encountered, indicative of liquid-origin cirrus (see Table 1). In the tropics (Fig. 3), some blue points are also detected at high altitudes of about $17 \mathrm{~km}$ from measurements made above the Asian monsoon in strong convective updrafts (see also Sect. 5) and consist of many ice crystals $\left(0.1-10 \mathrm{~cm}^{-3}\right)$ with medium $R_{\text {ice }}(20$ $70 \mu \mathrm{m})$.

Generally, the IWC roughly shows a vertical structure of decreasing IWC with increasing altitude. This is caused on the one hand by the amount of available water that decreases with decreasing temperature and on the other hand because cirrus of liquid origin predominate in lower layers, whereas cirrus with in situ origin become more abundant at higher altitudes, i.e., colder temperatures. This is in accordance with the findings of Luebke et al. (2016), Wernli et al. (2016), and Wolf et al. (2018), where Luebke et al. (2016) and Wolf et al. (2018) experimentally investigated the two cloud types in midlatitudes and in the Arctic, respectively, while Wernli et al. (2016) analyzed 12 years of ERA-Interim data in the North Atlantic region (see also Sect. 6.2).

While IWC is an indication for the cirrus type, $N_{\text {ice }}$ values (Fig. 3b) provide a hint to the freezing mechanism, either heterogeneous or homogeneous: high ice crystal numbers $N_{\text {ice }}\left(\gtrsim 0.5 \mathrm{~cm}^{-3}\right.$, dark red and blue diamonds, Fig. 3b) are an indicator for homogeneous ice formation in fast updrafts caused by waves or convection, for both in situ-origin and liquid-origin cirrus. At midlatitudes, they are found, for example, at the tops of mountain wave clouds (the ice nucleation zone), which were observed for example behind the Norwegian mountains at around $62^{\circ}$ north. High $N_{\text {ice }}$ values have also been observed in tropical deep convection around $10^{\circ}$ north, corresponding to measurements reported by Jensen et al. (2009).

Another source of midlatitude high $N_{\text {ice }}$ is young contrails. Note however, that these high $N_{\text {ice }}$ values exist only for a short time. This is because high ice crystal numbers are associated with small ice crystal sizes (yellow diamonds in the bottom left panel; see also Fig. 4) that grow and/or evaporate quickly. At lower altitudes, $N_{\text {ice }}$ tends to be lower and the crystals are larger, because large crystals having lower concentrations sediment out from the cloud tops, and, as mentioned above, liquid-origin cirrus with characteristic large ice crystals are also common in this altitude range. In the tropics, high $N_{\text {ice }}$ values at high altitudes are induced by in situ ho- 

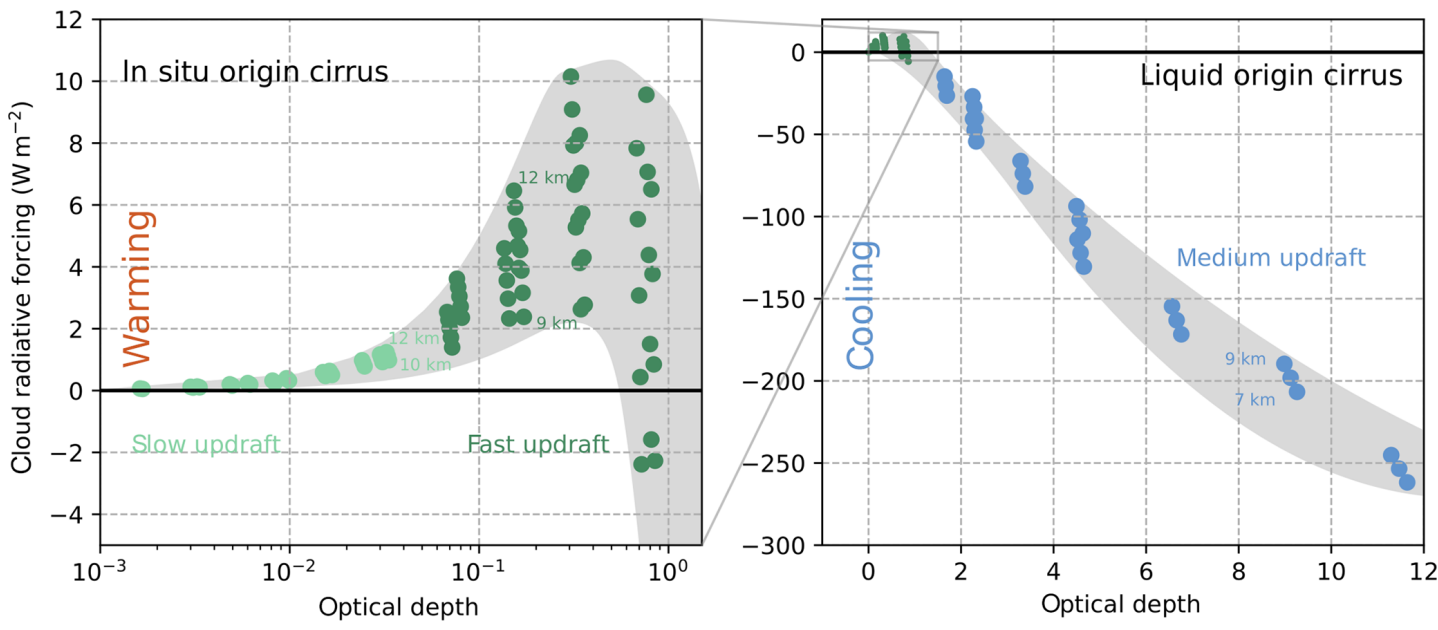

\begin{tabular}{|c|ccccc|}
\hline Cirrus origin & $\mathrm{N}_{\mathrm{ice}}\left(\mathrm{cm}^{-3}\right)$ & $\mathrm{R}_{\mathrm{ice}}(\mu \mathrm{m})$ & $\mathrm{IWC}\left(\mathrm{mg} \mathrm{m}^{-3}\right)$ & $\mathrm{z}$ tropop. $(\mathrm{km})$ & cirrus layers \\
\hline in-situ slow & $0.001-0.02$ & $15-25$ & $0.01-0.5$ & 12.5 & 3 layers: $10-12 \mathrm{~km}$ \\
in-situ fast & $0.1-5$ & $5-15$ & $0.1-7.5$ & 12.5 & 5 layers: $9-12 \mathrm{~km}$ \\
liquid & $0.05-2$ & $50-70$ & $30-375$ & 10 & 3 layers: $7-9 \mathrm{~km}$ \\
\hline
\end{tabular}

Figure 5. Simulated radiative forcing versus optical depth for exemplary in situ-origin slow- and fast-updraft cirrus (light and dark green dots) as well as liquid-origin cirrus (blue dots); the idealized scenarios are summarized in the table. Description of the idealized scenarios: a temperature profile is prescribed representative for midlatitude conditions; the surface temperature is set to $288 \mathrm{~K}$ (at $p=1000 \mathrm{hPa}, p$ exponentially decreases with height). The vertical profile of relative humidity over ice is also established, with a saturated layer of $1000 \mathrm{~m}$ thickness, constant subsaturation below the layer, and a strong decrease in humidity towards the stratosphere. A cirrus cloud with constant ice mass and number concentration is placed in the saturated layer. From the measurements (see Fig. 4), typical values of $N_{\text {ice }}, R_{\text {ice }}$ and IWC are chosen for the three cirrus types (see table above). The vertical profiles are adjusted with respect to tropopause height ( $z$ tropop.) and placement of the cirrus layers in accordance with the cirrus types. For the radiative transfer calculations, the well-known two-stream radiative transfer model for ice particles by Fu and Liou (1993), with 6 bands in the solar and 12 bands in the thermal infrared regime, is used. The simulations are realized for a geographic latitude of $\varphi=50^{\circ}$, solar surface albedo of 0.3 , infrared surface emissivity of 1 and solar constant $S=1340 \mathrm{~W} \mathrm{~m}^{-2}$; we assume equinox conditions (e.g., end of March) at local time $t=12 \mathrm{~h}$ (for these settings, we use the modified model of Joos et al., 2014). The net cloud radiative forcing (CRF) is calculated using the fluxes at the top of atmosphere in the short wave and long wave ranges in comparison with a clear-sky case.

mogeneous freezing in convection or gravity waves (see also Jensen et al., 2013a). At cloud bases, such high $N_{\text {ice }}$ values are most probably of liquid origin, initiated by homogeneous freezing of supercooled drops.

A more detailed discussion of the microphysical properties of cirrus including frequencies of occurrence of specific signatures which cannot be seen from Fig. 3 is given in Sect. 4 .

Radiative characteristics. A motivation to study cirrus clouds is to investigate the radiative properties on the basis of the findings on their microphysical properties. In the Cirrus Guide I, Krämer et al. (2016) speculated that the physically and optically thinner in situ, slow-updraft cirrus cause a warming effect, while thicker fast-updraft in situ-origin and, particularly, thick liquid-origin cirrus have the potential to cool. Here, we show a first estimate of the radiative forcing of typical in situ-origin slow- and fast-updraft as well as liquidorigin cirrus (Fig. 5). To this end, radiative transfer calculations for idealized scenarios under specific conditions are conducted, with solar zenith angles corresponding to noon at the equinox, which are briefly described in the caption of Fig. 5.

In the left panel of Fig. 5, the radiative forcing of the slow (light green) and fast (dark green) in situ-origin cirrus is displayed with respect to optical depth. This panel is expanded from the right panel, where the forcing of the liquid-origin cirrus is shown. Obviously, the net radiative forcing of the in situ-origin cirrus is much smaller than that of liquid origin and, moreover, changes the sign from warming to cooling.

In more detail, the slow in situ-origin cirrus have only small optical depth $(\tau)$ between 0.001 and 0.05 , resulting in a slight net warming effect of not larger than about $1.5 \mathrm{~W} \mathrm{~m}^{-2}$. The optical depth of fast in situ-origin cirrus is larger $(\tau$ : $0.05-1)$, but most of them are also warming $\left(2-10 \mathrm{~W} \mathrm{~m}^{-2}\right)$. The thickest fast-updraft in situ-origin cirrus at the lowest altitudes change the sign of their net forcing; i.e., they switch to a slight cooling effect. The reason for the sign change is 
the warmer temperature at lower altitude that reduces the warming effect of the longwave infrared radiation. The results of the radiative forcing calculations for the slow- and fast-updraft cirrus are in agreement with investigations from lidar observations reported by Kienast-Sjögren et al. (2016) and Campbell et al. (2016), who observed cirrus with optical depth up to 1 and 3, respectively, and found a decreasing warming effect with decreasing optical depth. Campbell et al. (2016) even reported a slight cooling effect at the warmest observed cirrus. The liquid-origin cirrus, however, mostly found in the warmest cirrus layers, have large optical depths ( $\tau$ : 1-12), which is larger than the range of cirrus optical depth reported in many studies (the maximum optical depth is often found to be 1-3, e.g., Sassen et al., 2008; KienastSjögren et al., 2016; Campbell et al., 2016; Mitchell et al., 2018; note that this is likely because the lidar technique, often used to investigate cirrus cloud optical properties, has restrictions in the $\tau$ determination of thicker ice clouds). A consequence of the large optical thickness is a quite strong net cooling effect $\left(-15\right.$ to $-250 \mathrm{~W} \mathrm{~m}^{-2}$ ) of liquid-origin cirrus. These values are of the same order of magnitude as reported from direct measurements inside of cirrus clouds (Wendisch et al., 2007; Joos, 2019).

Thus, from these first very idealized simulations, we can conclude that in situ-formed cirrus clouds are most likely to warm the atmosphere, whereas liquid-origin ice clouds have the potential for strong cooling. Note here that we only investigate local time $12 \mathrm{~h}$, where the cooling is probably most pronounced. For lower sun position (i.e., larger zenith angle) the cooling is probably reduced, and during nighttime cirrus clouds can only warm the atmosphere (due to the thermal greenhouse effect). Thus, the net effect of cirrus clouds averaged over the whole daily cycle is not yet clear. Such investigations go beyond the scope of this study and are the subject of future work.

\subsubsection{Humidity}

The distribution of in-cloud and clear-sky $\mathrm{RH}_{\text {ice }}$ as well as water vapor $\mathrm{H}_{2} \mathrm{O}$ with latitude and altitude is shown in Fig. 3 (right column, panels $\mathrm{d}-\mathrm{f}$ ). It can nicely be seen how the amount of $\mathrm{H}_{2} \mathrm{O}$ decreases with altitude (panel f). The clearsky $\mathrm{RH}_{\text {ice }}$ (panel e) ranges from very dry conditions $(<70 \%$ green and orange diamonds) up to highly supersaturated regions ( $>130 \%$, dark red and blue diamonds), which mainly are found at high altitudes in the tropics. Such high supersaturations are also occasionally found inside of the tropical cirrus clouds (panel d). The behavior of $\mathrm{RH}_{\text {ice }}$ will be further discussed in Sects. 4 and 5.

\section{In situ climatologies}

With the term climatologies we refer here to statistical evaluations of the available variables with regard to temperature or potential temperature.

\subsection{The IWC-T parameter space: median $N_{\text {ice }}, R_{\text {ice, }}$, and $\mathrm{RH}_{\text {ice }}$}

In the Cirrus Guide I (Krämer et al., 2016), observations and model simulations are portrayed in the ice water contenttemperature (IWC- $T$ ) parameter space. One result of the simulations is that IWC and $N_{\text {ice }}$ are correlated with each other. This relationship has been confirmed for some meteorological situations by examples from six individual field campaigns. The database of combined IWC $-N_{\text {ice }}$ measurements has grown considerably since then and with it the covered temperature range of the observations. In the Cirrus Guide I, only a few observations below $200 \mathrm{~K}$ were available.

With the extended Cirrus Guide II data set, we further investigate the statistics of $N_{\text {ice }}$ but also the corresponding mean mass size $R_{\text {ice }}$ and the in-cloud $\mathrm{RH}_{\text {ice }}$ in the IWC- $T$ parameter space. In Fig. 6, medians of the respective parameters are presented in intervals (five IWC intervals per order of magnitude, $1 \mathrm{~K}$ temperature intervals) covering the entire IWC- $T$ parameter space. The variability of the parameters can be seen in Figs. S1-S3 of the Supplement, where the 25th, 50th (median), and 75th percentiles for the variables are shown.

\subsubsection{IWC $-T-N_{\text {ice }}$ and $R_{\text {ice }}$ relation}

Observational evidence for the correlation between IWC and $N_{\text {ice }}$ can be nicely seen in the upper panel of Fig. 6. Almost symmetrical colored bands of $N_{\text {ice }}$ can be seen across the entire IWC- $T$ parameter space $\left(N_{\text {ice }}\right.$ concentration increases from yellow to blue). With decreasing temperature, the same $N_{\text {ice }}$ numbers cause lower IWC values, which is caused by the likewise decreasing available water content of the air. This finding might be of importance for parametrizations used in global models or satellite retrieval algorithms, where IWC is often the only available parameter that characterizes cirrus clouds, but functions are used to assign $N_{\text {ice }}$ to specific IWCs. This new analysis can be used (after some smoothing of the bands, which will be the subject of a followup study) as a lookup table to derive $N_{\text {ice }}$ from the information of temperature and IWC.

The ice crystal sizes also form colored bands in the IWC$T$ parameter space (Fig. 6, middle panel; $R_{\text {ice }}$ increases from yellow to blue, running diagonally through the IWC $-T$ room with the size of the ice crystals increasing with increasing temperature (and thus decreasing amount of available water). This is because $R_{\text {ice }}$ is calculated from the third root of the IWC divided by $N_{\text {ice }}$, as described in Sect. 1 . However, the $R_{\text {ice }}$ bands are somewhat less clearly delineated from 

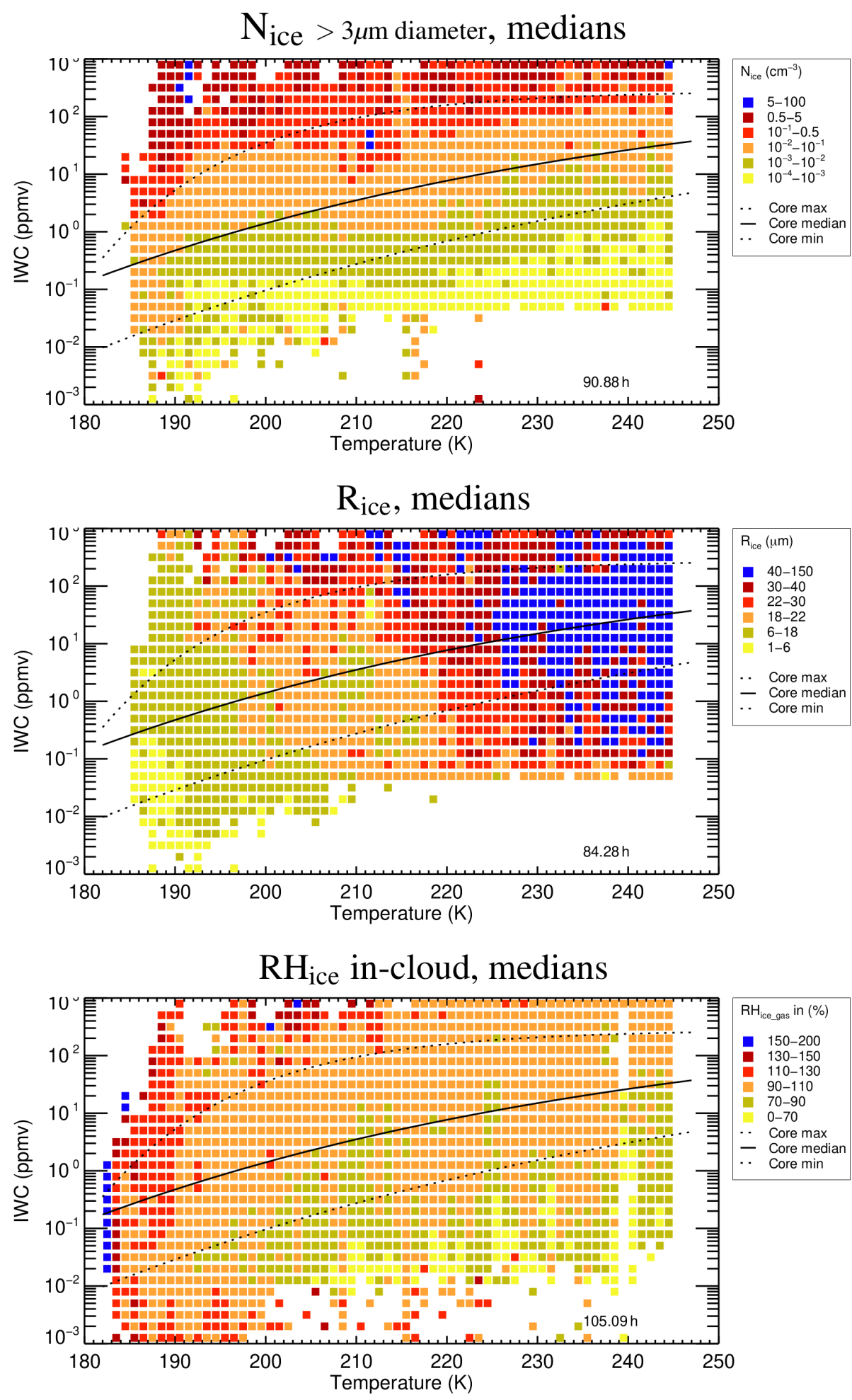

Figure 6. Median $N_{\text {ice }}, R_{\text {ice }}$, and $\mathrm{RH}_{\text {ice }}$ in intervals in the IWC- $T$ parameter space (five IWC intervals per order of magnitude, $1 \mathrm{~K}$ temperature intervals). The color codes of $N_{\text {ice }}$ and $\mathrm{RH}_{\text {ice }}$ range from yellow to blue with increasing amount of the respective parameter; for $R_{\text {ice }}$, the color code is reversed to indicate that high and low $N_{\text {ice }}$ values belong to small and large $R_{\text {ice }}$. Black solid and dotted lines: median, min, and max IWC of the core IWC band of Schiller et al. (2008). The variability of the parameters (25th, 50th (median), and 75th percentiles) is shown in Figs. S1-S3 of the Supplement. 
each other than the $N_{\text {ice }}$ bands. They might be smoothed in the follow-up study, so that $R_{\text {ice }}$ can also be assigned to the IWC- $T$ data points.

One could have expected to find distinct patterns for in situ-origin and liquid-origin cirrus in this type of analysis to quantify the characteristics of the cirrus types shown in Table 1 . However, the differences are merged by the calculation of median values in the overlap regions of the types in the IWC $-T$ parameter space. Nevertheless, we believe that the more heterogeneous structure of the $R_{\text {ice }}$ bands is caused by the different cirrus types, because the ice crystal size is their most pronounced difference. A longer-term research goal is to derive the IWC $-T-N_{\text {ice }}-R_{\text {ice }}$ relations separately for in situ-origin and liquid-origin cirrus.

\subsubsection{IWC- $T-\mathrm{RH}_{\text {ice }}$ relation}

In the bottom panel of Fig. 6, median in-cloud $\mathrm{RH}_{\text {ice }}$ values are shown in the IWC- $T$ parameter space. For $\mathrm{RH}_{\text {ice }}$ patterns are also visible: $\mathrm{RH}_{\text {ice }}$ decreases with decreasing IWC. Above the median IWC (black solid line), $\mathrm{RH}_{\text {ice }}$ is mostly between $90 \%$ and $110 \%$ (orange data points), i.e., around saturation. This corresponds to the existence phase of the cirrus (between $110 \%-100 \%$ and $100 \%-90 \%$, the ice crystals slowly grow and/or evaporate). Below the median IWC, the median $\mathrm{RH}_{\text {ice }}$ values decrease with decreasing IWC (green and yellow data points), reflecting the evaporation phase of the cirrus clouds. Interesting is the distribution of the higher supersaturations (red and blue points): at low temperatures, the clouds tend to higher supersaturations. This has been discussed by Krämer et al. (2009) for thin cirrus (low IWC) and explained by the corresponding low $N_{\text {ice }}$, whose small ice surface cannot efficiently deplete the water vapor. However, the supersaturations are also seen at high IWC $(\sim$ high $N_{\text {ice }}$ ). The reason for that is the vertical velocity, which is - together with the ice surface and temperature - a driver of the $\mathrm{RH}_{\text {ice }}\left(\mathrm{RH}_{\text {ice }}=\mathrm{H}_{2} \mathrm{O} / \mathrm{H}_{2} \mathrm{O}_{\text {sat,ice }}(T)\right)$. The air inside of clouds is supersaturated in cases in which the depletion of $\mathrm{H}_{2} \mathrm{O}$ on the available ice surface (decrease in $\mathrm{RH}_{\text {ice }}$ ) cannot compensate for the increase in $\mathrm{RH}_{\text {ice }}$ caused by the cooling of the air (decrease in $\mathrm{H}_{2} \mathrm{O}_{\text {sat, ice }}(T)$ with decreasing temperature). High IWC, always coinciding with high $N_{\text {ice }}$, appears in high updrafts, in in situ-origin as well as in liquid-origin cirrus. These high updrafts allow that the supersaturations remain high despite the large ice surfaces available for deposition of excess water vapor. This was also reported by Petzold et al. (2017), who observed high $\mathrm{RH}_{\text {ice }}$ together with high $N_{\text {ice }}$ in tropical convective cirrus onboard passenger aircraft (IAGOS).

\subsection{Entire in situ climatologies}

The Cirrus Guide II data set shown in Fig. 3 is now displayed as frequencies of occurrence as a function of temperature (binned in $1 \mathrm{~K}$ intervals, Fig. 7) and discussed in compari- son to the earlier in situ climatologies presented by Schiller et al. (2008), Krämer et al. (2009), and Luebke et al. (2013) (Fig. S6, Supplement). Further, as mentioned above, the new data set is large enough to split it in midlatitude and tropical cirrus. The differing cirrus cloud properties are presented in Fig. 8 and the respective clear-sky and in-cloud $\mathrm{RH}_{\text {ice }}$ in Fig. 9.

\subsubsection{Ice water content (IWC-T)}

Figure 7a depicts the IWC. The black solid and dotted lines represent the median, minimum, and maximum IWC of the core IWC band, that is the envelope of the most frequent IWC (> 5\% per IWC- $T$ bin; Schiller et al., 2008).

The number of hours spent sampling in cirrus clouds increased from $27 \mathrm{~h}$ in Schiller et al. (2008), $38 \mathrm{~h}$ in Luebke et al. (2013), and $94 \mathrm{~h}$ in (Krämer et al., 2016) to $168 \mathrm{~h}$ in the new extended data set. Part of the additional data are due to the new IWC data product that is applied to all campaigns and combines the IWC from total water measurements and the IWC derived from cloud particle size distributions (see Appendix A2.1).

However, the median IWC and the core IWC band - decreasing with temperature as described by Schiller et al. (2008) - is still valid, showing that the IWC measurement techniques are robust and that the IWC is a stable parameter describing cirrus clouds. Note here that at temperatures $\lesssim 200 \mathrm{~K}$ data points underneath the lower dotted line are not unambiguously identified as clouds, while above about $200 \mathrm{~K}$ this threshold is 0.05 ppmv. For more detail see also Appendix A2.1.

\subsubsection{Ice crystal number $\left(N_{\text {ice }}-T\right)$}

About $90 \mathrm{~h}$ of $N_{\text {ice }}$ observations are shown in Fig. $7 \mathrm{~b}^{5}$, which is an increase of about a factor of 10 in comparison to the data set of Krämer et al. (2009), who compiled 8.5 h (Fig. S6, Supplement). For $N_{\text {ice }}$, the picture has greatly changed when comparing the old and the new data sets. This change is on the one hand due to an extension of the lower detection limit of $N_{\text {ice }}$ from $4 \times 10^{-3}$ to $10^{-4} \mathrm{~cm}^{-3}$ (see Appendix A2.2), but also because the new data set represents a better mixture of different meteorological situations. For example, the higher $N_{\text {ice }}$ values at warmer temperatures in the Krämer et al. (2009) data set (Fig. S6, Supplement) were caused by flights where lee wave cirrus behind the Norwegian mountains were probed (see also Fig. 3, blue diamonds at around $60^{\circ}$ north). Also, at temperatures colder than about $200 \mathrm{~K}$, $N_{\text {ice }}$ was most often very low. Further, the enhanced occurrence frequencies at the lowest concentrations seen in the earlier data set are corrected in the new data evaluation procedures (Figs. A2 and S6, Supplement, middle left panel).

\footnotetext{
${ }^{5}$ Note that for $N_{\text {ice }}$ - and thus $R_{\text {ice }}$ - the number of hours spent in clouds in Fig. 7 is less than in Fig. 3. For details see figure caption.
} 

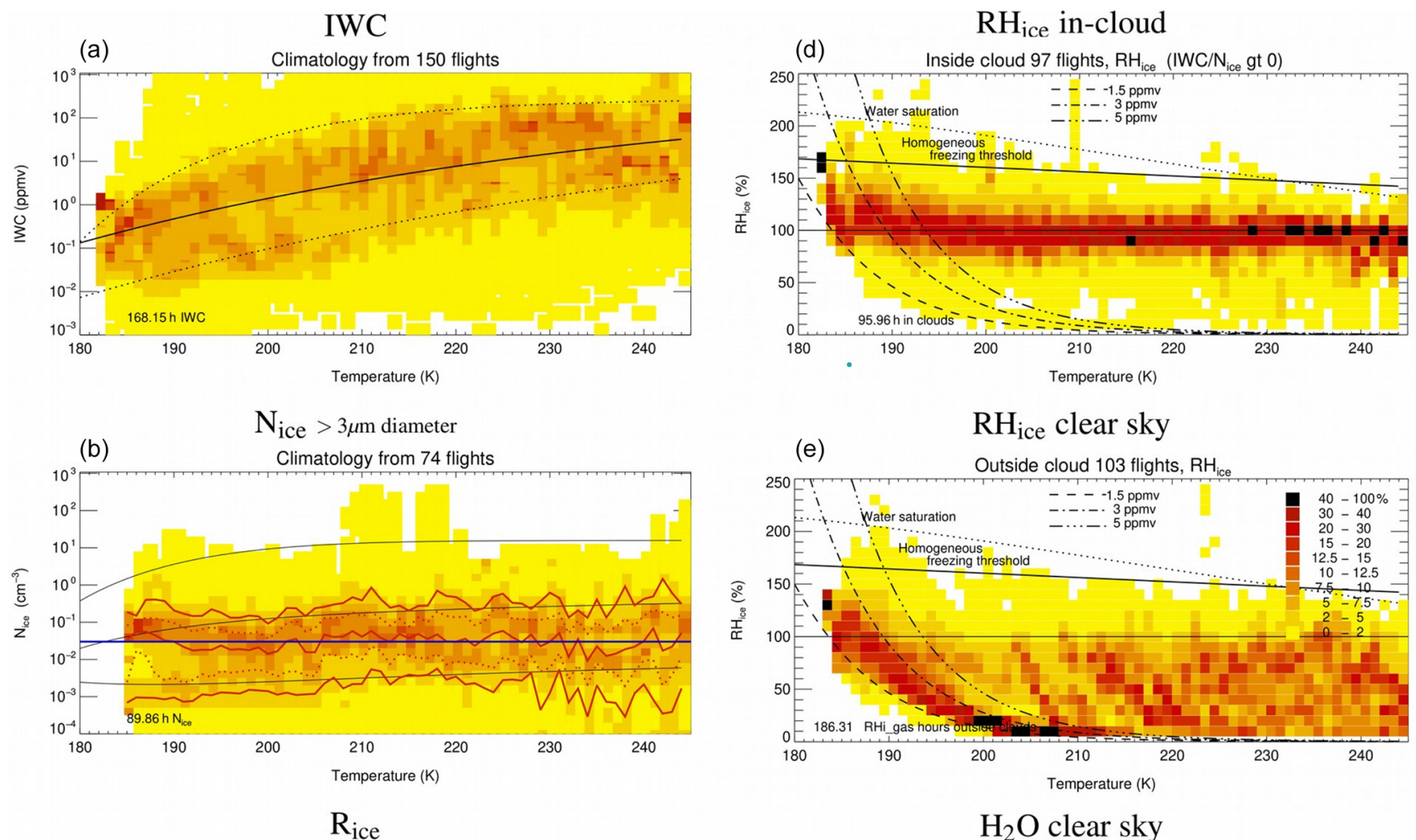

(c)

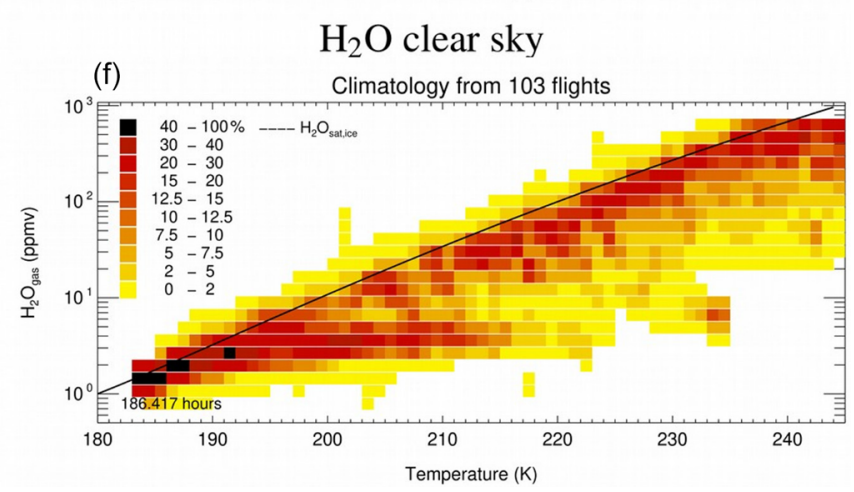

Figure 7. Frequencies of occurrence in dependence on temperature, binned in $1 \mathrm{~K}$ intervals of ice water content (IWC; a; black solid and dotted lines: median, min, and max IWC of the core IWC band of Schiller et al., 2008). Ice crystal number $\left(N_{\text {ice}}\right.$, size $>3 \mu \mathrm{m}$ diameter, $\mathbf{b}$; red lines: 10th, 25th, 50th, 75th, and 90th $N_{\text {ice }}$ percentiles; blue line: fit through median $N_{\text {ice values (median } N_{\text {ice }}: 0.03 \mathrm{~cm}}{ }^{-3} ; 10$ th, 25 th, 75th, and 90th percentiles: 0.002, 0.007, 0.102, $0.3 \mathrm{~cm}^{-3}$ ); black lines: minimum, middle, and maximum $N_{\text {ice }}$ of Krämer et al., 2009). Mass mean radius ( $R_{\text {ice }}$ : calculated from IWC and $N_{\text {ice }}, \mathbf{c}$; red lines: 10th, 25th, 50th, 75th, 90th $R_{\text {ice }}$ percentiles; black lines: minimum, middle, and maximum $R_{\text {ice }}$ of Krämer et al., 2009). In-cloud and clear-sky relative humidity with respect to ice ( $\left.\mathrm{RH}_{\mathrm{ice}}, \mathbf{d}, \mathbf{e}\right)$, and water vapor volume mixing ratio $\left(\mathrm{H}_{2} \mathrm{O}, \mathbf{f}\right)$. The field campaigns included in the data analysis are listed in Table A2. Data evaluation methods and detection ranges of the parameters are described in Appendix A. Note that for $N_{\text {ice }}-$ and thus $R_{\text {ice }}-$ the hours spent in clouds is less than in Fig. 3. The reason is that for the calculation of data frequency distributions only measurements covering the same detection range are used (see also Appendix A2).

A total of $90 \mathrm{~h}$ of aircraft $N_{\text {ice }}$ observations within cirrus clouds is a tremendous amount when taking into account the necessary effort. However, this is still far from being representative for the distribution of $N_{\text {ice }}$ in the atmosphere. We nevertheless calculated 10th, 25th, 50th, 75th, and 90th percentiles, which are shown as thin, dotted, and solid lines in Fig. 7b. Note that the 10th and 90th percentiles enclose the core region of $N_{\text {ice }}$, i.e., the envelope of the most fre- quent $N_{\text {ice }}\left(>5 \%\right.$ per $N_{\text {ice }}-T$ bin). Fits through these percentiles and the median $N_{\text {ice }}$ reveal no temperature dependence of $N_{\text {ice }}\left(10 \%\right.$, median, and $90 \% N_{\text {ice }}: 0.002,0.03$, and $0.3 \mathrm{~cm}^{-3}$ ). This is different to the slight decrease with temperature of the minimum, middle, and maximum $N_{\text {ice }}$ lines shown by Krämer et al. (2009), which was, as discussed above, caused by two flights with high $N_{\text {ice }}$ at comparatively warm temperatures. 
It is an open question why the $N_{\text {ice }}$ values do not increase with decreasing temperature, as would be expected from theoretical homogeneous freezing calculations (see e.g., Kärcher and Lohmann, 2002). This has been investigated by Gryspeerdt et al. (2018) based on a 10-year global data set retrieved from satellite observations (DARDAR$N_{\text {ice }}$; Sourdeval et al., 2018a; see also Sect. 6). Gryspeerdt et al. (2018) analyzed the $N_{\text {ice }}(>5 \mu \mathrm{m})$ only at cloud tops and also those throughout the cirrus clouds. From the cloud top analysis, a clear increase in $N_{\text {ice }}$ with decreasing temperature was obvious; while integrating throughout the cirrus this temperature dependence becomes much weaker, though it is still present. Gryspeerdt et al. (2018) propose that the missing temperature dependence in the in situ results could be due to a lack of in situ measurements near the cloud top, where the temperature dependence is strongest. Another reason could be that the higher $N_{\text {ice }}$ values are short-lived (see Sect. 3.1.1) and thus not easy to trace by aircraft.

A further consideration of $N_{\text {ice }}$ frequencies of occurrence on global and regional scales derived from satellite remote sensing will be presented in Sect. 6 .

\subsubsection{Ice crystal mean mass radius $\left(R_{\mathrm{ice}}-T\right)$}

The ice crystal mean size is calculated as mean mass radius $R_{\text {ice }}$ as shown in Footnote 2. $R_{\text {ice }}$ is close to the common effective cloud particle radius $R_{\text {eff }}(\sim$ ice volume divided by area) but can be calculated without knowing details of the ice particle size distribution (see also Krämer et al., 2016).

A total of $84 \mathrm{~h}$ of observations are compiled in Fig. 7c. Overall, the mean mass $R_{\text {ice }}$ ranges from about 1 to $100 \mu \mathrm{m}$, while individual ice crystals in cirrus can reach sizes up to $1000 \mu \mathrm{m}$ or even larger. The $R_{\text {ice }}$ core band (frequencies $\gtrsim 5 \%$ per $R_{\text {ice }}-T$ bin) decreases slightly as the temperature decreases, which is caused by the decrease in the IWC core band, since the $N_{\text {ice }}$ band is not dependent on temperature (see previous section).

The 10th, 25th, 50th, 75th, and 90th percentiles of the data set are plotted as thin, dotted, and solid red lines. The black lines represent the minimum, middle, and maximum $R_{\text {ice }}$ shown by Krämer et al. (2009) (see Fig. S6, Supplement). The range of $R_{\text {ice }}$ has shifted slightly to larger sizes in the new data set, which is caused by the $N_{\text {ice }}$ range extended towards lower concentrations that mainly consist of larger ice crystals.

Remarkable is the drop of the most frequent $R_{\text {ice }}$ from larger to smaller ice crystals seen at around $215 \mathrm{~K}$. This is probably the approximate temperature up to which liquidorigin clouds are detected (see Luebke et al., 2016; Sourdeval et al., 2018a, and also Sect. 6.2), which are characterized by larger ice crystals than in situ-origin cirrus (Krämer et al., 2016). At higher temperatures where both liquid and in situorigin cirrus prevail, higher IWCs - and thus also a larger $R_{\text {ice }}$ - occur more often than at lower temperature, where only the thinner in situ-origin clouds exist. This is especially true at midlatitudes. In the tropics the liquid-origin cirrus also reach lower temperatures and thus no sudden drop of $R_{\text {ice }}$ is observed (see Fig. 8c, f). The bifurcated structure of the most frequent $R_{\text {ice }}$ which can be seen for temperatures $\lesssim 190 \mathrm{~K}$ is discussed in Sect. 4.3.1 (vii).

\subsubsection{Clear-sky and in-cloud $\mathrm{RH}_{\mathrm{ice}}\left(\mathrm{RH}_{\mathrm{ice}}-\mathrm{T}\right)$}

The new $\mathrm{RH}_{\text {ice }}$ clear-sky and in-cloud data sets are displayed in Fig. 7e, d. The respective earlier data sets of Krämer et al. (2009) are shown in Fig. S6, Supplement. The overall picture of the $\mathrm{RH}_{\text {ice }}$ distributions has not changed substantially, though the amount of in-cloud data in the database has increased from $10 \mathrm{~h}$ of measurements to about $96 \mathrm{~h}$, and the clear-sky observation time has increased from 16 to $186 \mathrm{~h}$. The only small difference is found in the in-cloud $\mathrm{RH}_{\text {ice }}$, potentially caused by the larger amount of data: below about $200 \mathrm{~K}$, where high supersaturations $(>120 \%)$ occur more often and low subsaturations $(<80 \%)$ less often. At higher temperatures, the peak of $\mathrm{RH}_{\text {ice }}$ frequencies at $100 \%$ is more pronounced.

For the new data set, in addition to the clear-sky $\mathrm{RH}_{\text {ice }}$ the absolute water vapor volume mixing ratio $\mathrm{H}_{2} \mathrm{O}$ in Fig. $7 \mathrm{f}$ is plotted. To guide the eye, water vapor saturation with respect to ice, $\mathrm{H}_{2} \mathrm{O}_{\text {sat }}$, ice, is drawn as a black solid line. The decrease in $\mathrm{H}_{2} \mathrm{O}$ with temperature is nicely seen in this panel, and clear-sky supersaturations appear in this portrayal as data points above $\mathrm{H}_{2} \mathrm{O}_{\text {sat, }}$,ice.

\subsection{Midlatitudes and tropics}

\subsubsection{Midlatitude and tropical cirrus clouds}

The data sets of midlatitude and tropical cirrus consist of 67 and $101 \mathrm{~h}$ of IWC, 29 and $61 \mathrm{~h}$ of $N_{\text {ice }}$, and 28 and $56 \mathrm{~h}$ of $R_{\text {ice }}$ measurements, respectively. This section describes some of the pronounced characteristics of midlatitudes and tropical cirrus, which are displayed in Fig. 8 (greenish and reddish colors represent midlatitude and tropical cirrus).

- Temperature ranges. Comparing midlatitude and tropical cirrus, the first obvious difference - as expected when looking at the temperature profiles in Fig. 2 - is the temperature range. The observed midlatitude cirrus rarely occur below $200 \mathrm{~K}$, while tropical cirrus are detected down to temperatures of $182 \mathrm{~K}$. The core IWC, $N_{\text {ice }}$, and $R_{\text {ice }}$ ranges of both midlatitude and tropical cirrus correspond to the total climatology (see Fig. 7).

ii. Midlatitude WCBs and MCS. At European midlatitudes, the most frequent cirrus can be assigned to slow updrafts in frontal systems (WCBs: warm conveyor belts) containing both liquid-origin and in situ-origin cirrus. High IWCs stem mostly from liquid-origin WCB cirrus. Above the central USA, small and mesoscale convective systems (MCSs) with faster updrafts are more 


\section{Cirrus Guide II - Climatologies}

\section{Mid-Latitudes}

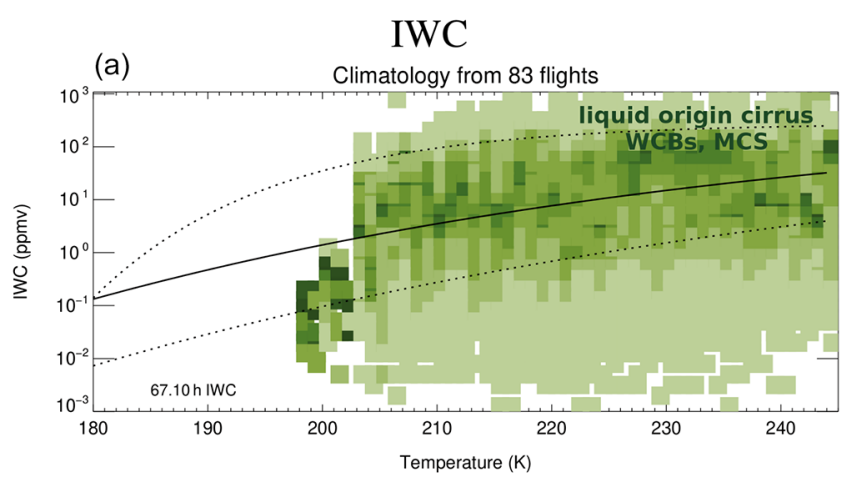

(b)

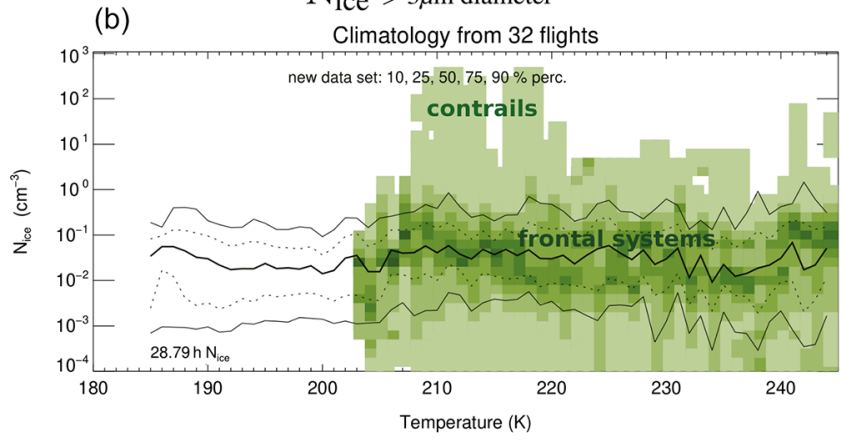

(c)

$\mathrm{R}_{\text {ice }}$

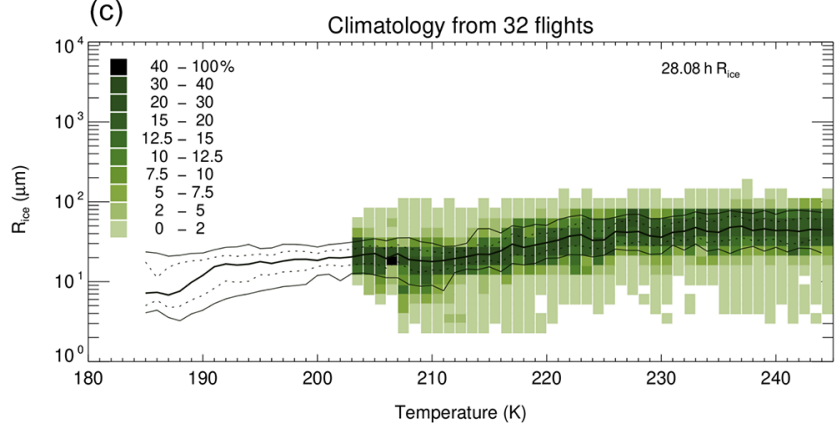

TROPICS
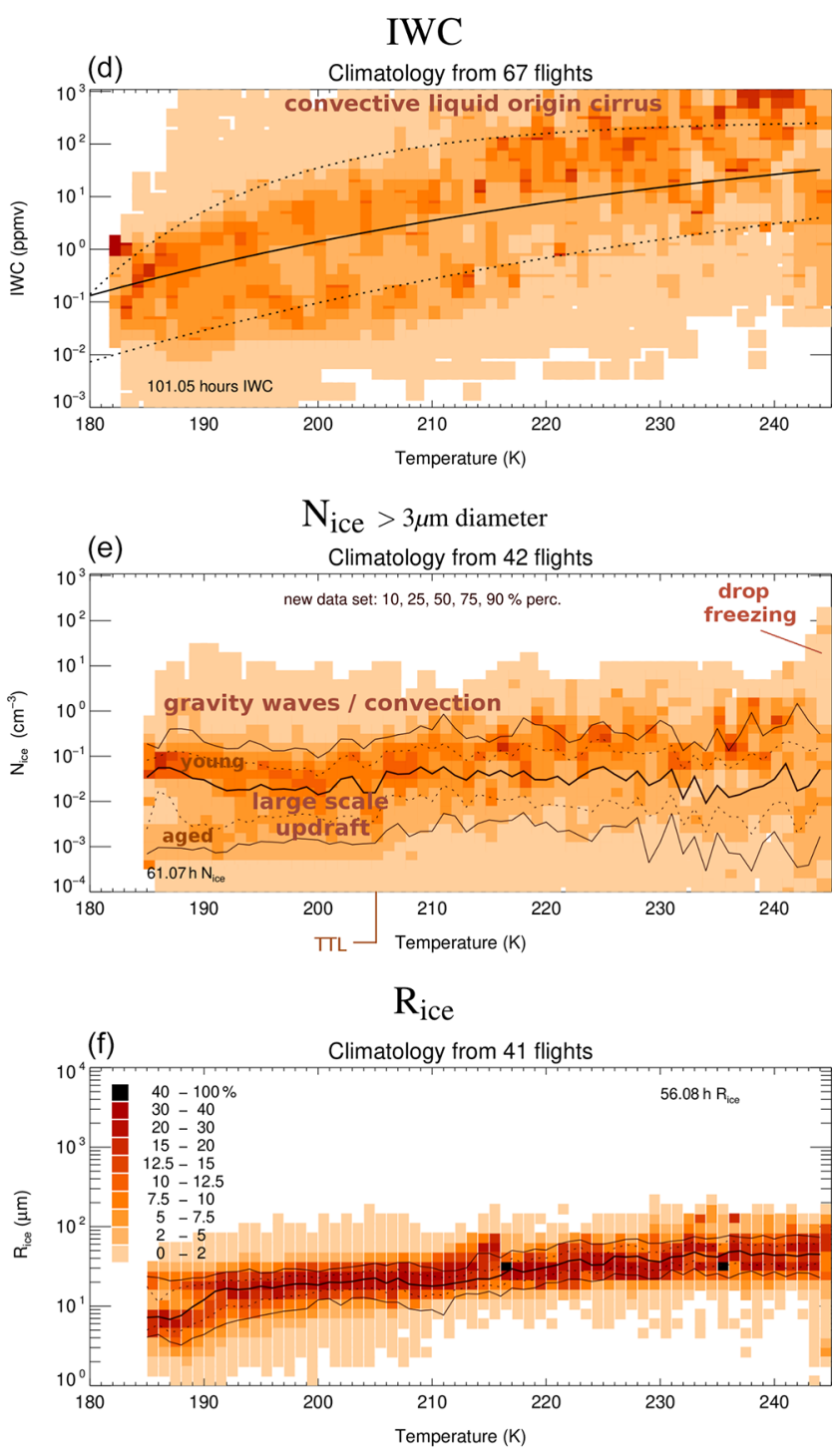

Figure 8. Same as Fig. 7a-c, but for midlatitudes and tropics (WCBs: warm conveyor belts; MCS: mesoscale convective systems; TTL: tropical tropopause layer). The field campaigns are listed in Table A2.

frequent. The resulting liquid-origin cirrus are thicker than the European cirrus; i.e., the ice crystals are larger and the IWC is higher (see also Krämer et al., 2016).

iii. Contrails. A striking feature in the cirrus observations is $N_{\text {ice }}$ values of up to several hundreds per cubic centimeter, which are found at midlatitudes in the temperature range of about $210-220 \mathrm{~K}$, which corresponds to about $10 \mathrm{~km}$ altitude (see Fig. 2), the typical cruising level of passenger aircraft. They can be attributed to young contrails, which were a topic of investigation during COALESC 2011 (Jones et al., 2012) and also ML-CIRRUS
2014 (Voigt et al., 2017). Higher midlatitude $N_{\text {ice }}$ at higher temperatures are most probably in situ-origin cirrus caused by stronger updrafts in, for example, mountain waves.

iv. Drop freezing. High $N_{\text {ice }}$ values between 10 and $100 \mathrm{~cm}^{-} 3$ or even more are found above $235 \mathrm{~K}$. Such high concentrations together with small $R_{\text {ice }}$ values are typical for supercooled liquid cloud drops that might be frozen by spontaneous homogeneous drop freezing (which occurs at the latest at around $235 \mathrm{~K}$ in the atmosphere). In any case, these cloud particles are an in- 
dication for liquid-origin clouds caused by tropical or midlatitude convective systems with fast updrafts.

v. Tropical convection. In contrast, in tropical cirrus, and particularly for temperatures $\gtrsim 220 \mathrm{~K}$, high IWCs and $N_{\text {ice }}$ above the core range - corresponding to convective liquid-origin cirrus - become more frequent, while $R_{\text {ice }}$ tends to be smaller. This is most likely caused by the fast convective vertical velocities that often let clouds in the mixed-phase temperature regime rise to the cirrus altitude range.

vi. Tropical deep convection. Also remarkable is that in the tropics, massive convective liquid-origin cirrus carrying a high IWC - often accompanied by high $N_{\text {ice }}-$ are detected down to very cold temperatures $(<200 \mathrm{~K})$, which corresponds to high altitudes up to $17 \mathrm{~km}$. The thickest cirrus with very high IWC and $N_{\text {ice }}$ can also be seen in Fig. 3a, b (distribution of cirrus with latitude; blue data points represent liquid-origin cirrus with a high IWC and $N_{\text {ice }}$ ) at around $25^{\circ}$ northern latitude and $16-18 \mathrm{~km}$ altitude. These exceptional thick and cold cirrus at high altitudes were observed in the Asian monsoon tropical tropopause layer (TTL). The numerous observed small ice crystals are most likely generated by in situ homogeneous ice nucleation, triggered either by fast updrafts in gravity waves (see also Spichtinger and Krämer, 2013; Jensen et al., 2013a) or by deep convection. They often occur in the tops of massive liquid-origin cirrus with very high IWC; a theoretical description of such clouds is given by Jensen and Ackerman (2006).

vii. TTL cirrus. The discussion of cirrus clouds in the tropical tropopause layer is presented in Sect. 5.

\subsubsection{Midlatitude and tropical humidity}

The midlatitude and tropical humidity data sets include 24 and $72 \mathrm{~h}$ of in-cloud $\mathrm{RH}_{\text {ice }}$ and 51 and $132 \mathrm{~h}$ of clear-sky $\mathrm{RH}_{\text {ice }}$ and $\mathrm{H}_{2} \mathrm{O}$ measurements, which are displayed in Fig. 9 with the same color code as in Fig. 8.

In clear sky at temperatures higher than about $200 \mathrm{~K}$, $\mathrm{RH}_{\text {ice }}$ is most often below saturation and randomly distributed in both midlatitudes and tropics (Fig. 9b, e). Clearsky supersaturations occurs less frequently, simply because they only take place in those periods when moist air parcels are cooled towards the ice nucleation thresholds (heterogeneous or homogeneous), which are rare compared to drier conditions of the atmosphere.

Below about $200 \mathrm{~K}$, i.e., in the TTL (see also Sect. 5), the clear-sky $\mathrm{RH}_{\text {ice }}$ distribution looks very different. In this region, $\mathrm{H}_{2} \mathrm{O}$ is low and its variability is only small (Fig. 9c, f). We plotted lines of constant $\mathrm{H}_{2} \mathrm{O}(1.5,3$, and 5 ppmv) in the clear-sky $\mathrm{RH}_{\text {ice }}$ panels to illustrate that for constant $\mathrm{H}_{2} \mathrm{O}, \mathrm{RH}_{\text {ice }}$ increases only due to the decrease in tempera-

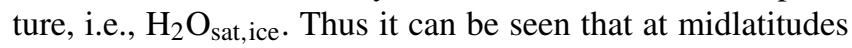

$\mathrm{RH}_{\text {ice }}$ values mostly represent $\mathrm{H}_{2} \mathrm{O}$ values around 3 ppmv and in the tropics between 1.5 and 3 ppmv. Since in the tropics much colder temperatures are reached, the respective $\mathrm{RH}_{\text {ice }}$ ranges from 10 up to about $150 \%$ or even more (see also Jensen et al., 2017b; Krämer et al., 2009, who already presented parts of the data shown here).

Clear-sky $\mathrm{RH}_{\text {ice }}$ values above the homogeneous freezing line are under discussion, because they would indicate that no supercooled liquid aerosol particles are present to initiate freezing or that the homogeneous freezing is prevented, for example by organic material contained in the aerosol particles. More probably, these few data points are outliers; note also that the uncertainty of $\mathrm{RH}_{\text {ice }}$ rises from approximately $10 \%$ at warmer temperatures to about $20 \%$ at colder temperatures (Krämer et al., 2009).

Inside of cirrus, the peak of the $\mathrm{RH}_{\text {ice }}$ frequency distribution is mostly around the thermodynamical equilibrium value of $100 \%$ (saturation) at midlatitudes as well as in the tropics (Fig. 9a, d; see also Jensen et al., 2017b; Krämer et al., 2009). However, in the TTL, at the coldest prevailing temperatures $(\lesssim 190 \mathrm{~K})$, supersaturation increasingly becomes the most common condition, which is discussed in more detail in Sect. 5. High supersaturations at low temperatures were also reported by Krämer et al. (2009) and Jensen et al. (2013a), and the reason given for the existence of such high supersaturation is low $N_{\text {ice }}$ concentrations, which were mostly present at low temperatures in these observations (Fig. S6, Supplement). However, Jensen et al. (2013a) also showed that $\mathrm{RH}_{\text {ice }}$ rapidly drops to saturation in the presence of many ice crystals. As can be seen from Fig. 8e (and discussed in Sect. 4.2.2), in the new data set $N_{\text {ice }}$ values cover a broader concentration range in comparison to the earlier data (Fig. S6, Supplement), while $\mathrm{RH}_{\text {ice }}$ is supersaturated in most cases. This is not straightforward to understand due to the complex relation between $\mathrm{RH}_{\text {ice }}$ and $N_{\text {ice }}$. We will investigate the TTL supersaturations in cirrus clouds in a follow-up study.

\section{TTL in situ climatologies in- and outside of the Asian monsoon anticyclone}

The tropical tropopause layer is the region above the upper level of main convective outflow, where the transition from the troposphere to stratosphere occurs. It is placed at temperatures $<205 \mathrm{~K}$ between $\sim 150 \mathrm{hPa}, 355 \mathrm{~K}$ potential temperature and $14 \mathrm{~km}$, and $70 \mathrm{hPa}, 425 \mathrm{~K}$ and $18.5 \mathrm{~km}$ (Fueglistaler et al., 2009; see also Fig. 2). The coldest temperatures are found here at the point where the slope of the temperature profile reverses (cold point tropopause, CPT). In the TTL, the prevailing dynamical conditions are very slow large-scale updrafts superimposed by a spectrum of high-frequency gravity waves (i.e., Spichtinger and Krämer, 2013; Dinh et al., 2016; Jensen et al., 2017a; Podglajen et al., 2017). In addi- 


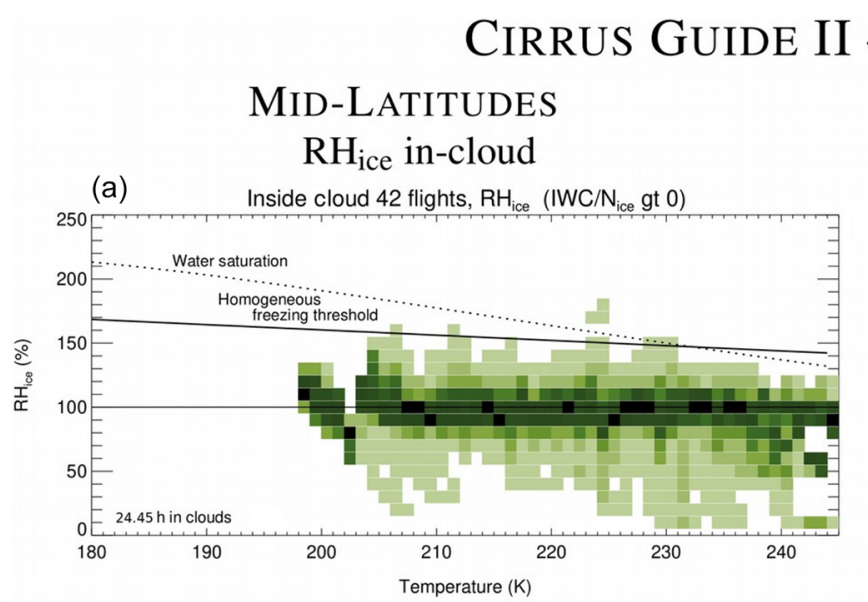

\section{- Climatologies}
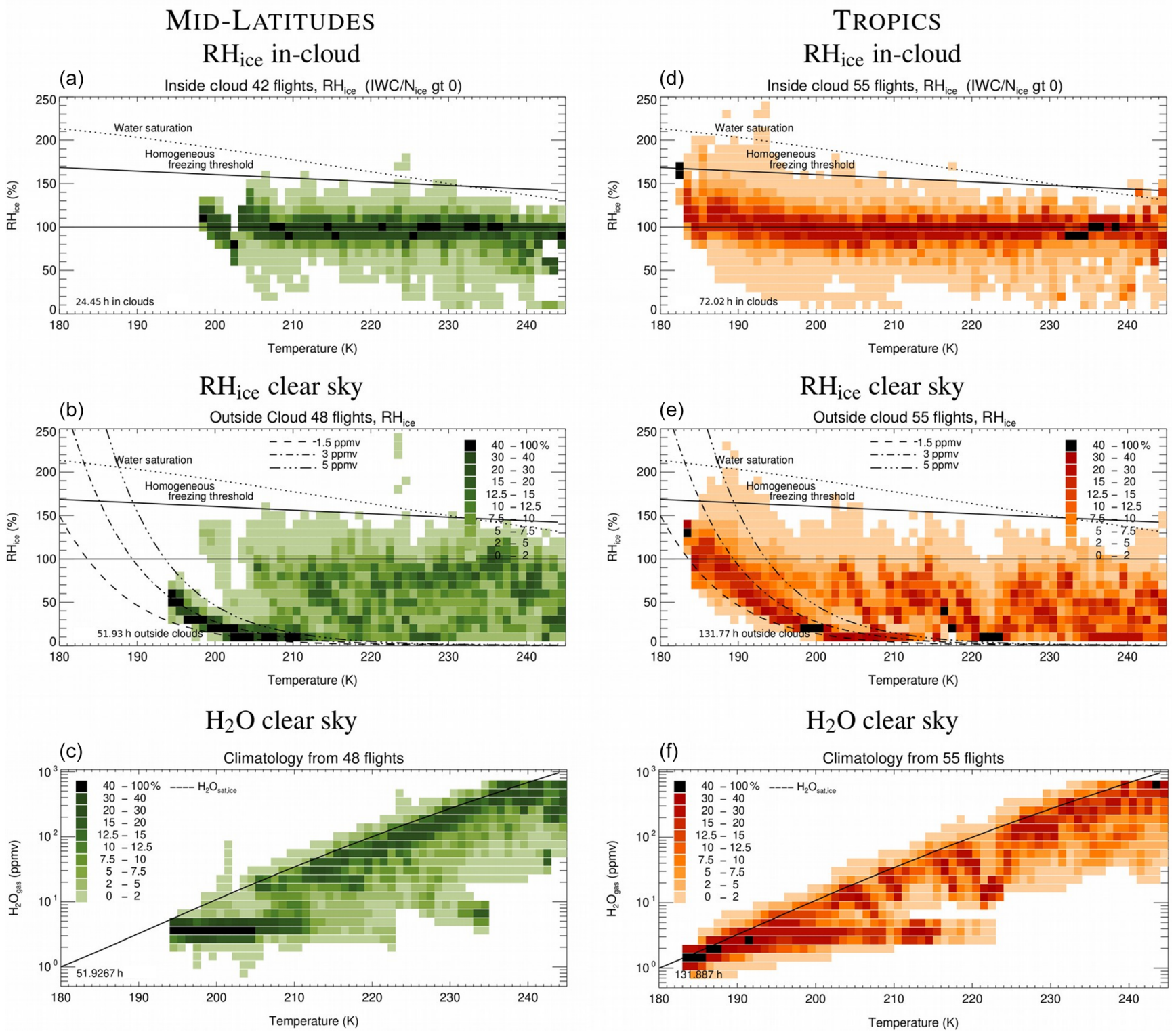

Figure 9. Same as Fig. 7d-f, but for midlatitudes and tropics. The field campaigns are listed in Table A2.

tion, deep convection with fast updrafts occasionally overshoots into the TTL.

Cirrus clouds and humidity in the TTL deserve a special consideration, because this region represents the main pathway by which water vapor enters the upper troposphere and lower stratosphere (UT-LS) where it is further distributed over long distances (e.g., Brewer, 1949; Holton et al., 1995; Rolf et al., 2018; Vogel et al., 2016; Ploeger et al., 2013). This is of importance, because water vapor is a greenhouse gas that has a significant impact on the climate, with the greatest sensitivity in the tropical UT-LS (Solomon et al., 2010; Riese et al., 2012), but also in the LS at high latitudes where it is being transported from the tropics. Cirrus clouds are of particular relevance as regulators of the partitioning of $\mathrm{H}_{2} \mathrm{O}$ between gas and ice phases. Furthermore, they have a climate feedback themselves by influencing the Earth's radiation balance (e.g., Boucher et al., 2013). Thus, the simultaneous observation and analysis of both cirrus clouds and humidity $\left(\mathrm{H}_{2} \mathrm{O}\right)$ in this climatically crucial region are of special interest.

This section specifically reports cirrus clouds together with humidity (from the climatologies presented in Sect. 4), which was recently observed for the first time in the TTL in the Asian monsoon anticyclone (June to September) in comparison to observations in the surrounding tropical regions. As the Asian monsoon is characterized by strong con- 
vective activity, this comparison will show the difference to less active, calmer areas (note here that the ATTREX and POSIDON campaigns were in western Pacific highly convective regions; however, the flights from these campaigns generally did not sample fresh convective outflow). Observations of Asian monsoon TTL cirrus clouds and humidity are of particular importance because, amongst other trace species, large amounts of $\mathrm{H}_{2} \mathrm{O}$ and also cloud particles are convectively transported upwards from far below, where the additional $\mathrm{H}_{2} \mathrm{O}$ in turn often causes cirrus formation (e.g., Ueyama et al., 2018, and references therein). Directly injected $\mathrm{H}_{2} \mathrm{O}$ or $\mathrm{H}_{2} \mathrm{O}$ from sublimated ice crystals can then be mixed up into the stratosphere. Thus, the Asian monsoon anticyclone represents a significant gateway for $\mathrm{H}_{2} \mathrm{O}$ between UT and LS (e.g., Fueglistaler et al., 2009; Ploeger et al., 2013), and currently it is under discussion to what extent cirrus cloud particles contribute to the amount of $\mathrm{H}_{2} \mathrm{O}$ entering the stratosphere (e.g., Ueyama et al., 2018, and references therein).

The airborne measurements in the Asian monsoon (see Fig. 1 and Tables A1 and A2) were performed during July-August 2017 out of Kathmandu, Nepal, during a field campaign as part of the StratoClim project (http://www. stratoclim.org/, last access: 15 January 2020). An overview of the observations is given in Figs. 10, 11, and 12, where the frequencies of IWC, $N_{\text {ice }}, R_{\text {ice }}$, and in-cloud, clear-sky $\mathrm{RH}_{\text {ice }}$ as well as the clear-sky $\mathrm{H}_{2} \mathrm{O}$ volume mixing ratio are shown in the temperature and also the potential temperature $\Theta$ parameter space. $^{6}$

Most of the measurements during StratoClim are performed at temperatures $\lesssim 205 \mathrm{~K}$, corresponding to potential temperatures $\gtrsim 355 \mathrm{~K}$ and altitudes $\gtrsim 14 \mathrm{~km}$, i.e., in the TTL (marked in the middle panels of the figures).

The surrounding, typically calmer tropical TTL regions are represented by observations during the campaigns shown in Fig. 1 and listed in Tables A1 and A2. The majority of the data were sampled during ATTREX_2014 and POSIDON_2016. The TTL measurements in the temperature parameter space are shown in Figs. 8 and 9; in these plots, the Asian monsoon observations are included, but since the measurements represent only a small part of all TTL observations, excluding the StratoClim campaign only slightly changes the frequency distributions. Thus, the figures are representative for the TTL outside of the Asian monsoon anticyclone, and we refrain from showing an additional figure. The measurements in the $\Theta$ parameter space (StratoClim excluded) are presented in Figs. 11, left column, and 12, left column.

\footnotetext{
${ }^{6}$ The additional $\Theta$ portrayal provides a more detailed impression of the distribution of cirrus clouds and humidity around the CPT, i.e., at the transition between troposphere and stratosphere (see Fig. 2).
}

\subsection{TTL cirrus clouds}

\subsubsection{Temperature parameter space}

In the tropics outside of the Asian monsoon (Fig. 8, right column, panels d-f)), cirrus IWC and $N_{\text {ice }}$ range from very low to quite high values. We want to draw attention to a special feature of the most frequently occurring cirrus $N_{\text {ice }}$ (panel e). Two main branches of most frequent $N_{\text {ice }}$ are found, one at very low $\left(\sim 10^{-3} \mathrm{~cm}^{-3}\right)$ and the other at moderate $(\sim$ $\left.5 \times 10^{-2} \mathrm{~cm}^{-3}\right) N_{\text {ice }}$. These two branches are also reflected in $R_{\text {ice, }}$, where the larger ice crystals are found together with lower concentrations and vice versa, as shown in Fig. 4. More precisely, cirrus with $N_{\text {ice }} \lesssim 1.5 \times 10^{-2} \mathrm{~cm}^{-3}$ consist of ice particles larger than about $20 \mu \mathrm{m}^{7}$. That means that the ice crystal spectra of the low $N_{\text {ice }}$ cirrus most likely represent aged clouds (in situ origin or liquid origin) where the smaller nucleation mode ice crystals are either grown to larger sizes in supersaturations or evaporated in the case of subsaturated conditions (see also Sect. 3.1.1). The higher $N_{\text {ice }}$ cirrus containing ice crystals smaller than $20 \mu \mathrm{m}$ are most likely young cirrus that have formed in situ, because these small crystals quickly (on a timescale of 10-20 min) grow to larger sizes. It is impossible to speculate if they have formed homo- or heterogeneously, since both pathways might produce such $N_{\text {ice }}$ in the slow updrafts prevailing in the TTL. The reason that the aged cirrus marked in Fig. 8e become visible only in the TTL, though they certainly occur in all cirrus regions, is probably the calmer dynamic environment with - in comparison to lower altitudes - less frequently occurring temperature fluctuations. These fluctuations likely cause new ice nucleation events superimposed on the aged cirrus.

The clouds observed in the Asian monsoon include in situ-formed cirrus as well as cirrus clouds from overshooting deep convection. In the much more convectively unstable Asian monsoon conditions, IWC and $N_{\text {ice }}$ are most frequently above the median lines derived from the entire climatology (Fig. 10, left column, panels a-c) and also high in comparison to the tropical climatology (Fig. 8, right column, panels d-f). Here, the highest observed values (at temperatures $<205 \mathrm{~K}$ ) are found with IWC mixing ratios of up to $1000 \mathrm{ppmv}$ and a maximum $N_{\text {ice }}$ as high as $30 \mathrm{~cm}^{-3}$ (note that the ice crystal shattering was significantly minimized; see Sect. A2.2). Such high values have also been observed before during the TC-4 mission 2007 in tropical anvils (Jensen et al., 2009) and even higher in lee wave cirrus during Cirrus 2006 (Krämer et al., 2009). Also, the ice crystals mean mass size, $R_{\text {ice }}$, is above the median, especially at very low temperatures, which means that large ice crystals are found around the cold point. These exceptional findings are recorded during flights in strong convection, where

\footnotetext{
${ }^{7}$ It should be noted that concentrations $\lesssim 0.1 \mathrm{~cm}^{-3}$ of cloud particles $\lesssim 20 \mu \mathrm{m}$ are below the detection limit of cloud spectrometers; i.e., small ice crystals with such low concentrations could be present (see Appendix A2.2).
} 
liquid-origin clouds from far below are detected in the upper part of the Asian monsoon anticyclone simultaneously with freshly homogeneously nucleated ice crystals. The observations were possible due to the pilot of the Geophysica aircraft, who dared to fly into the strong updrafts. Because of the dangerous nature of measurements under such conditions, the frequency of convective - and also orographic wave cirrus - is underrepresented in the entire in situ climatology.

\subsubsection{Potential temperature $(\Theta)$ parameter space}

The distribution of Asian monsoon cirrus clouds in the $\Theta$ parameter space is shown in Fig. 11 (right column, panels df). TTL average upper and lower boundaries and the average CPT are marked in panels (b) an (e) of the figure following the definition of Fueglistaler et al. (2009). In Fig. 11 (left column, panels a-c), the climatologies of the tropical observations excluding the Asian monsoon measurements are shown.

From Fig. 11a, d, it can be nicely seen how steeply the IWC increases during the transition from the TTL to the free troposphere. In the tropics outside of the Asian monsoon, the maximum $\Theta$ where ice is detected is about $420 \mathrm{~K}$ $(\sim 19 \mathrm{~km})$. The mixing ratios of these highest cirrus are about 0.05 ppmv. At about $380 \mathrm{~K}$ (CPT, $\sim 16-18 \mathrm{~km})$, the range of the most frequent IWCs broadens, ranging between about 0.005 and 1 ppmv. Some higher IWCs are also detected in the upper TTL, indicating that overshooting convection (liquidorigin cirrus) is also embedded in these measurements. Below about $380 \mathrm{~K}$ the most frequent IWC increases steadily up to values of around $10 \mathrm{ppmv}$ at $355 \mathrm{~K}$ and $1000 \mathrm{ppmv}$ at $340 \mathrm{~K}$ and farther below.

In the Asian monsoon, the maximum $\Theta$ where ice is detected is about $415 \mathrm{~K}(\sim 0.5 \mathrm{ppmv})$, and at $400 \mathrm{~K}$ the IWC ranges between 0.05 and $0.1 \mathrm{ppmv}$, as outside of the Asian monsoon. But, at $380 \mathrm{~K}$ (CPT), the range of most frequent IWCs rises to $0.5-2 \mathrm{ppmv}$ and then steadily increases below about $380 \mathrm{~K}$ to values of around $50-500 \mathrm{ppmv}$ at $355 \mathrm{~K}$. Obviously, IWC near and below the CPT within the Asian monsoon anticyclone is enhanced by a factor of 10 or more by injection of liquid-origin cirrus in overshooting events. The highest TTL IWCs (up to 1000 ppmv) are detected in the Asian monsoon up to $390 \mathrm{~K}$.

These overshooting cirrus around and below the CPT are also seen in high ice crystal numbers $N_{\text {ice }}\left(\gtrsim 0.5 \mathrm{~cm}^{-3}\right)$ when comparing the Asian monsoon with the other tropical regions (Fig. 11b, e). Striking are again the high $N_{\text {ice }}$ values up to $30 \mathrm{~cm}^{-3}$ in the Asian monsoon, already discussed with respect to the temperature parameter space. Here it is visible that this burst of in situ homogeneous ice nucleation in a strong convective event (theoretically described by Jensen and Ackerman, 2006) took place below the CPT.

Above $390 \mathrm{~K}$, at the transition to the stratosphere, $N_{\text {ice }}$ is very low, mostly lower than $0.1 \mathrm{~cm}^{-3}$. Recall that these low concentrations only contain particles $>20 \mu \mathrm{m}$ (Footnote 6 and Appendix A2.2). This means that in the Asian monsoon (Fig. 11e) low concentrations of larger ice crystals (together with higher IWCs) are more often present at such altitudes in comparison to the surrounding tropics.

In the TTL outside of the Asian monsoon, the two branches of more frequent $N_{\text {ice }}$ (and $R_{\text {ice }}$ ) - discussed with respect to the temperature parameter space (Fig. 8e) - are also very clearly visible. The smaller and larger ice crystals with higher and lower concentrations were identified as young and aged cirrus clouds, which most probably have formed in situ. Farther below, $N_{\text {ice }}$ further increases with decreasing $\Theta$ and altitude, and more and more small liquidorigin cloud particles (frozen or liquid) with higher concentrations appear.

\subsection{TTL humidity}

\subsubsection{Temperature parameter space}

Considering the in-cloud and clear-sky $\mathrm{RH}_{\mathrm{ice}}$ in the Asian monsoon (Fig. 10, right column, panels $\mathrm{d}-\mathrm{f}$ ) in comparison to the entire tropical climatologies (Fig. 9, right column, panels $d-f$ ), significant differences are visible. Below about $200 \mathrm{~K}$, the most frequent in-cloud $\mathrm{RH}_{\text {ice }}$ values are found in supersaturated air in the Asian monsoon cirrus. In the entire climatology (Fig. 9, right column, panels d-f) this occurs only below about $185 \mathrm{~K}$. The same is seen in clear-sky $\mathrm{RH}_{\text {ice }}$ : higher supersaturations already occur frequently at higher temperatures in the Asian monsoon comparison to the entire tropical climatology. These higher supersaturations are likely to be influenced by the stronger dynamics in the Asian monsoon but additionally reflect a higher amount of water vapor in the Asian monsoon TTL, visible through the dashed lines in Fig. 10e. They show the increase in $\mathrm{RH}_{\text {ice }}$ caused by the decrease in $\mathrm{H}_{2} \mathrm{O}_{\text {sat,ice }}$ during cooling of air at a constant $\mathrm{H}_{2} \mathrm{O}$ mixing ratio. These lines correspond to $\mathrm{H}_{2} \mathrm{O}$ between 3 and 5 ppmv in the Asian monsoon, while in the total tropical climatology the most frequent $\mathrm{H}_{2} \mathrm{O}$ ranges only between 1.5 and 3 ppmv (Fig. 9; also compare the bottom panels of the figures, where $\mathrm{H}_{2} \mathrm{O}$ is plotted). Due to the higher water vapor mixing ratios, supersaturation already occurs at higher temperatures. Implications of the observed supersaturations are further discussed in Sect. 5.3.

\subsubsection{Potential temperature $(\Theta)$ parameter space}

The high $\mathrm{RH}_{\text {ice }}$ values in and outside of cirrus clouds in the Asian monsoon are also visible in the $\Theta$ representation of the humidity (see Fig. 12d, e). In the tropical climatology outside of the Asian monsoon (Fig. 12a), $\mathrm{RH}_{\text {ice }}$ values most frequently center around saturation inside of the cirrus clouds. In the cloud-free TTL outside of the Asian monsoon (Fig. 12b), a humidification of the layer between $\sim 360$ and $380 \mathrm{~K}$ to $\mathrm{RH}_{\text {ice }}$ around $90 \%$ can be seen (for more details see Schoeberl et al., 2019). 


\section{ASIAN MONSOON \\ StratoClim 2017}
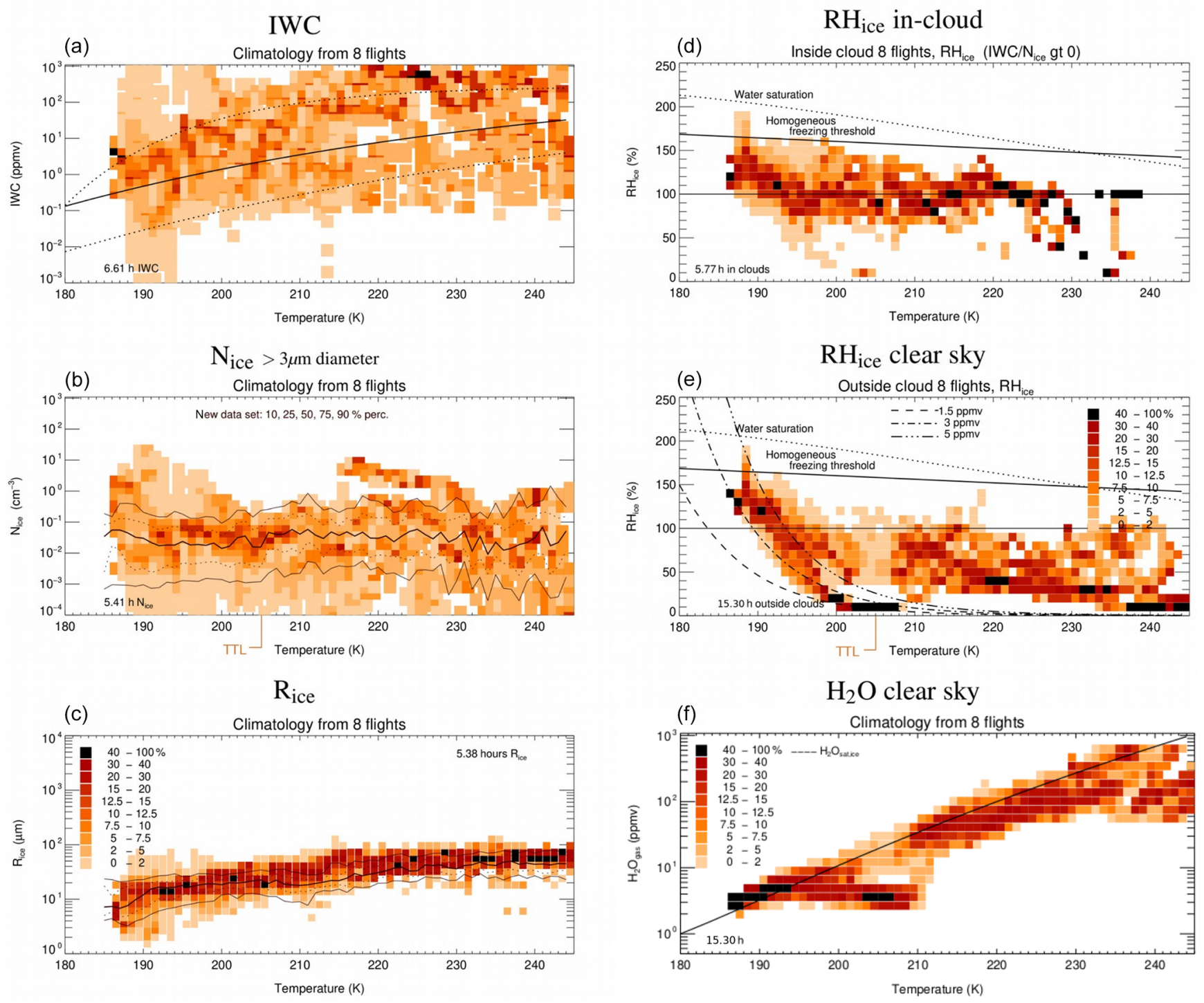

Figure 10. Same as Fig. 7, but for the field campaign StratoClim 2017 above the Asian monsoon.

In the Asian monsoon, on the other hand, the in-cloud $\mathrm{RH}_{\text {ice }}$ in the TTL exceeds saturation (Fig. 12d). In particular, between 380 and $400 \mathrm{~K}$ the most frequent $\mathrm{RH}_{\text {ice }}$ is around $130 \%$. Also outside of clouds (Fig. 12e), around the CPT supersaturation is frequently detected, and in general the humidification is higher than in the surrounding tropical regions. This is in agreement with Schoeberl et al. (2019), who reported high $\mathrm{RH}_{\text {ice }}$ coincident with the Himalaya monsoon during summer and closely associated with convection. The higher $\mathrm{RH}_{\text {ice }}$ in the Asian monsoon in comparison to the other tropical regions, influenced on the one hand by the stronger dynamics as mentioned in the previous section, can also be seen in the $\mathrm{H}_{2} \mathrm{O}$ volume mixing ratios (Fig. 12c, f). In the tropics outside the Asian monsoon, the most frequent $\mathrm{H}_{2} \mathrm{O}$ between 365 and $410 \mathrm{~K}$ is $1.5-4$ ppmv, while in the Asian monsoon we found 3-8 ppmv, as also seen in the temperature parameter space. This finding is in accordance with other studies but has been observed in situ from aircraft directly in the Asian monsoon for the first time. For example, analyzing the air mass histories of higher in situ $\mathrm{H}_{2} \mathrm{O}$ observations at other locations (highest values of $8 \mathrm{ppmv}$ ), Schiller et al. (2009) found that those air masses had passed the Asian monsoon region. Also, Ueyama et al. (2018) (and references therein) reported 5-7 ppmv at $100 \mathrm{hPa}$ from Microwave Limb Sounder (MLS) observations and extensive model simulations over the Asian summer monsoon region. 


\section{TROPICS}

(without Asian monsoon)

IWC
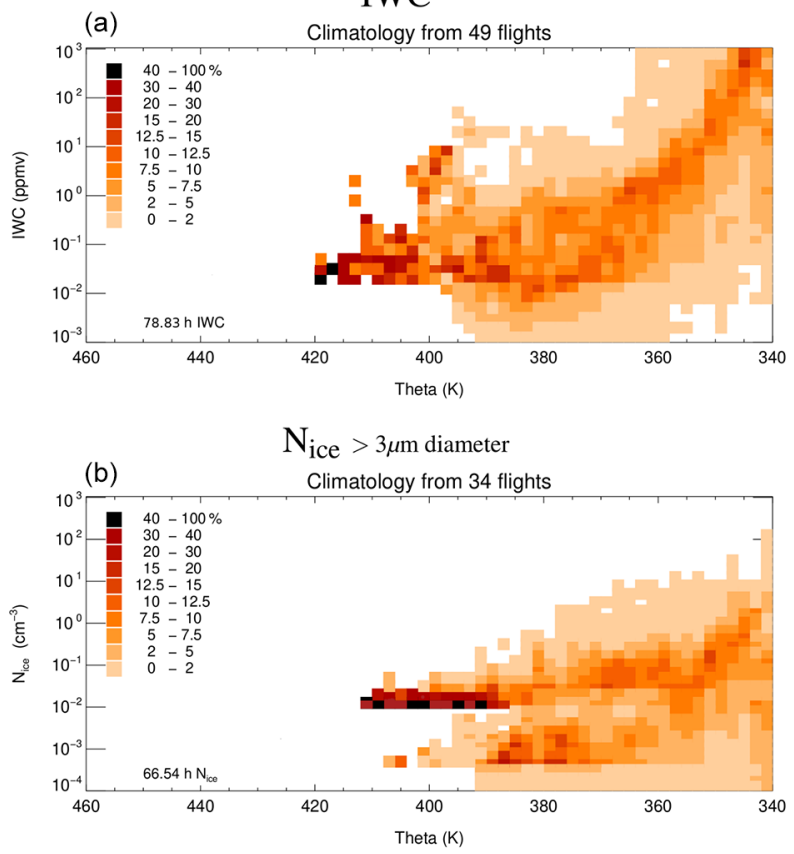

$\mathrm{R}_{\text {ice }}$

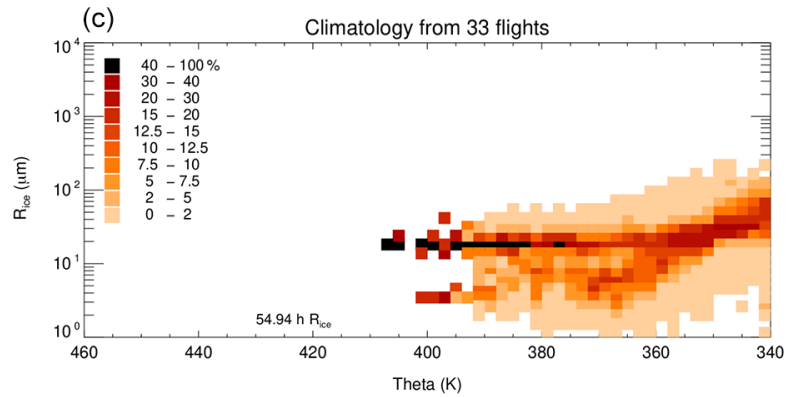

\section{ASIAN MONSOON}

StratoClim 2017
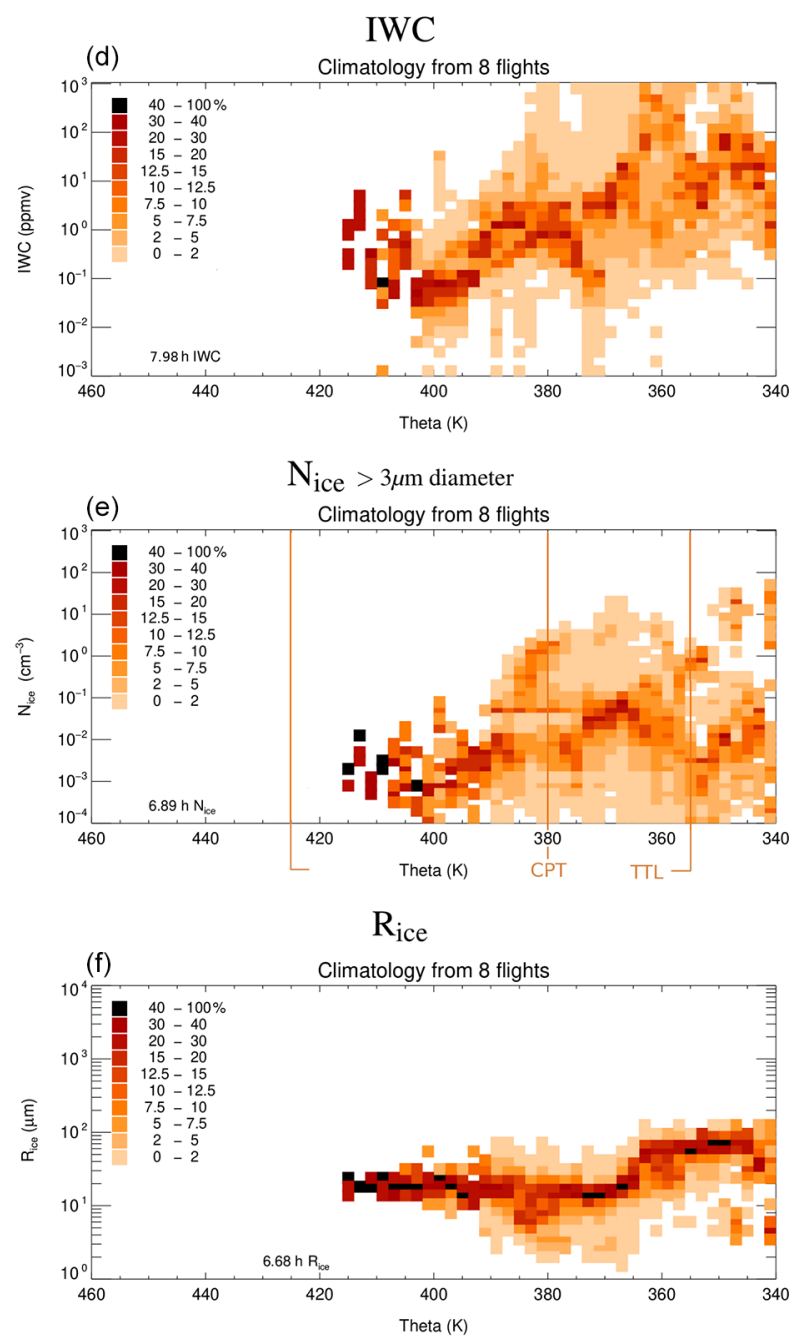

Figure 11. Climatology of cirrus clouds as a function of potential temperature $\Theta$ (left column, panels a-c: tropics without Asian monsoon; right column, panels d-e: Asian monsoon). (b, e) The range of the TTL (after Fueglistaler et al., 2009) and the cold point tropopause (CPT, derived from the observed temperature profiles); the corresponding altitude range is $\sim 14$ to $20 \mathrm{~km}$. Note that in the tropics $355-330$ $\approx 235-275 \mathrm{~K}\left(-38-0{ }^{\circ} \mathrm{C}\right)$ and that the TTL spans from about 425 to $355 \mathrm{~K}$. The field campaigns are listed in Table A2.

\section{3 $\mathrm{H}_{2} \mathrm{O}$ and IWC for transport to the stratosphere}

The $\mathrm{H}_{2} \mathrm{O}$ transport to the stratosphere is regulated by the coldest temperature an air parcel experiences during transition through the tropopause region. The water amount passing the tropopause is set by the freeze-drying process associated with this transition (Jensen and Pfister, 2004) and is discussed to be as low as $\mathrm{H}_{2} \mathrm{O}$ saturation at the minimum temperature (e.g., Schiller et al., 2009).

However, e.g., Rollins et al. (2016) showed for the ATTREX 2014 observations that the water vapor at the stratospheric entry point is higher by $\sim 10 \%$, because the water vapor depletion by ice crystals becomes increasingly ineffi- cient at temperatures below $200 \mathrm{~K}$ (note that this is a rough estimate of the excess water vapor at the stratospheric entry point based on the actual temperature, which could be somewhat different from the minimum temperature of the air parcel's back trajectory). This is of importance, since already small amounts of $\mathrm{H}_{2} \mathrm{O}$ can influence the stratospheric radiation budget (Solomon et al., 2010; Riese et al., 2012).

High supersaturations at the coldest points of the TTL are also discussed in Sect. 5.2.1. The ATTREX 2014 and also POSIDON 2016 observations are included in Fig. 9 (right column, panels $\mathrm{d}-\mathrm{f}$ ), where the most frequent in-cloud and clear-sky $\mathrm{RH}_{\text {ice }}$ at these temperatures can be seen to increase with decreasing temperature as discussed by Rollins 

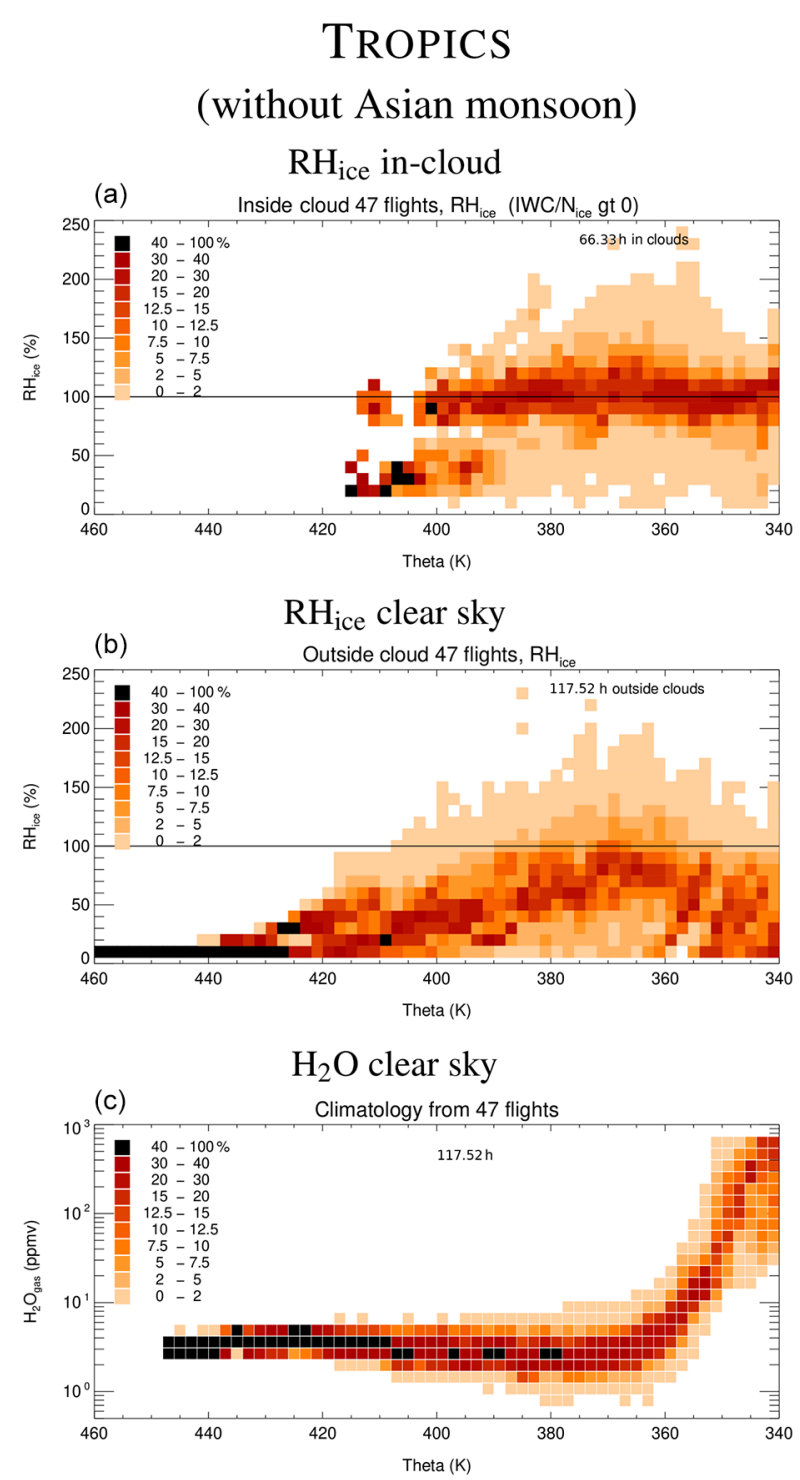

\section{ASIAN MONSOON}

StratoClim 2017
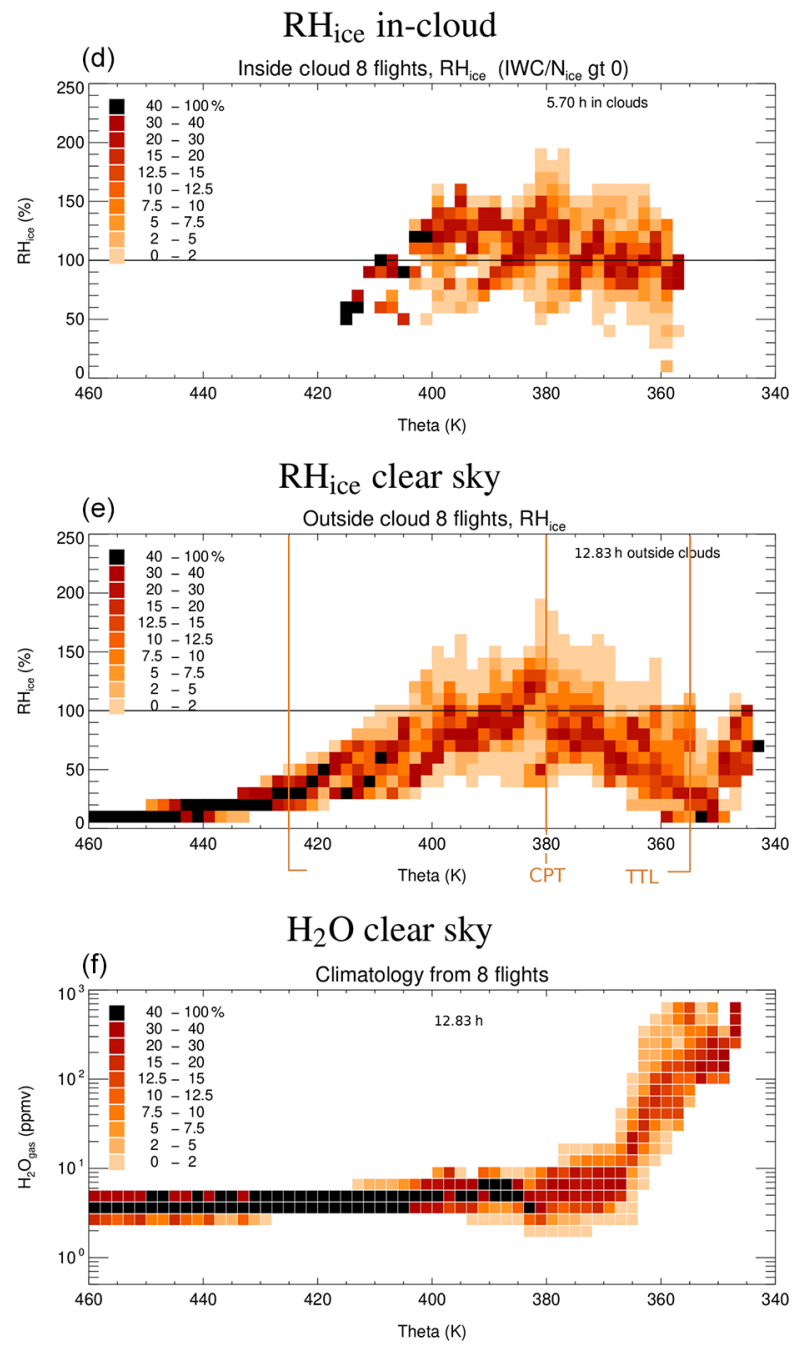

Figure 12. Climatology of humidity as a function of potential temperature $\Theta$ (left column, panels a-c: tropics without Asian monsoon; right column, panels d-f: Asian monsoon). The range of the TTL (after Fueglistaler et al., 2009) and the cold point temperature (CPT, derived from the observed temperature profiles) are marked in panels (b,e); the corresponding altitude range is $\sim 14$ to $20 \mathrm{~km}$. Note that in the tropics $355-330 \approx 235-275 \mathrm{~K}\left(-38-0^{\circ} \mathrm{C}\right)$ and that the TTL spans from about 425 to $355 \mathrm{~K}$. The field campaigns are listed in Table A2.

et al. (2016). However, in the Asian monsoon measurements (Fig. 8, right column, panels $\mathrm{d}-\mathrm{f}$ ), $\mathrm{RH}_{\text {ice }}$ at the coldest temperatures is even higher above saturation than in the calmer tropics outside; the saturation is exceeded by about $20 \%-$ $50 \%$ below $195 \mathrm{~K}$. Therefore, we hypothesize that the conclusion of Rollins et al. (2016) might be extended: taking saturation at the stratospheric entry of an air mass as the set point for water vapor transport to the stratosphere, the transport is underestimated by $\sim 10 \%$ in regions of weak convective activity. In convective regions the underestimation increased to $20 \%-50 \%$ in our observations. Note however that this hypothesize is based on a limited set of measurements and needs to be confirmed for the climatological conditions that prevail in the Asian monsoon TTL.

As mentioned earlier, the question of how much $\mathrm{H}_{2} \mathrm{O}$ from convectively injected ice crystals is transported from above the CPT further into the lower stratosphere is a subject of recent research. In the study of Ueyama et al. (2018), it is concluded that over the Asian monsoon at $100 \mathrm{hPa}$, convection is the dominant driver of the localized $\mathrm{H}_{2} \mathrm{O}$ and that nearly all of the convective enhancements in $\mathrm{H}_{2} \mathrm{O}$ are due to the effect of convective humidification, while convectively detrained ice crystals have a negligible impact.

From our measurements in and above the Asian monsoon anticyclone, it is difficult to estimate to what extent cirrus 
cloud particles contribute to the amount of $\mathrm{H}_{2} \mathrm{O}$ that might enter the stratosphere. Nevertheless, from Sect. 5.1 we know that the most frequent IWCs between about 365 and $400 \mathrm{~K}$ range from about 10 down to $0.5 \mathrm{ppmv}$. Above $400 \mathrm{~K}$, up to $415 \mathrm{~K}$ some overshoots with IWCs between 0.5 and 8 ppmv are detected (Fig. 11d). These IWCs are similar to the amount of gas phase $\mathrm{H}_{2} \mathrm{O}$, which is between 3 and 8 ppmv in this region above the CPT (see last section). Such amounts of $\mathrm{H}_{2} \mathrm{O}$ and IWC indicate that the air masses originate from an altitude of about $15 \mathrm{~km}$ (Fig. 3), which corresponds approximately to the lower boundary of the TTL (see Fig. 2).

The question remains of whether the ice particles found in the upper TTL will further grow and sediment out in supersaturated conditions (dehydration) or evaporate and add $\mathrm{H}_{2} \mathrm{O}$ to the gas phase $\mathrm{H}_{2} \mathrm{O}$ in subsaturation (hydration; see Jensen et al., 2007; Schoeberl et al., 2018). Inspecting the in-cloud $\mathrm{RH}_{\text {ice }}$ (see Fig. 12d) related to the respective IWCs, it can be seen that the air in the overshoots $\gtrsim 400 \mathrm{~K}$ with the fairly high IWCs ( 0.5 to $8 \mathrm{ppmv})$ is subsaturated, while at lower altitudes both super- and subsaturation occur. This means that convective overshoots in the Asian monsoon can locally contribute a significant amount of water that might be further transported into the stratosphere. Unfortunately, we cannot say anything about the frequency of these events in this study.

Above the CPT in the surrounding tropics outside of the Asian monsoon, the in-cloud $\mathrm{RH}_{\text {ice }}$ values at $\gtrsim 400 \mathrm{~K}$ are also subsaturated. Here, the IWCs range only between 0.02 and 2 ppmv, with some single data points up to about 2 ppmv. The related $\mathrm{H}_{2} \mathrm{O}$ is 1.5 to 3 ppmv.

Comparing gas phase $\mathrm{H}_{2} \mathrm{O}$ and IWC above the Asian monsoon CPT (both 3-8 ppmv) with the surrounding tropical regions (1.5-3 and 0.02-2 ppmv) might be an indication by in situ observations that, driven by overshooting convection, the Asian monsoon could be an important source for transport of $\mathrm{H}_{2} \mathrm{O}$ to the stratosphere.

\section{Global cirrus $N_{\text {ice }}$ climatology from satellite remote sensing}

Though the new in situ cirrus climatologies presented in Sect. 4 represent a considerable data set from research aircraft from which substantial insights are gained, it is still a mixture of different meteorological situations encountered during various field campaigns that does not necessarily display a statistically representative overall picture of the distribution of cirrus cloud properties. For this purpose, longterm global satellite remote sensing observations would be the method of choice, though retrievals of cirrus microphysical properties also have their own difficulties and limitations. This is especially true for the ice crystal number $N_{\text {ice }}$, which is particularly challenging to estimate from satellite remote sensing. The new retrieval method for $N_{\text {ice }}$ introduced in Sect. 2.2, DARDAR-Nice, has however demonstrated the ability to satisfactorily reproduce in situ ice concentrations (Sourdeval et al., 2018a).

In this section, we show a global climatology of $N_{\text {ice }}$ derived from DARDAR-Nice in the same presentation as the in situ $N_{\text {ice }}$ climatology. Median $N_{\text {ice }}, 25$ th and 75th, and 10th and 90th percentiles are provided for a global data set. In addition, median $N_{\text {ice }}$ values are discussed for the Arctic region, the northern midlatitudes, the tropics, the southern midlatitudes, and Antarctica.

\subsection{Comparison of remote sensing and in situ $\mathrm{N}_{\text {ice }}$}

As a base for reliable $N_{\text {ice }}$ climatologies from satellite remote sensing, in situ measurements of PSDs (ice particle size distributions) from five campaigns of the Cirrus Guide II are used for an evaluation of the DARDAR-Nice retrieval algorithm (see Sect. 2.2). This directly follows the evaluation of DARDAR-Nice presented in Sourdeval et al. (2018a), in which a subset of campaigns from the Cirrus Guide II data set was used. This section therefore focuses on these five campaigns, which are nevertheless representative of a wide range of midlatitude and tropical ice clouds (see Fig. 1 and caption of Fig. 13). Figure 13a shows the $N_{\text {ice }}$ frequencies of occurrence in $1 \mathrm{~K}$ temperature bins of the in situ measurements; the corresponding frequencies obtained from DARDAR-Nice are shown in panel (b). The latter are derived on the basis of two input parameters which are extracted from the in situ PSDs of the five campaigns listed in the figure caption, rather than being constrained from lidar-radar measurements during usual retrievals. This approach allows the identification of inherent incompatibilities between the satellite retrieval assumptions and the in situ measurements, by assuming that the in situ PSD parameters are perfectly constrained by the lidar-radar. Therefore, possible differences should only be attributed to other retrieval assumptions, such as the PSD shape. Sourdeval et al. (2018a) showed that this approach is efficient for identifying algorithmic limitations while still being representative of actual satellite retrievals. Note that DARDAR-Nice provides concentrations of ice crystals $>5 \mu \mathrm{m}$, as it has not been evaluated for smaller sizes, while $N_{\text {ice }}$ from in situ observations includes sizes $>3 \mu \mathrm{m}$; however, the resulting difference in the ice concentrations is negligible. Also, the $1 \mathrm{~Hz}$ in situ PSDs are here sampled into $10 \mathrm{~s}$ averages to simulate the $1.7 \mathrm{~km}$ horizontal resolution of the DARDAR-Nice retrievals (assuming a flight speed of about $170 \mathrm{~m} \mathrm{~s}^{-1}$ ).

The black solid and dotted lines of the in situ climatology indicate the 50th, 25 th, and 75 th percentiles, which agree well with those of the entire in situ climatology (see Fig. 7b). This demonstrates that the selected subset is statistically representative of the entire database (indeed, the entire $N_{\text {ice }}$ climatology contains only one additional campaign; see Table A2). A satisfactory agreement between DARDAR-Nice and the in situ observations is also seen, demonstrating that 


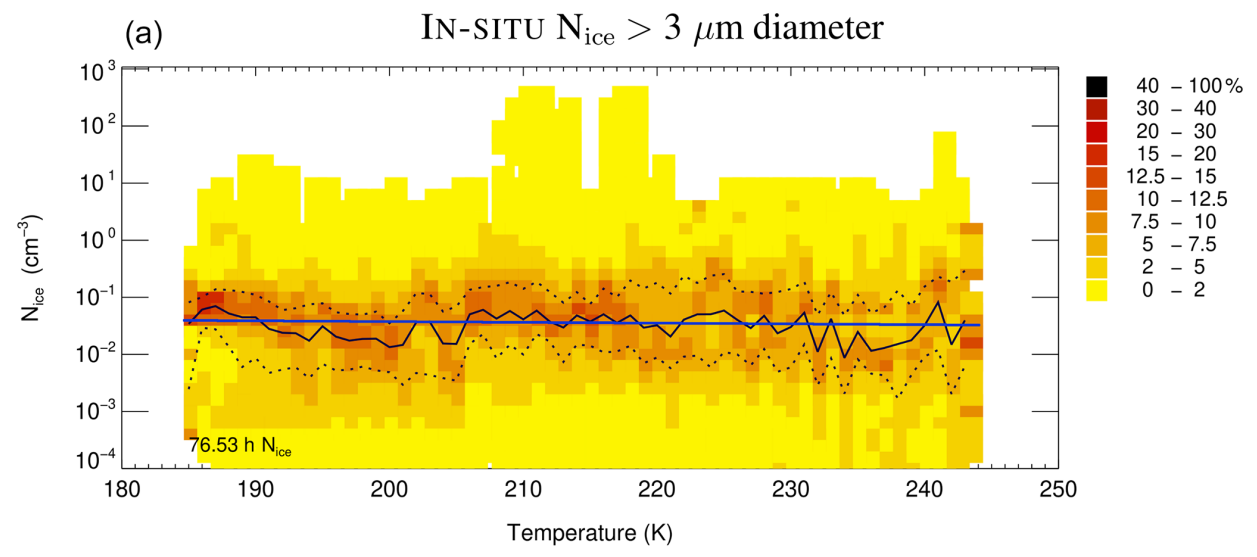

(b)

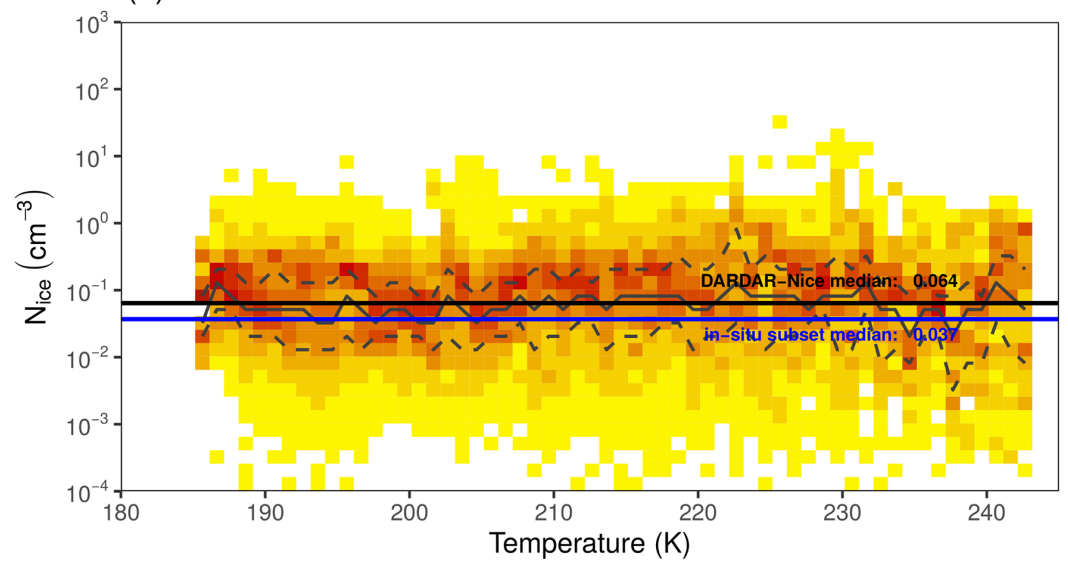

Figure 13. $N_{\text {ice }}$-temperature climatologies from (a) in situ measurements during the field campaigns COALESC2011, ATTREX2014, ACRIDICON2014, ML-CIRRUS2014, and STRATOCLIM2017 and (b) satellite remote sensing, applying the algorithm DARDAR-Nice $f\left(N_{0}^{\star}, D_{\mathrm{m}}\right)$ to $N_{0}^{\star}$. $D_{\mathrm{m}}$ derived from the in situ observations. The black contours represent the 25th, 50th, and 75th percentiles. Straight black line: DARDAR-Nice average median $N_{\text {ice }}\left(0.064 \mathrm{~cm}^{-3}\right)$; straight blue line: in situ average median $N_{\text {ice }}\left(0.037 \mathrm{~cm}^{-3}\right)$. The excess of $N_{\text {ice }}$ by a factor of 1.73 in DARDAR is caused by the retrieval method; for more information see the text.

DARDAR-Nice $N_{\text {ice }}$ retrievals match the in situ database for known size distributions very well.

A detailed comparison of the DARDAR-Nice percentiles (black solid and dashed lines) with those of the in situ observations, however, yields a small offset by a factor of 1.73 , which is visualized in Fig. 13 by the average medians of DARDAR-Nice (straight black line, $0.064 \mathrm{~cm}^{-3}$ ) and in situ (straight blue line, $0.037 \mathrm{~cm}^{-3}$ ). One reason for this offset lies in the method of the retrieval. The two parameters, $N_{0}^{\star}$ and $\mathrm{D}_{\mathrm{m}}$, calculated here from the in situ PSDs (usually from lidar-radar observations) are fed into a predefined fourparameter gamma-modified function to calculate ice particle size distributions (PSDs; see Sect. 2.2). $N_{\text {ice }}$ is then calculated by summing up individual ice concentrations over a grid of size bins distributed over the gamma-shaped PSD for the entire range of observed ice crystal sizes (usually, a continuous integration of the PSD is performed). However, in the in situ measurements, there are often PSDs that do not contain ice particles $<20 \mu \mathrm{m}$; i.e., these size bins are empty. Such PSDs represent aged cirrus after the ice nucleation phase where the smaller ice crystals have grown to larger sizes (see Sect. 4.3.1). DARDAR-Nice, however, assumes a modified gamma distribution including all size bins, which partly explains the described positive offset. This behavior was also found by Wolf et al. (2019), who parameterized in situ-origin and liquid-origin cirrus from balloonborne measurements by gamma functions. It is of note that when subtracting the ice concentrations of the "empty bins" of in situ PSDs from the retrieved DARDAR-Nice in a direct intercomparison, the agreement of $N_{\text {ice }}$ is improved (not shown here). This is an important finding, as gamma functions are often used to represent cirrus PSDs, both in remote sensing retrieval algorithms and in global models. On the other hand it has to be noted that an offset on the order of a factor of 1.73 is tolerable given the variability of $N_{\text {ice }}(6$ 
orders of magnitude) and other possible error sources in the measurements, both in situ and remote sensing.

Other assumptions on the PSD shape by the satellite remote sensing method might also contribute to this bias. The PSD shape indeed is provided by four parameters, two of which are fixed and two are retrieved (see Sect. 2.2). Delanoë et al. (2014) showed that the two fixed PSD parameters defined by Delanoë et al. (2005) and used in DARDARNice might lead to a too steep representation of the small ice mode (i.e., too high $N_{\text {ice}}$ ) and should be updated in future algorithm versions. Also, the bimodality of the PSD towards temperature where growth processes become important is not accounted for and usually leads to small positive $N_{\text {ice }}$ biases (Sourdeval et al., 2018a). The causes of these assumptions are difficult to account for, as they most likely depend on the cloud type and on the thermodynamical environment, but they should to first order be reasonably captured by the 1.73 adjustment factor. Higher $N_{\text {ice }}$ values in DARDAR-Nice towards low temperatures are also not surprising, as Sourdeval et al. (2018a) reported that the PSD parametrization used by DARDAR-Nice predicts higher concentrations of small particles $\left(D_{\text {ice }}<25 \mu \mathrm{m}\right)$ than the in situ comparative measurements. The overestimation increases with decreasing temperature, as the small ice particles dominate the PSDs more and more. This might be caused by a sharper representation of small ice concentrations in the PSD parametrization in comparison to the in situ small ice particle measurements below $\sim 210 \mathrm{~K}$.

A further expected difference between the data sets arises from their detection limits. The lowest $N_{\text {ice }}$ that can be detected by the in situ instruments is $10^{-4} \mathrm{~cm}^{-3}$; for the highest $N_{\text {ice }}$ there is no limitation. Detection limits for DARDARNice depend on lidar-radar sensitivity but are also influenced by the instrumental resolution, which may cause specific features to remain undetected. This effect, however, is represented in Fig. 13 by the $10 \mathrm{~s}$ sampling of $1 \mathrm{~Hz}$ in situ PSDs. Indeed, DARDAR-Nice misses the high $N_{\text {ice }}$ in the temperature range $210-220 \mathrm{~K}$, but these are young, lineshaped contrails which are too small scale to be detected by satellite. Also, part of the thinnest cirrus are not represented by DARDAR-Nice. This will be further discussed in the next section describing the global $N_{\text {ice }}$ distribution from DARDAR-Nice.

Overall, following the abovementioned arguments, an overestimation within a factor of 2 in DARDAR-Nice by comparison to the in situ data set is expected, although there is still some uncertainty as to how this overestimation will propagate globally and over various ice cloud regimes. The ratio of 1.73 in $N_{\text {ice }}$ between DARDAR-Nice and the in situ data set, found from Fig. 13, should therefore be thought of as a minimum expected bias. Finally, the bias is expected to be stronger at low temperatures than at high temperatures, due to the increased likelihood of empty size bins as well as the higher importance of the representation of the small ice particle mode in the PSDs. A correction that depends on

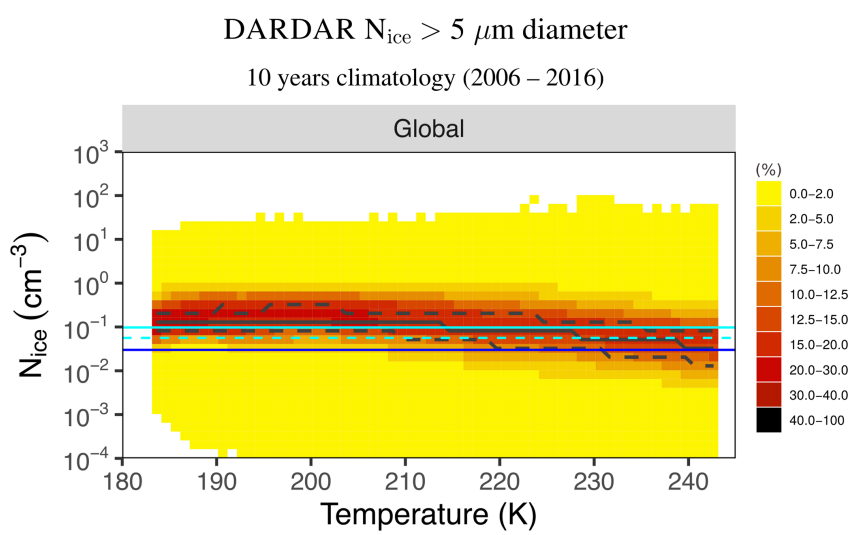

Figure 14. $N_{\text {ice }}$-temperature climatology from 10 years of satellite remote sensing observations using DARDAR-Nice. The data were collected twice a day, at midday and at midnight. Thick black lines: 25th, 50th, and 75th percentiles; thin plain cyan line: DARDARNice median $N_{\text {ice }}$; thin dotted cyan line: DARDAR-Nice median $N_{\text {ice }}$ adjusted to the offset factor of 1.73 between DARDAR-Nice and the in situ observations (see Fig. 13); blue line: in situ average median $N_{\text {ice }}$ (from Fig. 7). Temperature intervals containing fewer than 10 retrievals were excluded (results not sensitive to exact threshold).

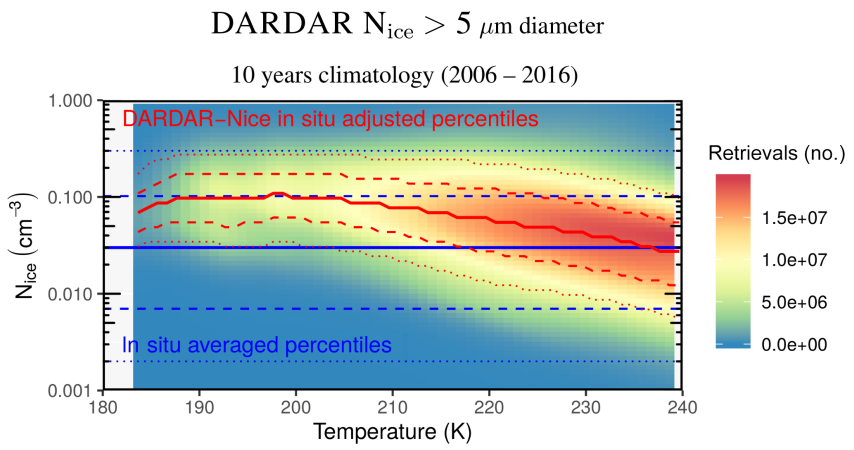

Figure 15. $N_{\text {ice }}$-temperature climatology across the entire $N_{\text {ice }}-T$ parameter space. Red lines: global DARDAR-Nice percentiles (adjusted to the in situ observations by the offset factor of 1.73 ; see Fig. 13). The 10th and 90th, 25th and 75th, and 50th percentiles are indicated by dotted, dashed, and plain lines, respectively. Blue lines: in situ average percentiles (from Fig. 7). The percentiles are recommended for intercomparison with other data sets (the corresponding numbers are listed in Table 2); regional median $N_{\text {ice }}$ values are shown in Table 3. The shaded background indicates the occurrence of retrievals, i.e., cirrus clouds. The cirrus appear most often at higher temperatures above about $225 \mathrm{~K}$.

temperature, and possibly IWC, might therefore be optimal but a simpler first-order correction of 1.73 for all $T$ and IWC ranges should here be sufficient for the needs of this study and considering the multitude of processes that can lead to this bias. Future studies will be required to precisely understand such inherent differences between satellite and in situ data set. 


\subsection{Global cirrus $N_{\text {ice }}$}

The global frequency distribution of $N_{\text {ice }}$ from 10 years of satellite observations is shown in Fig. 14. The data were collected twice a day, approximately at midday and at midnight (satellite Equator-crossing time is 01:30 and 13:30), from June 2006 to December 2016. It should still be noted that satellite retrievals are not continuously available throughout this period due to instrumental limitations, and nighttime retrievals are only available until 2011. This does not impact the conclusions presented here as diurnal cycles in $N_{\text {ice }}$ are not considered in this study. Such variations are also difficult to quantify from lidar-radar products, although a diurnal signature has been investigated in the DARDAR-Nice $N_{\text {ice }}$ data for tropical anvils (Wall et al., 2020). Overall, the global satellite data set consists of nearly $2 \times 10^{10} N_{\text {ice }}$ retrievals. The color code represents frequencies of occurrence, and the black contours represent the 25th, 50th, and 75th percentiles.

From the median (solid black line), a slight increase in $N_{\text {ice }}$ with decreasing temperature is visible, which is somewhat different to the in situ median $N_{\text {ice }}$ (solid blue line, from Fig. 7b), where no temperature dependence is found. The DARDAR-Nice temperature dependence was already noted and discussed by Gryspeerdt et al. (2018). Another difference is that at $T \gtrsim 210 \mathrm{~K}$, the maximum $N_{\text {ice }}$ of DARDAR-Nice reaches up to $100 \mathrm{~cm}^{-3}$, while the maximum in situ $N_{\text {ice }}$ is only about $10 \mathrm{~cm}^{-3}$ (outside of young contrails).

The slightly increasing median $N_{\text {ice }}$ with decreasing temperature might be attributed to homogeneous ice nucleation events, because homogeneous ice nucleation rates increase with decreasing temperature, but their appearance in space and time is transient, as discussed in Sect. 4.2.2. Such events are difficult to find by research aircraft and could be underrepresented in the aircraft observations.

The thinnest cirrus with low $N_{\text {ice }}$ are represented by DARDAR-Nice for temperatures $\gtrsim 190 \mathrm{~K}$. At $\lesssim 190 \mathrm{~K}$, however, a decreasing detectability of thin cirrus becomes apparent in the DARDAR-Nice climatology: in contrast to the in situ climatology, lesser or no thin cirrus are measured with decreasing temperature. The reason is that the colder the cirrus clouds, the smaller the ice crystals and the lesser their IWC (Fig. 10a, c). In the in situ $N_{\text {ice }}$ climatology, in the TTL $(\lesssim 205 \mathrm{~K})$, an increased occurrence of very thin cirrus with $N_{\text {ice }}$ around $0.001 \mathrm{~cm}^{-3}$ is reported in Sect. 4.3.1 and explained as aged cirrus consisting of only larger ice crystals. Though this type of clouds is partly missing in the DARDAR-Nice climatology, the median $N_{\text {ice }}$ decreases again at these temperatures. This might reflect the frequent presence of aged thin cirrus. Note, however, that the statistics at these temperatures is based on a lower number of observations than at higher temperatures (see Fig. 15).

The median $N_{\text {ice }}$ across all temperatures of the 10-year DARDAR-Nice climatology is about $0.100 \mathrm{~cm}^{-3}$ (Fig. 14, solid cyan line). Adjusting this number to the offset factor of 1.73 between DARDAR-Nice and the in situ observations reported in the previous section yields an in situ average median of $0.056 \mathrm{~cm}^{-3}$ (dashed cyan line; see also Table 3). It is nevertheless important to note that such a median is by construction computed assuming that all temperature bins have equal weight. When considering their actual relative occurrence as a function of temperature (see Fig. 15 and later discussion), the in situ adjusted global DARDAR-Nice median falls down to $0.046 \mathrm{~cm}^{-3}$. This is still larger than the average median of $0.03 \mathrm{~cm}^{-3}$ reported from the $N_{\text {ice }}$ in situ climatology (blue line; from Fig. 7). Nevertheless, in light of the offset between the data sets, the decreasing detectability of thin cirrus by DARDAR-Nice, and other sources of error in both methods, the agreement between the DARDAR-Nice and the in situ $N_{\text {ice }}$ climatology is good.

Altogether, both data sets have advantages and disadvantages: DARDAR-Nice has the advantage of the long, global time series where all atmospheric situations above the detection limit showing up at the times of observations are sampled. However, the thinnest cirrus at cold temperatures are not detected. Further, an offset is found between DARDARNice and the in situ observations. On the other hand, the in situ $N_{\text {ice }}$ climatology is based on a much smaller data set which is randomly distributed between different atmospheric situations. However, nearly the complete range of possible

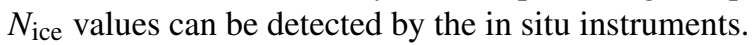

For comparisons with other $N_{\text {ice }}$ data sets or results from global models, the percentiles of the adjusted DARDARNice and the average in situ $N_{\text {ice }}$ values are shown in Fig. 14 and listed in Table 2 (note that an in situ data set slightly smaller than the data set presented here, but extended with regard to Krämer et al., 2009, is already used for this purpose by Bacer et al., 2018; Penner et al., 2018; Righi et al., 2020).

The DARDAR-Nice data set not only provides the $N_{\text {ice }}$ distribution with temperature as shown in Fig. 14, but, as it also contains the entire spatial and temporal $N_{\text {ice }}$ information, also the actual appearance of cirrus clouds in the $N_{\text {ice }}-T$ parameter space. This is shown in Fig. 15, where the occurrences of DARDAR-Nice $N_{\text {ice }}$ retrievals are indicated by the colored background. It can be noticed that, in regions of high frequency of occurrence (for $T \gtrsim 210 \mathrm{~K}$ ), the agreement between DARDAR-Nice and the in situ data set is best.

From this portrayal it can be seen that the cirrus clouds do not spread evenly across all temperatures, but that about $50 \%$ of the cirrus appear at temperatures above about $225 \mathrm{~K}$ (see also Table 3, temperature range of global "most frequent" median $N_{\text {ice }}$ ). This clustering of cirrus at warmer temperatures, also reported by Yang et al. (2010) from CALIPSO cloud climatologies, is likely because in situ-origin and liquid-origin cirrus clouds are both found in this warmest and lowest cirrus layer, while at colder temperatures and higher altitudes only in situ-origin cirrus are present (see also Sect. 3.1 and Fig. 3). This vertical structure of the cloud types is also reported from observations by Krämer et al. (2016), Luebke et al. (2016), and Wolf et al. (2018); from global 
Table 2. DARDAR-Nice and in situ observation $N_{\text {ice }}$ percentiles (as portrayed in Fig. 15) for intercomparison with global models or other data sets.

\begin{tabular}{crrrrr}
\hline $\begin{array}{c}\text { Temperature } \\
(\mathrm{K})\end{array}$ & \multicolumn{5}{c}{$\begin{array}{c}\text { In situ adj. DARDAR-Nice } \\
N_{\text {ice }}\left(\mathrm{cm}^{-3}\right)\end{array}$} \\
\hline & 10th perc. & 25th perc. & Median & 75th perc. & 90th perc. \\
\hline $180-190$ & 0.034 & 0.051 & 0.087 & 0.149 & 0.243 \\
$190-200$ & 0.033 & 0.055 & 0.100 & 0.173 & 0.274 \\
$200-210$ & 0.028 & 0.051 & 0.091 & 0.163 & 0.265 \\
$210-220$ & 0.017 & 0.034 & 0.068 & 0.133 & 0.239 \\
$220-230$ & 0.011 & 0.022 & 0.049 & 0.102 & 0.195 \\
$230-240$ & 0.007 & 0.015 & 0.033 & 0.068 & 0.130 \\
\hline Temperature & & \multicolumn{5}{c}{$N_{\text {ice }}\left(\mathrm{cm}^{-3}\right)$} \\
all & 10th perc. & 25th perc. & Median & 75 th perc. & 90th perc. \\
\hline & 0.002 & 0.007 & 0.03 & 0.102 & 0.3 \\
\hline
\end{tabular}

Table 3. DARDAR-Nice median $N_{\text {ice }}$ (as portrayed in Fig. 15) for five regional latitude bands, Arctic: 90-67.7, midlat. north: 67.7-23.3, tropics: 23.3 to $-23.3^{\circ}$, midlat. south: -23.3 to $-67.7^{\circ}$, Antarctica: -67.7 to $-90^{\circ}$, as well as global median $N_{\text {ice }}$. All temp.: median without temperature binning; $T$-int weighted: median using the relative occurrence of each temperature interval as a weight; most frequent: median considering those temperature intervals that contain $50 \%$ of the total $N_{\text {ice }}$ occurrence. $T$ range denotes the respective minimum and maximum temperatures.

\begin{tabular}{|c|c|c|c|c|}
\hline \multirow[t]{3}{*}{ Region } & \multicolumn{4}{|c|}{$\begin{array}{l}\text { In situ adj. DARDAR-Nice } \\
\qquad N_{\text {ice }}\left(\mathrm{cm}^{-3}\right)\end{array}$} \\
\hline & \multicolumn{4}{|c|}{ Medians } \\
\hline & All temp. & $T$-int weighted & Most frequent & $T$ range \\
\hline Arctic & 0.036 & 0.023 & 0.016 & $230-242 \mathrm{~K}$ \\
\hline Midlat. north & 0.057 & 0.040 & 0.030 & $227-242 \mathrm{~K}$ \\
\hline Tropics & 0.070 & 0.067 & 0.074 & $197-221 \mathrm{~K}$ \\
\hline Midlat. south & 0.057 & 0.043 & 0.031 & $227-242 \mathrm{~K}$ \\
\hline Antarctica & 0.050 & 0.045 & 0.029 & $222-242 \mathrm{~K}$ \\
\hline Global & 0.056 & 0.046 & 0.031 & $224-242 \mathrm{~K}$ \\
\hline
\end{tabular}

modeling by Gasparini and Lohmann (2016); from satellite and global modeling by Gasparini et al. (2018); and also from 12-year ERA-Interim data analysis in the North Atlantic region by Wernli et al. (2016).

Gasparini et al. (2018) provide global relative frequencies of liquid-origin cirrus with respect to temperature: more than $50 \%$ of the cirrus clouds in the range between 235 and $220 \mathrm{~K}$ are of liquid origin, decreasing rapidly to about $20 \%$ between 200 and $180 \mathrm{~K}$. These findings from satellite observations and global modeling are reasonably consistent with those from trajectory analysis by Wernli et al. (2016), who reported the relative frequencies of liquid-origin cirrus with respect to pressure to decrease from about $55 \%$ of the cirrus at $500 \mathrm{hPa}$ (roughly $240 \mathrm{~K}$ ) to $50 \%, 30 \%$, and $5 \%$ at 400 , 300 , and $200 \mathrm{hPa}$ (roughly 230, 215, $200 \mathrm{~K}$; see Fig. 2).

The analysis presented here provides the information that globally half of the cirrus are in the lowest, warmest cirrus layer between about 220 and $240 \mathrm{~K}$, where, as mentioned above, about half of the cirrus are of liquid origin. This is of importance because of the differing radiative properties of in situ-origin and liquid-origin cirrus shown in Sect. 3.1.1 (see Fig. 5): if the thick liquid-origin cirrus clouds occur with such a high frequency, their strong cooling effect might exceed the much smaller warming effect of the in situ-origin cirrus, which could lead to a general cooling by cirrus.

Note that an analysis of $N_{\text {ice }}$ in the IWC- $T$ space, similarly to Fig. 6, is shown in Fig. 5 of the Supplement. This figure shows a good climatological agreement between the satellite product and the Cirrus Guide II data set, with very similar distribution of $N_{\text {ice }}$ in the IWC- $T$ space. Differences could be attributed to lack of statistics in Fig. 6 (noisy patterns). However, one notable difference is the slope of the IWC- $T$ relation, which appears much flatter in the satellite 
product than in the in situ data, as indicated by the density isolines.

\subsection{Regional cirrus $N_{\text {ice }}$}

Lastly, we provide an impression of the regional variations in $N_{\text {ice }}$ (see Table 3). To this end, subsets of the DARDARNice data for five regional latitude bands between 90, 67.7, $23.3,-23.3,-67.7$, and $-90^{\circ}$ corresponding to the Arctic, midlat. north, the tropics, midlat. south, and Antarctica are considered, and three different $N_{\text {ice }}$ medians are computed for each region and for the global data set. A first median (labeled "All temp.") corresponds to the median $N_{\text {ice }}$ value across all temperatures and considering all temperature bins to be equally probable, i.e., the same as used in Fig. 14. A second (labeled " $T$-int weighted") represents the median using the relative occurrence of each temperature interval as a weight. The last ("Most frequent") shows the most frequently appearing $N_{\text {ice }}$, considering those temperature intervals that contain $50 \%$ of the total $N_{\text {ice }}$ occurrence; $T$ range denotes the respective minimum and maximum temperatures (note that in the in situ data set all three methods would yield to an identical median due to the flat temperature dependence).

Comparing the three median $N_{\text {ice }}$ values, it is obvious that in most cases the " $T$-int weighted" and "most frequent" medians are smaller than those for "all temperatures". This behavior is found because the cirrus clouds often appear at warmer temperatures (see previous subsection) where $N_{\text {ice }}$ is moderate, which can be seen particularly in the most frequent medians, where the temperature range of the cirrus occurrence is given.

The global most frequent median $N_{\text {ice }}$ is $0.031 \mathrm{~cm}^{-3}$ (in comparison to 0.056 and $0.046 \mathrm{~cm}^{-3}$ for all temperatures and $T$-int weighted) in the temperature range between 224 and $242 \mathrm{~K}$ (note that, to avoid representing mixed-phase clouds in the DARDAR-Nice analysis, $242 \mathrm{~K}$ is chosen as the maximum temperature). The lowest $N_{\text {ice }}$ values are found in the Arctic (most frequent median $0.016 \mathrm{~cm}^{-3}$ between 230 and $242 \mathrm{~K}$ ), which is most probably because the updrafts in the Arctic regions are generally lower than in other regions. In Antarctica, the most frequent median is higher $\left(0.029 \mathrm{~cm}^{-3}\right.$ between 224 and $\left.242 \mathrm{~K}\right)$. This could be traced back to stronger orographic uplifts in austral winter. The boreal and austral midlatitude cirrus clouds are similar to the global, with most frequent medians of 0.030 and $0.031 \mathrm{~cm}^{-3}$ in the temperature range of $227-242 \mathrm{~K}$. This points to moderate updrafts on average, though regionally orography and convection can cause higher updrafts and high $N_{\text {ice }}$, which is also shown by Sourdeval et al. (2018a).

Tropical cirrus clouds are different from those in the other regions. The most frequent cirrus have the highest median $\left(0.074 \mathrm{~cm}^{-3}\right)$ and appear at much colder temperatures (197$221 \mathrm{~K}$ ), i.e., higher altitudes. This finding corresponds to the in situ observations presented in Sect. 3.1 (see Fig. 3) and also the DARDAR-Nice analyses of the vertical distribution of $N_{\text {ice }}$ shown by Sourdeval et al. (2018a). The reason is the strong convection prevailing in tropical regions, lifting liquid-origin clouds up to high altitudes and cold temperatures, while also homogeneously nucleating a large number of in situ ice crystals (see also Sect. 5).

For all regions, except the tropics, more than half of the cirrus clouds are found at temperatures warmer than about $225 \mathrm{~K}$ and contain a considerable amount of liquid-origin cirrus, as discussed in the previous subsection. The same is true in the tropics, but for colder temperatures.

\section{Summary and conclusions}

The Cirrus Guide II aims to represent cirrus clouds and their environment from the perspective of in situ and satellite remote sensing observations. To this end, an in situ database is created, which is based on measurements with state-ofthe-art instrumentation and extended in comparison to earlier studies (Schiller et al., 2008; Krämer et al., 2009; Luebke et al., 2013; Krämer et al., 2016). The in situ database consists now of about $168 \mathrm{~h}$ of ice water content IWC, 90 and $84 \mathrm{~h}$ of ice crystal number concentration and mass-mean radius $N_{\text {ice }}$ and $R_{\text {ice }}, 96$ and $186 \mathrm{~h}$ of in-cloud and clear-sky $\mathrm{RH}_{\mathrm{ice}}$, and, correspondingly, $186 \mathrm{~h}$ of clear-sky water vapor $\left(\mathrm{H}_{2} \mathrm{O}\right)$. The measurements span the altitude range between 5 and $20 \mathrm{~km}$ and cover the latitude band from $75^{\circ}$ north to $20^{\circ}$ south. The remote sensing database includes 10 years (2006-2016) of global ice crystal number concentration $N_{\text {ice }}$ measurements. The main results from the evaluation of the two data sets are summarized in the following.

\subsection{Characteristics and distribution of in situ-origin and liquid-origin cirrus (Sect. 3)}

From the extended Cirrus Guide II in situ data set, we generally confirm the typical characteristics of in situ-origin and liquid-origin cirrus introduced by Krämer et al. (2016) with some additions (see Table 1).

- In situ-origin and liquid-origin cirrus consist of two subclasses determined by the updraft (1: slow updrafts few large ice crystals form from heterogeneous freezing; 2: fast updrafts - many small ice crystals nucleate homogeneously).

New in this concept is that liquid-origin cirrus also differ in the two updraft regimes. Often, the two subclasses occur in succession and form a bimodal size distribution.

- Liquid-origin cirrus are thicker (higher IWC) than in situ-origin cirrus and are usually characterized by larger ice crystals.

- The differences between the cirrus types are most pronounced in the formation phase of the clouds and 
are blurred with increasing lifetime due to ice crystal growth and sedimentation or additional ice formation.

In addition, we present a picture of the distribution of cirrus with respect to altitude and latitude, including an impression of the vertical structure of liquid-origin and in situorigin cirrus (Fig. 3).

- Across all latitudes, the thicker liquid-origin cirrus predominate at lower altitudes, while at higher altitudes the thinner in situ-origin cirrus prevail. In between, the two cirrus types overlap. This finding is in agreement with Luebke et al. (2016) and Wernli et al. (2016) for midlatitude cirrus and Wolf et al. (2018) for Arctic cirrus.

Finally, a first estimate of the radiative characteristics of typical, specific, and idealized in situ-origin and liquidorigin cirrus scenarios is given (Fig. 5).

- Slow in situ-origin cirrus have a small optical depth $(\tau$ : $0.001-0.05)$, resulting in a slight net warming effect of not larger than about $1.5 \mathrm{~W} \mathrm{~m}^{-2}$.

- The optical depth of fast in situ-origin cirrus is larger $(\tau$ : $0.05-1)$, but most of them are also warming (2$10 \mathrm{~W} \mathrm{~m}^{-2}$ ). The thickest fast in situ-origin cirrus at the lowest altitudes can change the sign of their net forcing; they switch to a slight cooling effect.

- Liquid-origin cirrus have large optical depths ( $\tau: 1-12)$ and consequently exhibit a quite strong net cooling effect $\left(-15\right.$ to $\left.-250 \mathrm{~W} \mathrm{~m}^{-2}\right)$.

\subsection{Cirrus and humidity in the tropical tropopause layer (TTL) (Sect. 5)}

The new in situ data set is extended by observations in the tropical TTL outside, but also, for the first time, inside of the Asian monsoon anticyclone. Therefore, we put special emphasis on the analysis of the TTL environment.

\section{TTL cirrus clouds (Fig. 11).}

- Two types of most likely in situ-formed cirrus are identified in slow large-scale updrafts at low temperatures $(T \lesssim 205 \mathrm{~K}, \Theta \gtrsim 355 \mathrm{~K})$. The first is interpreted as young cirrus ( $N_{\text {ice }}$ around $0.1-1 \mathrm{~cm}^{-3} \gtrsim 3 \mu \mathrm{m}$ diameter) and the second as aged cirrus $\left(N_{\text {ice }}\right.$ around $0.001 \mathrm{~cm}^{-3}$ $\gtrsim 20 \mu \mathrm{m}$ diameter) where the smaller ice crystals have grown to larger sizes.

- The highest $N_{\text {ice }}$ (up to $30 \mathrm{~cm}^{-3}$ around the cold point tropopause, CPT) and IWC (up to $1000 \mathrm{ppmv}$ around the CPT) are found in deep convective systems in the Asian monsoon. Such systems represent massive liquidorigin cirrus (very high IWC) superimposed by a fresh strong homogeneous in situ ice nucleation event (many small ice crystals $\lesssim 20 \mu \mathrm{m}$ ) in fast updrafts.
TTL humidity (Fig. 12).

- In the Asian monsoon, in-cloud and clear-sky $\mathrm{RH}_{\text {ice }}$ is higher (often supersaturated around and above the CPT) than in the surrounding tropics. This is caused by the stronger dynamics and a higher amount of $\mathrm{H}_{2} \mathrm{O}$ in the Asian monsoon (most frequently 3 to 5 ppmv) in comparison to the tropics outside (1.5 to 3 ppmv).

- Taking saturation at the stratospheric entry of an air mass as set point for water vapor transport to the stratosphere, the transport is underestimated by $\sim 10 \%$ in regions of weak convective activity (see also Rollins et al., 2016). In convective regions, the underestimation increased to $20 \%-50 \%$ in our observations in the Asian monsoon.

- Convectively injected ice over the Asian monsoon CPT $\left(\Theta \gtrsim 400 \mathrm{~K}, \mathrm{RH}_{\text {ice }} \lesssim 100 \%\right)$ can locally contribute a significant amount of water (up to an IWC of 8 ppmv, in comparison to only $2 \mathrm{ppmv}$ in the surrounding tropics) that might be evaporated and further transported into the stratosphere.

\subsection{In situ and satellite climatologies (Sects. 4 and 6)}

Cirrus Guide II in situ cirrus and humidity climatologies.

- Median $N_{\text {ice }}, R_{\text {ice }}$, and $\mathrm{RH}_{\text {ice }}$ are presented in the IWC$T$ parameter space (Fig. 6).

Distinct patterns are found: $N_{\text {ice }}$ forms bands parallel to IWC, while $R_{\text {ice }}$ is sorted diagonally in the IWC$T$ space. At tropical cold temperatures, supersaturations occur in thin as well as in thick cirrus.

- The entire extended data set (Fig. 7) is compared to the earlier studies (Fig. S6, Supplement).

The median IWC and the core IWC band are the same in both data sets, showing that the in situ IWC measurement techniques are robust and that the IWC is a stable parameter describing cirrus clouds.

The overall picture of the in-cloud and clear-sky $\mathrm{RH}_{\mathrm{ice}}$ distributions has also not changed, demonstrating that high-altitude water vapor measurements that were under discussion earlier have improved and stabilized.

An extended view is presented for $N_{\text {ice }}$, which is due to the better lower $N_{\text {ice }}$ detection limit and a better mixture of the dynamical situation. The new $N_{\text {ice }}-T$ percentiles are lower and show no distinct temperature dependence (average 10th, median, and 90th $N_{\text {ice }}$ percentiles: 0.002, 0.03 , and $0.3 \mathrm{~cm}^{-3}$ ) in comparison to the earlier observations that show a slight decrease in $N_{\text {ice }}$ with temperature and an average median $N_{\text {ice }}$ of about $0.1 \mathrm{~cm}^{-3}$.

- The in situ data set is subdivided into midlatitude and tropical climatologies (Figs. 8 and 9), and typical cirrus 
and humidity characteristics of the respective regions are presented.

DARDAR-Nice satellite global cirrus $N_{\text {ice }}$ climatology

(Figs. 14 and 15).

- A global climatology of $N_{\text {ice }}$ values from 10 years (2006-2016) of satellite observations is provided that can be used for comparison with global models or other data sets.

The $N_{\text {ice }}$ from satellite observations are validated by and adjusted to in situ measurements from a subset of five campaigns of the Cirrus Guide II.

- The global median $N_{\text {ice }}$ from satellite observations is almost 2 times higher than the in situ median and increases slightly with decreasing temperature.

- $N_{\text {ice }}$ medians sorted by geographical regions are highest in the tropics, followed by austral and boreal midlatitudes, Antarctica, and the Arctic.

- In the satellite climatologies of $N_{\text {ice }}$, half of the cirrus are located in the lowest, warmest cirrus layer and contain a significant amount of liquid-origin cirrus. Their global median $N_{\text {ice }}$ is $0.031 \mathrm{~cm}^{-3}$.

- Regarding the frequent appearance of liquid-origin cirrus together with strong cooling effect is a motivation to investigate their influence on the overall cirrus radiative feedback on climate in future studies. 


\section{Appendix A: Methods}

\section{A1 Field campaigns and instrumentation}

The field campaigns, locations, and deployed instruments are listed in Table A1, which is an extended version of the respective Table in the Cirrus Guide: Part 1. For a brief description of the instruments already introduced there, we refer to Krämer et al. (2016). Other instruments used during START 2008, CONTRAST 2014, ATTREX 2014, POSIDON 2016, and LTU 2012-2018 are briefly introduced here.

ATTREX 2014 and POSIDON 2016. IWC and $\mathrm{RH}_{\text {ice }}$ are measured with the dual-channel NOAA- $\mathrm{H}_{2} \mathrm{O}$ instrument, a dual-channel TDL hygrometer which detects both $\mathrm{H}_{2} \mathrm{O}_{\text {tot }}$ $\left(=\mathrm{H}_{2} \mathrm{O}_{\text {gas }}+\right.$ IWC $)$ and $\mathrm{H}_{2} \mathrm{O}_{\text {gas }}$ by using a forward- and a backward-directed inlet. The detection limit of the IWC is 0.03 ppmv $\left(\approx 0.003 \mathrm{mg} \mathrm{m}^{-3}\right)$. Cloud particle size distributions (PSDs) and thus $N_{\text {ice }}$ are recorded by a FCDP and a 2D-S. The size range of the FCDP is $1-50 \mu \mathrm{m}$ in diameter, and the 2D-S counts cloud particles between 25 and $3005 \mu \mathrm{m}$.

Start-08 and CONTRAST. IWC and $N_{\text {ice }}$ are both derived from PSD measurements by a CDP and a 2D-C. The size range of the CDP is $2-50 \mu \mathrm{m}$ in diameter, and the $2 \mathrm{D}-\mathrm{C}$ counts cloud particles between 60 and $1100 \mu \mathrm{m}$.

LTU 2012-2018. IWC and $N_{\text {ice }}$ are both derived from PSD measurements by the Balloon-borne Ice Cloud particle Imager (B-ICI), detecting ice particle sizes between 10 and $1200 \mu \mathrm{m}$ in diameter. Note that the measurements are not from aircraft but from balloons launched at Kiruna, Sweden.

\section{A2 Data evaluation methods}

The data evaluation methods, detection ranges, and data quality criteria of the measurements of IWC, $N_{\text {ice }}, R_{\text {ice }}$, $\mathrm{RH}_{\text {ice, }}$, and $\mathrm{H}_{2} \mathrm{O}$ are described in the following. The instruments measuring the respective parameters are listed in Table A1; the estimated uncertainties are mentioned in the table caption. For the calculation of frequency distributions of the data, only those campaigns where the measured parameters cover the same detection range are used, since mixing of data with differing detection ranges influences the calculation of percentiles. Thus, the list of analyzed campaigns varies for each parameter, since not all parameters are available for the same detection ranges in all campaigns, or the data quality is considered suspicious. In Table A2 the available parameters are listed for each campaign. The resulting data coverage of the parameters over the entire temperature range is shown in Fig. A1.

\section{A2.1 Ice water content (IWC)}

In the earlier studies of Schiller et al. (2008) and Luebke et al. (2013), the IWC was detected as the difference between total water $\left(\mathrm{H}_{2} \mathrm{O}_{\text {tot }}\right.$ : water vapor + evaporated ice crystals $)$ and gas phase water $\left(\mathrm{H}_{2} \mathrm{O}_{\text {gas }}\right)$; this product is named here $\operatorname{IWC}\left(\mathrm{H}_{2} \mathrm{O}\right)$. Krämer et al. (2016) also determined the IWC by integrating the ice particle size distributions (PSDs) measured by cloud spectrometers in cases where no total water measurements were available; we call this IWC(PSD). A detailed description of both methods is given in Afchine et al. (2018). Also, Afchine et al. (2018) demonstrated good agreement between the two methods under reliable sampling conditions. Agreement between IWC $\left(\mathrm{H}_{2} \mathrm{O}\right)$ and IWC(PSD) is also a criterion for the quality of the IWC data (see also Thornberry et al., 2017), as well as for the measurements of $\mathrm{H}_{2} \mathrm{O}$ and the PSDs (for the data quality of $\mathrm{H}_{2} \mathrm{O}$ and $N_{\text {ice }}$ see also the following subsections).

Unlike in the earlier studies, we here combine the two methods, IWC $\left(\mathrm{H}_{2} \mathrm{O}\right)$ and IWC(PSD). In case both measurements are available, $\operatorname{IWC}\left(\mathrm{H}_{2} \mathrm{O}\right)$ is used as the first choice for each flight second. But if $\operatorname{IWC}\left(\mathrm{H}_{2} \mathrm{O}\right)$ is zero or missing, IWC(PSD) is used. This combination of IWCs can fill times of measuring failures or signals beyond detection limits of one instrument and also compensates for some of the inhomogeneities in cirrus. If only one instrument is available, the respective IWC is taken.

As discussed by Schiller et al. (2008) and Afchine et al. (2018), the lower detection limit of $\operatorname{IWC}\left(\mathrm{H}_{2} \mathrm{O}\right)$ depends on the temperature and cannot be clearly defined. Data points below the lower dotted line drawn in the IWC- $T$ parameter space in Fig. A1a represent observations where the difference between both the $\mathrm{H}_{2} \mathrm{O}_{\text {tot }}$ and $\mathrm{H}_{2} \mathrm{O}_{\text {gas }}$ measurements is not significant to unambiguously identify a cloud. This is where the ratio $\mathrm{H}_{2} \mathrm{O}_{\text {enh }} / \mathrm{H}_{2} \mathrm{O}_{\text {gas }}<1.07$; note here that $\mathrm{H}_{2} \mathrm{O}_{\text {enh }}$ is the originally measured total water quantity, which is enhanced due to the sampling characteristics of the system (for more detail see Schiller et al., 2008; Afchine et al., 2018). The lower detection limit of IWC(PSD) is $0.05 \mathrm{ppmv}\left(\approx 0.005 \mathrm{mg} \mathrm{m}^{-3}\right)$ for NIXE-CAPS and $0.01 \mathrm{ppmv}\left(\approx 0.001 \mathrm{mg} \mathrm{m}^{-3}\right)$ for the combination of FCDP and 2D-C.

\section{A2.2 Ice crystal number $\left(N_{\text {ice }}\right)$}

From the campaigns where cloud particle size distributions (PSDs) are measured, we chose those where cloud particles between 3 and $\sim 1000 \mu \mathrm{m}$ in diameter are recorded when calculating $N_{\text {ice }}$ (see Table A2). We calculate $N_{\text {ice }}$ as the sum of ice crystal concentrations over all size bins larger than $3 \mu \mathrm{m}$ on a $1 \mathrm{~Hz}$ time resolution, because this time span represents around $200 \mathrm{~m}$ flight distance - which might already not resolve cirrus inhomogeneities. Thus, when averaging $N_{\text {ice }}$ over longer flight times, cloud-free segments might influence the ice crystal concentrations.

Two instruments are needed to be deployed to cover the complete cirrus ice particle size range, one for smaller and the other for larger cloud particles. The PSDs from NIXECAPS (CAS-Depol + CIPgs) and FCDP + 2D-S are merged between 20 and $25 \mu \mathrm{m}$ to avoid overlap of particle sizes, those of CDP $+2 \mathrm{D}-\mathrm{C}$ at $55 \mu \mathrm{m}$. In earlier campaigns where only FSSP measurements $(3-30 \mu \mathrm{m})$ are available, we cal- 
Table A1. Overview of campaigns and instruments. IWC: ice water content (uncertainties $\sim 20 \%$ ); $\mathrm{RH}_{\mathrm{ice}}$ : relative humidity over ice (uncertainties $\sim 10 \%-15 \%$ ); $N_{\text {ice }}$ : ice crystal number concentration (uncertainties $\sim 10 \%-100 \%$ ); the sampling rate of all aircraft instruments is $1 \mathrm{~Hz}$.

\begin{tabular}{|c|c|c|c|c|}
\hline Aircraft & Locations & IWC & $\mathrm{RH}_{\text {ice }}$ & $N_{\text {ice }}$ \\
\hline Geophysica & Seychelles ${ }^{1}$, Europe $^{2}$, Brazil $^{3}$, Australia $^{4}$, Africa $^{5}$ & FISH $^{\mathrm{a}}$ & $\mathrm{FLASH}^{\mathrm{c}}$ & FSSP-100i \\
\hline Geophysica & $\mathrm{Nepal}^{14}$ & FISH $^{\mathrm{a}}$ & FLASH $^{\mathrm{c}}$ & NIXE-CAPS ${ }^{m}$ \\
\hline Learjet & Europe $^{6}$ & FISH $^{\mathrm{a}}$ & OJSTER $^{\mathrm{d}}$, SEAL $^{\mathrm{e}}$ & FSSP-300j \\
\hline BAe-146 & $\mathrm{UK}^{9}$ & NIXE-CAPS ${ }^{m}$ & - & NIXE-CAPS ${ }^{m}$ \\
\hline HALO & Europe $^{10}$, Brazil $^{11}$ & NIXE-CAPS ${ }^{\mathrm{m}}$ & SHARC $^{\text {h }}$ & NIXE-CAPS ${ }^{m}$ \\
\hline Balloon & Europe $^{15}$ & $\mathrm{~B}-\mathrm{ICI}^{\mathrm{n}}$ & - & $\mathrm{B}-\mathrm{ICI}^{\mathrm{n}}$ \\
\hline WB-57 & USA $^{7,16}$, Costa Rica ${ }^{8}$ & $\mathrm{CLH}^{\mathrm{b}}$ & $\mathrm{HWV}^{\mathrm{f}}, \mathrm{JLH}^{\mathrm{g}}$ & CAPS $^{\mathrm{k}}, 2 \mathrm{D}-\mathrm{S}^{1}$ \\
\hline WB-57 & Guam $^{13}$ & $\mathrm{NOAA}-\mathrm{H}_{2} \mathrm{O}^{\mathrm{O}}$ & $\mathrm{NOAA}-\mathrm{H}_{2} \mathrm{O}^{\mathrm{O}}$ & $\mathrm{FCDP}^{\mathrm{p}}, 2 \mathrm{D}-\mathrm{S}^{\mathrm{l}}$ \\
\hline Global Hawk & Guam $^{12}$ & $\mathrm{NOAA}-\mathrm{H}_{2} \mathrm{O}^{\circ}$ & $\mathrm{NOAA}-\mathrm{H}_{2} \mathrm{O}^{\circ}$ & $\mathrm{FCDP}^{\mathrm{p}}, 2 \mathrm{D}-\mathrm{S}^{\mathrm{l}}$ \\
\hline GV HIAPER & $\mathrm{USA}^{17}, \mathrm{Guam}^{19}$ & $\mathrm{CDP}^{\mathrm{q}}, 2 \mathrm{D}-\mathrm{C}^{\mathrm{r}}$ & VCSEL ${ }^{\mathrm{s}:}$ & $\mathrm{CDP}^{\mathrm{q}}, 2 \mathrm{D}-\mathrm{C}^{\mathrm{r}}$ \\
\hline Learjet & $\mathrm{USA}^{18}$ & $2 \mathrm{D}-\mathrm{S}^{1}$ & - & $\mathrm{FSSP}^{\mathrm{i}}, 2 \mathrm{D}-\mathrm{S}^{\mathrm{l}}$ \\
\hline
\end{tabular}

${ }^{1}$ APE-THESEO 1999. ${ }^{2}$ ENVISAT 2002, EUPLEX 2003, ENVISAT 2003. ${ }^{3}$ TROCCINOX 2005. ${ }^{4}$ SCOUT-O $_{3} 2005 . ~{ }^{5}$ AMMA 2006. ${ }^{6}$ CIRRUS 2003, CIRRUS 2004, CIRRUS 2006, AIRTOSS-ICE 2013. ${ }^{7}$ MidCix 2004, MACPEX 2011. ${ }^{8}$ TC-4 2007. ${ }^{9}$ COALESC 2011. ${ }^{10}$ ML-CIRRUS 2014. ${ }^{11}$ ACRIDICON-CHUVA 2014. ${ }^{12}$ ATTREX 2014. ${ }^{13}$ POSIDON 2016. ${ }^{14}$ StratoClim 2017. ${ }^{15}$ LTU 2012-2015. ${ }^{16}$ CRYSTAL-FACE 2002. ${ }^{17}$ START 2008. ${ }^{18}$ SPARTICUS 2010.

${ }^{19}$ CONTRAST 2014. ${ }^{a}$ Lyman- $\alpha$ fluorescence hygrometer (Schiller et al., 2008; Krämer et al., 2009; Meyer et al., 2015). ${ }^{\mathrm{b}}$ Tunable diode laser hygrometer (Luebke et al., 2013). ${ }^{\mathrm{c}}$ Lyman- $\alpha$ fluorescence hygrometer (Sitnikov et al., 2007). ${ }^{\mathrm{d}}$ Tunable diode laser hygrometer (Krämer et al., 2009). ${ }^{\mathrm{e}}$ Tunable diode laser hygrometer (Buchholz et al., 2013). ${ }^{\mathrm{f}}$ Lyman- $\alpha$ fluorescence hygrometer (Rollins et al., 2014). ${ }^{\mathrm{g}}$ Tunable diode laser hygrometer (May, 1998). ${ }^{\mathrm{h}}$ Tunable diode laser hygrometer (Meyer et al., 2015). ${ }^{\mathrm{i}}$ Light-scattering cloud probe (Baumgardner et al., 2017). ${ }^{\mathrm{j}}$ Light-scattering cloud probe (Baumgardner et al., 2017). ${ }^{\mathrm{k}}$ Light-scattering and optical imaging cloud probe (Baumgardner et al., 2001). ${ }^{1}$ Optical imaging cloud probe (Lawson et al., 2006). ${ }^{\mathrm{m}}$ Light-scattering and optical imaging cloud probe (Meyer, 2012; Luebke et al., 2016). ${ }^{\mathrm{n}}$ Cloud particle imager (Wolf et al., 2018). ${ }^{\circ}$ Tunable diode laser hygrometer (Thornberry et al., 2017). ${ }^{\mathrm{P}}$ Light-scattering cloud probe (McFarquhar et al., 2007). ${ }^{\mathrm{q}}$ Light-scattering cloud probe (Baumgardner et al., 2017). ${ }^{\mathrm{r}}$ Optical imaging cloud probe (Baumgardner et al., 2017). ${ }^{\mathrm{s}}$ Tunable diode laser hygrometer (Zondlo et al., 2010). The campaigns under ${ }^{1-6}$ are described by Schiller et al. (2008), Krämer et al. (2009), and Finger et al. (2016), ${ }^{7-8}$ by Luebke et al. (2013) and Jensen et al. (2013b, 2009), ${ }^{9}$ Jones et al. (2012), ${ }^{10}$ Voigt et al. (2017), ${ }^{11}$ Wendisch et al. (2016), ${ }^{12}$ Jensen et al. (2017a),

$13 \mathrm{https}: / /$ espo.nasa.gov/posidon (last access: 29 September 2020), ${ }^{14} \mathrm{http}: / /$ www.stratoclim.org (last access: 15 January 2020), ${ }^{15}$ Wolf et al. (2018),

16 https://espo.nasa.gov/crystalface (last access: 29 September 2020), ${ }^{17}$ Pan et al. (2010), ${ }^{18}$ Muhlbauer et al. (2014), and ${ }^{19}$ Pan et al. (2017).

culate $N_{\text {ice }}$ without the larger particles, since they contribute only a negligible part to $N_{\text {ice }}$ (these campaigns are marked as $y^{\star}$ in Table A2). However, for the calculation of occurrence frequencies only the campaigns covering the whole size range are used.

\section{A2.3 Concentrations and frequencies of occurrence of small ice crystals: the effect of limited sampling volumes}

$N_{\text {ice }}$ is given by the number of cloud particle events recorded in the cloud volume that is sampled. Thus, the lowest concentration that can be detected is when only one particle is recorded. For the particle imaging probes (CIPgs, 2DS, 2D-C, used size range $\sim 20-1000 \mu \mathrm{m}$ ) that results to $\sim 10^{-4} \mathrm{~cm}^{-3}$, while for the light-scattering probes (CASDepol, FCDP, CDP, used size range $\sim 3-20 \mu \mathrm{m}$ ) it reaches the higher value of $\sim 0.015 \mathrm{~cm}^{-3}$. The difference in the recorded concentration range is caused by the differing sampling volumes of the two instrument types. As a consequence, $N_{\text {ice }}$ concentrations $\lesssim 0.015 \mathrm{~cm}^{-3}$ contain only ice particles $\gtrsim 20 \mu \mathrm{m}$. Lower concentrations of smaller particles cannot be detected with current particle measurement techniques (see also Krämer et al., 2016; Baumgardner et al., 2017).
Figure A2a exemplarily shows $N_{\text {ice }}$ as a function of temperature, measured with NIXE-CAPS (NIXE-CAPS combines a CAS-Depol and a CIPgs) during the field campaign ML-Cirrus 2014, color coded by their frequencies of occurrence. CAS-DPOL samples $47.5 \mathrm{~cm}^{-3}$ at $190 \mathrm{~m} \mathrm{~s}^{-1}$ aircraft cruising speed in $1 \mathrm{~s}$ while CIPgs probes about 1000 $16000 \mathrm{~cm}^{-3}$ as a function of particle size in the same time interval and aircraft speed (Costa et al., 2017). Thus, one particle event in the CAS-DPOL corresponds to a higher concentration than in the CIPgs. The red line in Fig. A2a represents the lowest detectable $N_{\text {ice }}$ of CAS-DPOL and the blue line the same for CIPg. A notable feature in the figure is that directly above the lowest detectable $N_{\text {ice }}$ of CAS-DPOL (red line) the $N_{\text {ice }}$ frequencies jump to a higher level than below. The reason for this peak is an effect caused by the small sampling volumes of these instruments, which is often called "bad statistics". It concerns instruments whose lowest $N_{\text {ice }}$ detection limit is above the naturally occurring particle concentrations. When clouds with concentrations smaller than the lowest detectable $N_{\text {ice }}$ are probed, these concentrations appear in the sampling volume as "single-particle events" (in the size range $\lesssim 20 \mu \mathrm{m}$ ) and are assigned to the minimum detectable concentration of the respective instrument, since the occurrence of one particle per time unit cannot be related to the true larger air volume it belongs to. Therefore, the data sets of this study are cleared from the artificial concentration 
Table A2. Cirrus Guide II database for the IWC, $N_{\text {ice }}$, and $\mathrm{RH}_{\text {ice }}$ climatologies. $y$ : quality-checked measurements; -: no or questionable measurements; an overview of each campaign is given in the Supplement; $y^{\text {spe }}: N_{\text {ice }}$ is corrected for single-particle events (spe; see Sect. A2.2); $y^{\star}: N_{\text {ice }}$ from size-limited detection range $\left(3-30 \mu \mathrm{m} \rightarrow\right.$ contains $\gtrsim 90 \%$ of the ice particles), not spe corrected; $y>15: N_{\text {ice }}$ from sizelimited detection range ( $>15 \mu \mathrm{m} \rightarrow$ underestimating the full ice particle concentration), not included in the data analysis presented here; the campaigns written in italics are not contained in the occurrence frequencies. ${ }^{*} \mathrm{~S} \mathrm{~K} \mathrm{~L} \mathrm{k:} \mathrm{campaigns} \mathrm{contained} \mathrm{in} \mathrm{the} \mathrm{data} \mathrm{sets} \mathrm{of} \mathrm{Schiller} \mathrm{et} \mathrm{al.}$ (2008), Krämer et al. (2009), Luebke et al. (2013), and Krämer et al. (2016) (for S\&K see Fig. S5 of the Supplement).

\begin{tabular}{|c|c|c|c|c|}
\hline Campaign & Data sets* & IWC & $N_{\text {ice }}$ & $\mathrm{RH}_{\text {ice }} / \mathrm{H}_{2} \mathrm{O}$ \\
\hline \multicolumn{5}{|l|}{ Arctic } \\
\hline EUPLEX_2003 & SKL & $y$ & $y^{\star}$ & $y$ \\
\hline ENVISAT_2003_1 & SKL & $y$ & $y^{\star}$ & $y$ \\
\hline ENVISAT_2003_2 & SKL & $y$ & $y^{\star}$ & $y$ \\
\hline$L T U \_2012-18$ & & $y$ & $y^{\text {spe }}$ & - \\
\hline \multicolumn{5}{|l|}{ Midlatitude } \\
\hline ENVISAT_2002_2 & SK & $y$ & $y^{\star}$ & $y$ \\
\hline CIRRUS_2003 & SKL & $y$ & $y^{\star}$ & $y$ \\
\hline CIRRUS_2004 & SKL & $y$ & $y^{\star}$ & $y$ \\
\hline CIRRUS_2006 & SKL & $y$ & $y^{\star}$ & $y$ \\
\hline START_2008 & & $y$ & $y^{\text {spe }}$ & $y$ \\
\hline MIDCIX_2004 & $\mathrm{Lk}$ & $y$ & $y>15$ & - \\
\hline SPARTICUS_2010 & & $y$ & $y>15$ & - \\
\hline MACPEX_2011 & $\mathrm{k}$ & $y$ & $y>15$ & $y$ \\
\hline COALESC_2011 & $\mathrm{k}$ & $y$ & $y^{\text {spe }}$ & - \\
\hline AIRTOSS_2013 & $\mathrm{k}$ & $y$ & $y>15$ & $y$ \\
\hline ML-CIRRŪS_2014 & $\mathrm{k}$ & $y$ & $y^{\text {spe }}$ & $y$ \\
\hline \multicolumn{5}{|l|}{ Tropics } \\
\hline APE_THESEO_1999 & SK1 & $y$ & $y^{\star}$ & $y$ \\
\hline CRYSTAL-FACE_2002 & $\mathrm{L}$ & $y$ & - & - \\
\hline TROCCINOX_2005 & SKL & $y$ & $y^{\star}$ & $y$ \\
\hline SCOUT_2005 & SKL & $y$ & $y^{\star}$ & $y$ \\
\hline TC-4_2007 & $\mathrm{L}$ & $y$ & $y>15$ & - \\
\hline CONTRAST_2014 & & $y$ & $y^{\text {spe }}$ & - \\
\hline ACRIDICON_2014 & $\mathrm{k}$ & $y$ & $y^{\text {spe }}$ & $y$ \\
\hline ATTREX_2014 & & $y$ & $y^{\mathrm{spe}}$ & $y$ \\
\hline POSIDON_2016 & & $y$ & $y^{\mathrm{spe}}$ & $y$ \\
\hline STRATOCLIM_2017 & & $y$ & $y^{\text {spe }}$ & $y$ \\
\hline
\end{tabular}

feature at the instrument's detection limit by excluding $N_{\text {ice }}$ caused by one single particle in the respective instruments.

The effect of this correction on the occurrence frequencies can be seen in Fig. A2b, which shows the same data set as panel (a), but with single-particle events removed: the sharp edge at the lowest detectable $N_{\text {ice }}$ of the CAS-DPOL has disappeared; instead more lower concentrations from the CIPg become visible, which were hidden by the artificial concentrations from the CAS-DPOL single-particle events before.

Single-particle events are less common if the measurements are averaged over larger time periods. The considered time interval can be adapted according to the required spatial resolution of the measurements. However, as outlined above, for this study we choose to show the lowest time interval (1 s) to achieve the highest possible spatial resolution.

\section{A2.4 Ice crystal shattering}

Fragmentation of large ice crystals at the cloud probe housings distorted a correct recording of the ice crystal concentrations in earlier times. Today, new inlets and also postprocessing algorithms based on the interarrival times of the crystals in the sampling volume (Korolev and Field, 2015) have minimized this effect. Nevertheless, older data sets might be contaminated by small artifacts of shattered ice particles and need to be marked in the data set and not used in the data analyses. Shattering can be recognized when looking at the $N_{\text {ice }}$ frequencies of occurrence plotted versus the temperature, as can be seen in Fig. A3, where an example of a data set including shattered ice crystals is shown. Clearly, high frequencies of occurrence appear at $N_{\text {ice }}$ concentrations between 10 and $100 \mathrm{~cm}^{-3}$ for all temperatures. This ice particle 

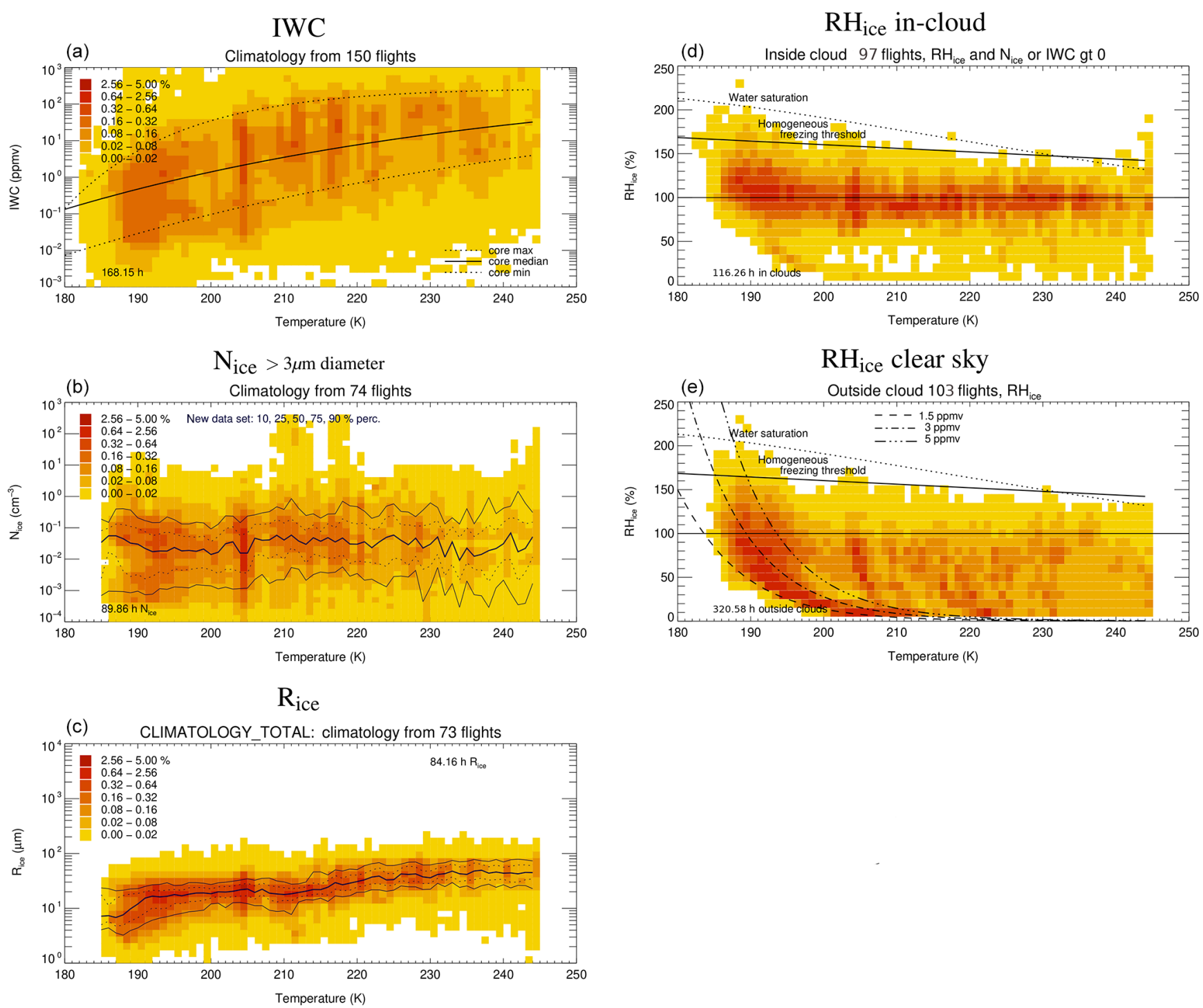

Figure A1. Data coverage of the Cirrus Guide II in situ database: IWC, $N_{\text {ice }}, R_{\text {ice}}$, and in-cloud and clear-sky $\mathrm{RH}_{\text {ice }}$ frequencies of occurrence as a function of temperature.

"mode" is not present in data sets not influenced by shattered ice crystals, as can be seen when comparing Figs. A3 and A2.

\section{A2.5 Water vapor and relative humidity with respect to ice $\left(\mathrm{H}_{2} \mathrm{O}\right.$ and $\left.\mathrm{RH}_{\text {ice }}\right)$}

Water vapor measurements where, as ice crystal concentrations, have been under discussion in the last decade (Peter et al., 2006). After some efforts to improve the quality of the measurements (e.g., Fahey et al., 2014), the water vapor instruments today provide high-precision data (see Rollins et al., 2014; Meyer et al., 2015; Thornberry et al., 2015; Buchholz et al., 2013; Kaufmann et al., 2018).

Nevertheless, we check the $\mathrm{H}_{2} \mathrm{O}$ data quality for each campaign, including the recent ones, best-by comparison of sev- eral $\mathrm{H}_{2} \mathrm{O}$ instruments as done by Kaufmann et al. (2018), for example. In case this is not possible, the frequencies of occurrence of in-cloud $\mathrm{RH}_{\text {ice }}$ are used to evaluate the quality of the measurements: inside of cirrus clouds, at temperatures $\gtrsim 200 \mathrm{~K}$, the frequencies should center around saturation, as can be seen in Fig. 7d. Figure A4 gives an example of a data set with a bias in the in-cloud $\mathrm{RH}_{\text {ice }}$. We should note that such a distortion might also be caused by a shift in the temperature measurements, which we, however, have not yet observed. In any case, such data sets are not used for the data analysis. 


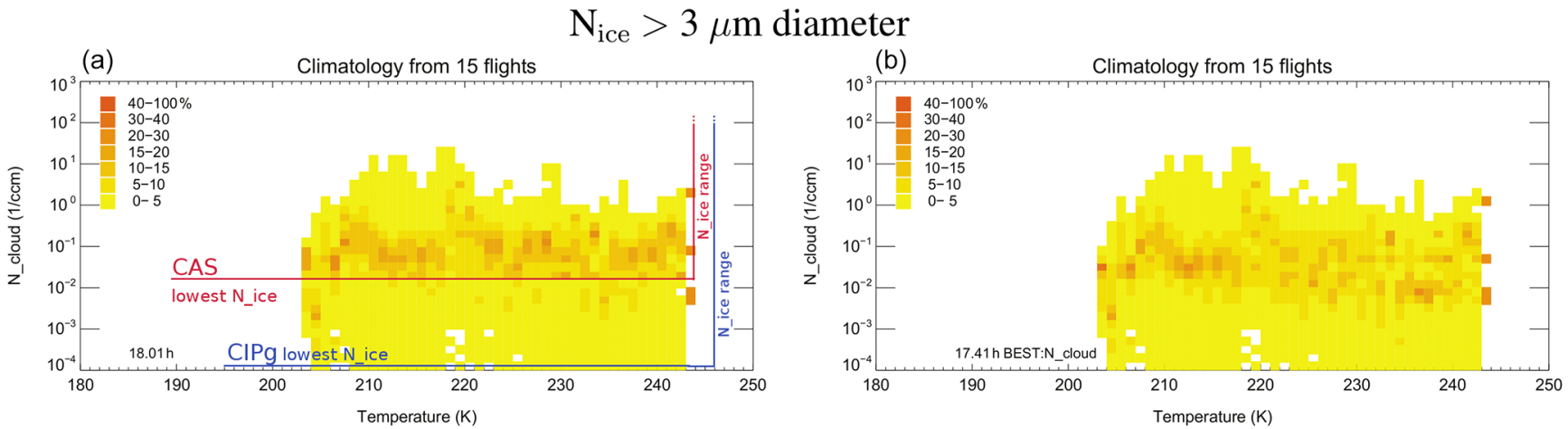

Figure A2. $N_{\text {ice }}$ frequencies of occurrence for ML-Cirrus 2014: (a) original data set, (b) corrected for "single-particle events". A further example of an uncorrected data set can be seen in Fig. S5 of the Supplement (middle left panel). For more details see text.

\section{$\mathrm{N}_{\text {ice }}>3 \mu \mathrm{m}$ diameter}

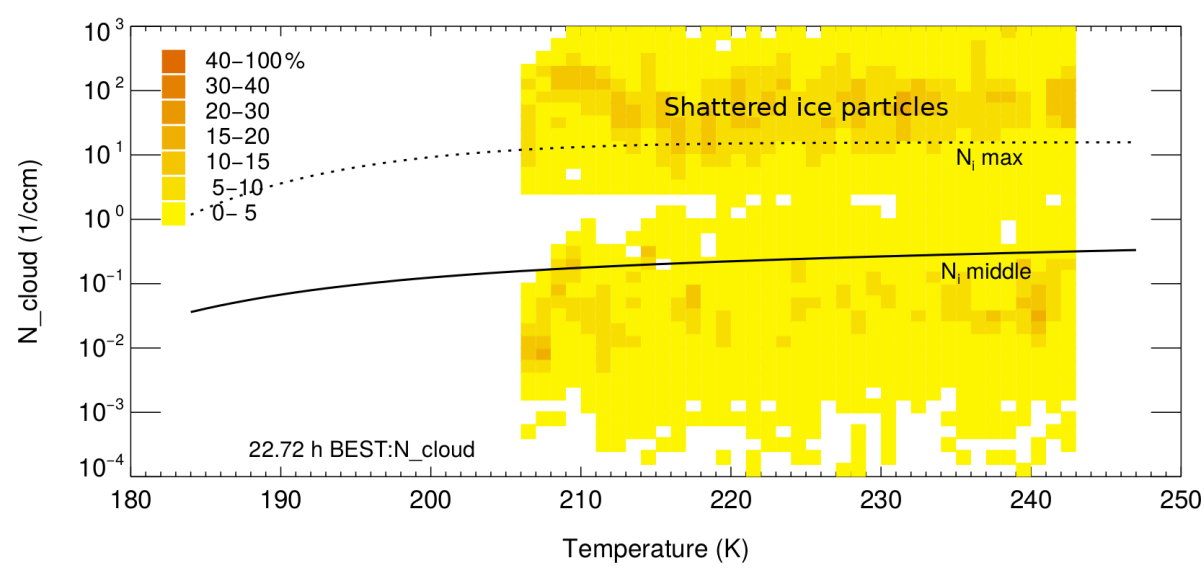

Figure A3. Example of $N_{\text {ice }}$ measurements biased by shattering of large ice particles, visible in the frequencies of occurrence: high frequencies appear at $N_{\text {ice }}$ concentrations between 10 and $100 \mathrm{~cm}^{-3}$ for all temperatures, which are not present in undisturbed measurements (see Fig. A2). The black lines denote the middle and maximum $N_{\text {ice }}$ lines from Krämer et al. (2009).

\section{$\mathrm{RH}_{\text {ice }}$ in-cloud}

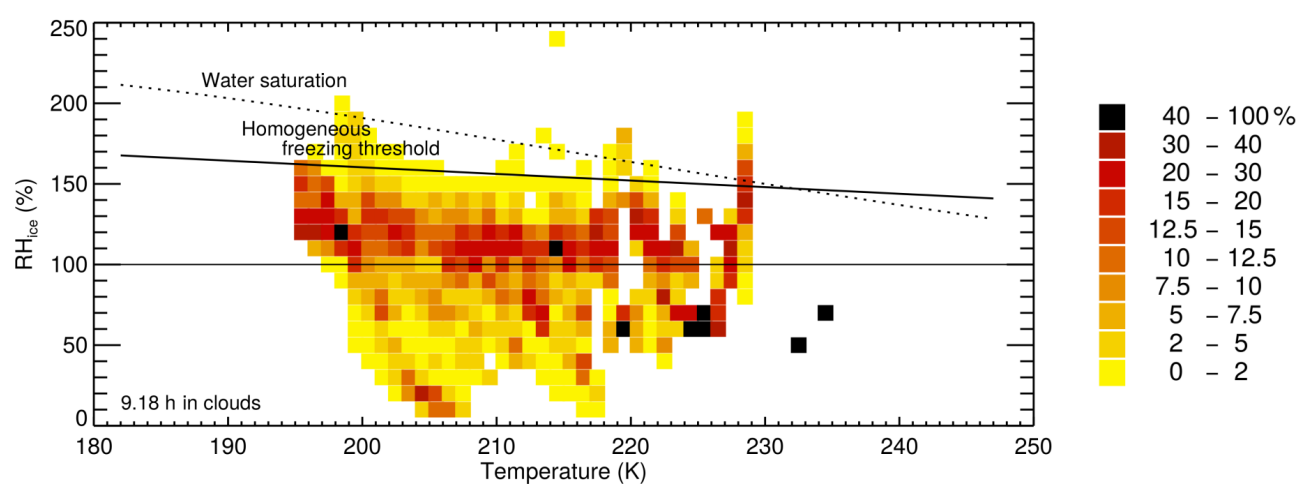

Figure A4. Example of biased $\mathrm{H}_{2} \mathrm{O}$ measurements, visible in the in-cloud $\mathrm{RH}_{\mathrm{ice}}$ frequencies: inside of cirrus clouds, at temperatures $\gtrsim 200 \mathrm{~K}$, the frequencies should center around saturation (see Fig. 7d). 
Data availability. The Cirrus Guide II in-situ data set is accessible under https://doi.org/10.34730/266ca2a41f4946ff97d874bfa458254c (Krämer et al., 2020), the DARDAR-Nice data set under https://doi.org/10.25326/09 (Sourdeval et al., 2018b).

Supplement. The supplement related to this article is available online at: https://doi.org/10.5194/acp-20-12569-2020-supplement.

Competing interests. The authors declare that they have no conflict of interest.

Acknowledgements. This paper is dedicated to our colleague Cornelius Schiller, who passed away much too early in 2012. He was the initiator of the StratoClim project, including the tropical aircraft campaign. Through this campaign, he intended to complement his work on hydration and dehydration in the tropical tropopause layer, based on observations over Brazil, Australia, and Africa (Schiller et al., 2009) with measurements over Asia. The campaign took place successfully out of Kathmandu, Nepal, in summer 2017, after several years of planning and many hurdles that had to be overcome.

The StratoClim project is funded by the European Commission within Framework program 7 under ENV.2013.6.1-2, grant agreement no. 603557. Funding for Cirrus Guide II is partly provided by the DFG HALO-SPP project ACIS (KR 2957/1-1).

Financial support. The article processing charges for this openaccess publication were covered by a Research

Centre of the Helmholtz Association.

Review statement. This paper was edited by Heini Wernli and reviewed by two anonymous referees.

\section{References}

Afchine, A., Rolf, C., Costa, A., Spelten, N., Riese, M., Buchholz, B., Ebert, V., Heller, R., Kaufmann, S., Minikin, A., Voigt, C., Zöger, M., Smith, J., Lawson, P., Lykov, A., Khaykin, S., and Krämer, M.: Ice particle sampling from aircraft - influence of the probing position on the ice water content, Atmos. Meas. Tech., 11, 4015-4031, https://doi.org/10.5194/amt11-4015-2018, 2018.

Bacer, S., Sullivan, S. C., Karydis, V. A., Barahona, D., Krämer, M., Nenes, A., Tost, H., Tsimpidi, A. P., Lelieveld, J., and Pozzer, A.: Implementation of a comprehensive ice crystal formation parameterization for cirrus and mixed-phase clouds in the EMAC model (based on MESSy 2.53), Geosci. Model Dev., 11, 40214041, https://doi.org/10.5194/gmd-11-4021-2018, 2018.

Baumgardner, D., Jonsson, H., Dawson, W., O'Connor, D., and Newton, R.: The cloud, aerosol and precipitation spectrometer (CAPS): A new instrument for cloud investigations, Atmos. Res., 59-60, 251-264, 2001.
Baumgardner, D., Abel, S. J., Axisa, D., Cotton, R., Crosier, J., Field, P., Gurganus, C., Heymsfield, A., Korolev, A., Krämer, M., Lawson, P., McFarquhar, G., Ulanowski, Z., and Um, J.: Cloud Ice Properties: In Situ Measurement Challenges; chap. 9 of "Ice Formation and Evolution in Clouds and Precipitation: Measurement and Modeling Challenges", Meteor. Mon., 58, 9.1-9.23, https://doi.org/10.1175/AMSMONOGRAPHS-D16-0011.1, 2017.

Boucher, O., Randall, D., Artaxo, P., Bretherton, C., Feingold, G., Forster, P., Kerminen, V.-M., Kondo, Y., Liao, H., Lohmann, U., Rasch, P., Satheesh, S., Sherwood, S., B., S., Zhang, X. Y., Stocker, T., Qin, D., Plattner, G.-K., Tignor, M., Allen, S., Boschung, J., Nauels, A., Xia, Y., Bex, V., and Midgley, P.: Clouds and aerosols. In: Climate Change 2013: The Physical Science Basis. Contribution of Working Group I to the Fifth Assessment Report of the Intergovernmental Panel on Climate Change, Cambridge University Press, Cambridge, United Kingdom and New York, NY, USA, https://doi.org/10.1017/CBO9781107415324.016, 2013.

Brewer, A. W.: Evidence for a world circulation provided by the measurements of helium and water vapour distribution in the stratosphere, Q. J. Roy. Meteor. Soc., 75, 351-363, https://doi.org/10.1002/qj.49707532603, 1949.

Buchholz, B., B., K., Smit, H., and Ebert, V.: Validation of an extractive, airborne, compact TDL spectrometer for atmospheric humidity sensing by blind intercomparison, Appl. Phys. B, 110, 249-262, 2013.

Campbell, J. R., Lolli, S., Lewis, J. R., Gu, Y., and Welton, E. J.: Daytime Cirrus Cloud Top-of-the-Atmosphere Radiative Forcing Properties at a Midlatitude Site and Their Global Consequences, J. Appl. Meteorol. Clim., 55, 1667-1679, https://doi.org/10.1175/JAMC-D-15-0217.1, 2016.

Costa, A., Meyer, J., Afchine, A., Luebke, A., Günther, G., Dorsey, J. R., Gallagher, M. W., Ehrlich, A., Wendisch, M., Baumgardner, D., Wex, H., and Krämer, M.: Classification of Arctic, midlatitude and tropical clouds in the mixed-phase temperature regime, Atmos. Chem. Phys., 17, 12219-12238, https://doi.org/10.5194/acp-17-12219-2017, 2017.

Delanoë, J., Protat, A., Testud, J., Bouniol, D., Heymsfield, A. J., Bansemer, A., Brown, P. R. A., and Forbes, R. M.: Statistical properties of the normalized ice particle size distribution, J. Geophys. Res.-Atmos., 110, 4204-4227, https://doi.org/10.1029/2004JD005405, 2005.

Delanoë, J. M. E., Heymsfield, A. J., Protat, A., Bansemer, A., and Hogan, R. J.: Normalized particle size distribution for remote sensing application, J. Geophys. Res.-Atmos., 119, 4204-4227, https://doi.org/10.1002/2013JD020700, 2014.

Dinh, T., Podglajen, A., Hertzog, A., Legras, B., and Plougonven, R.: Effect of gravity wave temperature fluctuations on homogeneous ice nucleation in the tropical tropopause layer, Atmos. Chem. Phys., 16, 35-46, https://doi.org/10.5194/acp-16-352016, 2016.

Fahey, D. W., Gao, R.-S., Möhler, O., Saathoff, H., Schiller, C., Ebert, V., Krämer, M., Peter, T., Amarouche, N., Avallone, L. M., Bauer, R., Bozóki, Z., Christensen, L. E., Davis, S. M., Durry, G., Dyroff, C., Herman, R. L., Hunsmann, S., Khaykin, S. M., Mackrodt, P., Meyer, J., Smith, J. B., Spelten, N., Troy, R. F., Vömel, H., Wagner, S., and Wienhold, F. G.: The AquaVIT-1 intercomparison of atmospheric water vapor measurement techniques, At- 
mos. Meas. Tech., 7, 3177-3213, https://doi.org/10.5194/amt-73177-2014, 2014.

Finger, F., Werner, F., Klingebiel, M., Ehrlich, A., Jäkel, E., Voigt, M., Borrmann, S., Spichtinger, P., and Wendisch, M.: Spectral optical layer properties of cirrus from collocated airborne measurements and simulations, Atmos. Chem. Phys., 16, 7681-7693, https://doi.org/10.5194/acp-16-7681-2016, 2016.

$\mathrm{Fu}$, Q. and Liou, K.: Parameterization of the Radiative Properties of Cirrus Clouds, J. Atmos. Sci., 50, 2008-2025, https://doi.org/10.1175/15200469(1993)050<2008:POTRPO>2.0.CO;2, 1993.

Fueglistaler, S., Dessler, A. E., Dunkerton, T. J., Folkins, I., Fu, Q., and Mote, P. W.: Tropical tropopause layer, Rev. Geophys., 47, 1-31, https://doi.org/10.1029/2008RG000267, 2009.

Gasparini, B. and Lohmann, U.: Why cirrus cloud seeding cannot substantially cool the planet, J. Geophys. Res.-Atmos., 121, 4877-4893, https://doi.org/10.1002/2015JD024666, 2016.

Gasparini, B., Meyer, A., Neubauer, D., Münch, S., and Lohmann, U.: Cirrus Cloud Properties as Seen by the CALIPSO Satellite and ECHAM-HAM Global Climate Model, J. Climate, 31, 1983-2003, https://doi.org/10.1175/JCLI-D-16-0608.1, 2018.

Gryspeerdt, E., Sourdeval, O., Quaas, J., Delanoë, J., Krämer, M., and Kühne, P.: Ice crystal number concentration estimates from lidar-radar satellite remote sensing - Part 2: Controls on the ice crystal number concentration, Atmos. Chem. Phys., 18, 1435114370, https://doi.org/10.5194/acp-18-14351-2018, 2018.

Heymsfield, A., Krämer, M., Luebke, A., Brown, P., Cziczo, D., Franklin, C., Lawson, P., Lohmann, U. McFarquhar, G., Ulanowski, Z., and Van Tricht, K.: Ice Formation and Evolution in Clouds and Precipitation: Measurement and Modeling Challenges, chap. 2: Cirrus Clouds, Eds. Baumgardner, D., McFarquhar, G. and Heymsfield, A., Meteor. Mon., 58, 2.1-2.26, https://doi.org/10.1175/AMSMONOGRAPHS-D16-0010.1, 2017a.

Heymsfield, A., Krämer, M., Wood, N. B., Gettelman, A., Field, P. R., and Liu, G.: Dependence of the Ice Water Content and Snowfall Rate on Temperature, Globally: Comparison of in Situ Observations, Satellite Active Remote Sensing Retrievals, and Global Climate Model Simulations, J. Appl. Meteorol. Clim., 56, 189-215, https://doi.org/10.1175/JAMC-D-16-0230.1, 2017b.

Holton, J. R., Haynes, P. H., McIntyre, M. E., Douglass, A. R., Rood, R. B., and Pfister, L.: Stratospheretroposphere exchange, Rev. Geophys., 33, 403-439, https://doi.org/10.1029/95RG02097, 1995.

Jensen, E. and Pfister, L.: Transport and freeze-drying in the tropical tropopause layer, J. Geophys. Res., 109, D022017, https://doi.org/10.1029/2003JD004022, 2004.

Jensen, E., Diskin, G., Lawson, P. Lance, S., Bui, T., Hlavka, D., McGill, M., Pfister, L., Toon, O., and Gao, R.: Ice nucleation and dehydration in the Tropical Tropopause Layer, P. Natl. Acad. Sci. USA, 110, 2041-2046, https://doi.org/10.1073/pnas.1217104110, 2013a

Jensen, E., Lawson, P., Bergman, J. W., Pfister, L., Bui, T. P., and Schmitt, C. G.: Physical processes controlling ice concentrations in synoptically forced, midlatitude cirrus, J. Geophys. Res., 118, 5348-5360, https://doi.org/10.1002/jgrd.50421, 2013b.

Jensen, E. J. and Ackerman, A. S.: Homogeneous aerosol freezing in the tops of high-altitude tropical cumu- lonimbus clouds, Geophys. Res. Lett., 33, L08802, https://doi.org/10.1029/2005GL024928, 2006.

Jensen, E. J., Ackerman, A. S., and Smith, J. A.: Can overshooting convection dehydrate the tropical tropopause layer?, J. Geophys. Res.-Atmos., 112, 1407-1413, https://doi.org/10.1029/2006JD007943, 2007.

Jensen, E. J., Lawson, P., Baker, B., Pilson, B., Mo, Q., Heymsfield, A. J., Bansemer, A., Bui, T. P., McGill, M., Hlavka, D., Heymsfield, G., Platnick, S., Arnold, G. T., and Tanelli, S.: On the importance of small ice crystals in tropical anvil cirrus, Atmos. Chem. Phys., 9, 5519-5537, https://doi.org/10.5194/acp-95519-2009, 2009.

Jensen, E. J., Pfister, L., and Bui, T. P.: Physical processes controlling ice concentrations in cold cirrus near the tropical tropopause, J. Geophys. Res.-Atmos., 117, D11205, https://doi.org/10.1029/2011JD017319, 2012.

Jensen, E. J., Pfister, L., Jordan, D. E., Bui, T. V., Ueyama, R., Singh, H. B., Thornberry, T. D., Rollins, A. W., Gao, R.-S., Fahey, D. W., Rosenlof, K. H., Elkins, J. W., Diskin, G. S., DiGangi, J. P., Lawson, R. P., Woods, S., Atlas, E. L., Rodriguez, M. A. N., Wofsy, S. C., Pittman, J., Bardeen, C. G., Toon, O. B., Kindel, B. C., Newman, P. A., McGill, M. J., Hlavka, D. L., Lait, L. R., Schoeberl, M. R., Bergman, J. W., Selkirk, H. B., Alexander, M. J., Kim, J.-E., Lim, B. H., Stutz, J., and Pfeilsticker, K.: The NASA Airborne Tropical Tropopause Experiment High-Altitude Aircraft Measurements in the Tropical Western Pacific, B. Am. Meteorol. Soc., 98, 129-143, https://doi.org/10.1175/BAMS-D14-00263.1, 2017a.

Jensen, E. J., Thornberry, T. D., Rollins, A. W., Ueyama, R., Pfister, L., Bui, T., Diskin, G. S., DiGangi, J. P., Hintsa, E., Gao, R.-S., Woods, S., Lawson, R. P., and Pittman, J.: Physical processes controlling the spatial distributions of relative humidity in the tropical tropopause layer over the Pacific, J. Geophys. Res.-Atmos., 122, 6094-6107, https://doi.org/10.1002/2017JD026632, 2017b.

Jones, H. M., Haywood, J., Marenco, F., O’Sullivan, D., Meyer, J., Thorpe, R., Gallagher, M. W., Krämer, M., Bower, K. N., Rädel, G., Rap, A., Woolley, A., Forster, P., and Coe, H.: A methodology for in-situ and remote sensing of microphysical and radiative properties of contrails as they evolve into cirrus, Atmos. Chem. Phys., 12, 8157-8175, https://doi.org/10.5194/acp12-8157-2012, 2012

Joos, H.: Warm Conveyor Belts and Their Role for Cloud Radiative Forcing in the Extratropical Storm Tracks, J. Climate, 32, 53255343, https://doi.org/10.1175/JCLI-D-18-0802.1, 2019.

Joos, H., Spichtinger, P., Reutter, P., and Fusina, F.: Influence of heterogeneous freezing on the microphysical and radiative properties of orographic cirrus clouds, Atmos. Chem. Phys., 14, 68356852, https://doi.org/10.5194/acp-14-6835-2014, 2014.

Kärcher, B. and Lohmann, U.: A parameterization of cirrus cloud formation: homogeneous freezing of supercooled aerosols, J. Geophys. Res., 107, 7433- 7462, 2002.

Kaufmann, S., Voigt, C., Heller, R., Jurkat-Witschas, T., Krämer, M., Rolf, C., Zöger, M., Giez, A., Buchholz, B., Ebert, V., Thornberry, T., and Schumann, U.: Intercomparison of midlatitude tropospheric and lower-stratospheric water vapor measurements and comparison to ECMWF humidity data, Atmos. Chem. Phys., 18, 16729-16745, https://doi.org/10.5194/acp-18-167292018, 2018. 
Kienast-Sjögren, E., Rolf, C., Seifert, P., Krieger, U. K., Luo, B. P., Krämer, M., and Peter, T.: Climatological and radiative properties of midlatitude cirrus clouds derived by automatic evaluation of lidar measurements, Atmos. Chem. Phys., 16, 7605-7621, https://doi.org/10.5194/acp-16-7605-2016, 2016.

Korolev, A.: Limitations of the Wegener-Bergeron-Findeisen Mechanism in the Evolution of Mixed-Phase Clouds, J. Atmos. Sci., 64, 3372-3375, https://doi.org/10.1175/JAS4035.1, 2007.

Korolev, A. and Field, P. R.: Assessment of the performance of the inter-arrival time algorithm to identify ice shattering artifacts in cloud particle probe measurements, Atmos. Meas. Tech., 8, 761777, https://doi.org/10.5194/amt-8-761-2015, 2015.

Krämer, M., Schiller, C., Afchine, A., Bauer, R., Gensch, I., Mangold, A., Schlicht, S., Spelten, N., Sitnikov, N., Borrmann, S., de Reus, M., and Spichtinger, P.: Ice supersaturations and cirrus cloud crystal numbers, Atmos. Chem. Phys., 9, 3505-3522, https://doi.org/10.5194/acp-9-3505-2009, 2009.

Krämer, M., Rolf, C., Luebke, A., Afchine, A., Spelten, N., Costa, A., Meyer, J., Zöger, M., Smith, J., Herman, R. L., Buchholz, B., Ebert, V., Baumgardner, D., Borrmann, S., Klingebiel, M., and Avallone, L.: A microphysics guide to cirrus clouds - Part 1: Cirrus types, Atmos. Chem. Phys., 16, 3463-3483, https://doi.org/10.5194/acp-16-3463-2016, 2016.

Krämer, M., Rolf, C., and Spelten, N.: The Cirrus Guide II In-situ Aircraft Data Set, B2SHARE-EUDAT, https://doi.org/10.34730/266ca2a41f4946ff97d874bfa458254c, 2020.

Kübbeler, M., Hildebrandt, M., Meyer, J., Schiller, C., Hamburger, Th., Jurkat, T., Minikin, A., Petzold, A., Rautenhaus, M., Schlager, H., Schumann, U., Voigt, C., Spichtinger, P., Gayet, J.-F., Gourbeyre, C., and Krämer, M.: Thin and subvisible cirrus and contrails in a subsaturated environment, Atmos. Chem. Phys., 11, 5853-5865, https://doi.org/10.5194/acp11-5853-2011, 2011.

Lawson, R., O'Connor, D., Zmarzly, P., Weaver, K., Baker, B., Mo, Q., and Jonsson, H.: The 2D-S (Stereo) probe: Design and preliminary tests of a new airborne, high-speed, high-resolution particle Imaging probe, J. Atmos. Ocean. Tech., 23, 1462-1477, 2006.

Lawson, R. P., Woods, S., Jensen, E., Erfani, E., Gurganus, C., Gallagher, M., Connolly, P., Whiteway, J., Baran, A. J., May, P., Heymsfield, A., Schmitt, C. G., McFarquhar, G., Um, J., Protat, A., Bailey, M., Lance, S., Muehlbauer, A., Stith, J., Korolev, A., Toon, O. B., and Krämer, M.: A Review of Ice Particle Shapes in Cirrus formed In Situ and in Anvils, J. Geophys. Res.-Atmos., 124, 10049-10090, https://doi.org/10.1029/2018JD030122, 2019.

Luebke, A. E., Avallone, L. M., Schiller, C., Meyer, J., Rolf, C., and Krämer, M.: Ice water content of Arctic, midlatitude, and tropical cirrus - Part 2: Extension of the database and new statistical analysis, Atmos. Chem. Phys., 13, 6447-6459, https://doi.org/10.5194/acp-13-6447-2013, 2013.

Luebke, A. E., Afchine, A., Costa, A., Grooß, J.-U., Meyer, J., Rolf, C., Spelten, N., Avallone, L. M., Baumgardner, D., and Krämer, M.: The origin of midlatitude ice clouds and the resulting influence on their microphysical properties, Atmos. Chem. Phys., 16, 5793-5809, https://doi.org/10.5194/acp-16-5793-2016, 2016.
May, R.: Open-path, near-infrared tunable diode laser spectrometer for atmospheric measurements of $\mathrm{H}_{2} \mathrm{O}$, J. Geophys. Res., 103, 19161-19172, https://doi.org/10.1029/98jd01678, 1998.

McFarquhar, G., Junshik, U., Freer, M., Baumgardner, D., Kok, G., and Mace, G.: The Importance of Small Ice Crystals to Cirrus Properties: Observations from the Tropical Warm Pool International Cloud Experiment (TWP-ICE), Geophys. Res. Lett., 34, L13803, https://doi.org/10.1029/2007GL029865, 2007.

Meyer, J.: Ice Crystal Measurements with the New Particle Spectrometer NIXE-CAPS, Schriften des Forschungszentrums Jülich Reihe Energie und Umwelt/Energy and Environment, 160, ISBN:9783893368402, 2012.

Meyer, J., Rolf, C., Schiller, C., Rohs, S., Spelten, N., Afchine, A., Zöger, M., Sitnikov, N., Thornberry, T. D., Rollins, A. W., Bozóki, Z., Tátrai, D., Ebert, V., Kühnreich, B., Mackrodt, P., Möhler, O., Saathoff, H., Rosenlof, K. H., and Krämer, M.: Two decades of water vapor measurements with the FISH fluorescence hygrometer: a review, Atmos. Chem. Phys., 15, 85218538, https://doi.org/10.5194/acp-15-8521-2015, 2015.

Mitchell, D. L., Garnier, A., Pelon, J., and Erfani, E.: CALIPSO (IIR-CALIOP) retrievals of cirrus cloud iceparticle concentrations, Atmos. Chem. Phys., 18, 17325-17354, https://doi.org/10.5194/acp-18-17325-2018, 2018.

Muhlbauer, A., Ackerman, T., Comstock, J., Diskin, G., Evans, S., Lawson, R., and Marchand, R.: Impact of largescale dynamics on the microphysical properties of midlatitude cirrus, J. Geophys. Res.-Atmos., 119, 3976-3996, https://doi.org/10.1002/2013JD020035, 2014.

Murphy, D. M.: Rare temperature histories and cirrus ice number density in a parcel and a one-dimensional model, Atmos. Chem. Phys., 14, 13013-13022, https://doi.org/10.5194/acp-14-130132014, 2014.

Pan, L. L., Bowman, K. P., Atlas, E. L., Wofsy, S. C., Zhang, F., Bresch, J. F., Ridley, B. A., Pittman, J. V., Homeyer, C. R., Romashkin, P., and Cooper, W. A.: The Stratosphere-Troposphere Analyses of Regional Transport 2008 (START08) Experiment, B. Am. Meteorol. Soc., 91, 327-342, https://doi.org/10.1175/2009BAMS2865.1, 2010.

Pan, L. L., Atlas, E. L., Salawitch, R. J., Honomichl, S. B., Bresch, J. F., Randel, W. J., Apel, E. C., Hornbrook, R. S., Weinheimer, A. J., Anderson, D. C., Andrews, S. J., Baidar, S., Beaton, S. P., Campos, T. L., Carpenter, L. J., Chen, D., Dix, B., Donets, V., Hall, S. R., Hanisco, T. F., Homeyer, C. R., Huey, L. G., Jensen, J. B., Kaser, L., Kinnison, D. E., Koenig, T. K., Lamarque, J.-F., Liu, C., Luo, J., Luo, Z. J., Montzka, D. D., Nicely, J. M., Pierce, R. B., Riemer, D. D., Robinson, T., Romashkin, P., Saiz-Lopez, A., Schauffler, S., Shieh, O., Stell, M. H., Ullmann, K., Vaughan, G., Volkamer, R., and Wolfe, G.: Convective Transport of Active Species in the Tropics (CONTRAST) experiment, B. Am. Meteorol. Soc., 98, 106-128, https://doi.org/10.1175/BAMS-D14-00272.1, 2017.

Penner, J. E., Zhou, C., Garnier, A., and Mitchell, D. L.: Anthropogenic Aerosol Indirect Effects in Cirrus Clouds, J. Geophys. Res.-Atmos., 123, 11652-11677, https://doi.org/10.1029/2018JD029204, 2018.

Peter, T., Marcolli, C., Spichtinger, P., Corti, T., Baker, M., and Koop, T.: When dry air is too humid, Science, 314, 1399-1401, 2006. 
Petzold, A., Krämer, M., Neis, P., Rolf, C., Rohs, S., Berkes, F., Smit, H. H., Gallagher, M., Beswick, K., Lloyd, G., Baumgardner, D., Spichtinger, P., Nédélec, P., Ebert, V., Buchholz, B., Riese, M., and Andreas, W.: Upper tropospheric water vapour and its interaction with cirrus clouds as seen from IAGOS longterm routine in-situ observations, Faraday Discuss., 200, 229-249, https://doi.org/10.1039/C7FD00006E, 2017.

Ploeger, F., Günther, G., Konopka, P., Fueglistaler, S., Müller, R., Hoppe, C., Kunz, A., Spang, R., Grooß, J.-U., and Riese, M.: Horizontal water vapor transport in the lower stratosphere from subtropics to high latitudes during boreal summer, J. Geophys. Res.-Atmos., 118, 8111-8127, https://doi.org/10.1002/jgrd.50636, 2013.

Podglajen, A., Bui, T. P., Dean-Day, J. M., Pfister, L., Jensen, E. J., Alexander, M. J., Hertzog, A., Kärcher, B., Plougonven, R., and Randel, W. J.: Small-Scale Wind Fluctuations in the Tropical Tropopause Layer from Aircraft Measurements: Occurrence, Nature, and Impact on Vertical Mixing, J. Atmos. Sci., 74, 38473869, https://doi.org/10.1175/JAS-D-17-0010.1, 2017.

Riese, M., Ploeger, F., Rap, A., Vogel, B., Konopka, P., Dameris, M., and Forster, P.: Impact of uncertainties in atmospheric mixing on simulated UTLS composition and related radiative effects, J. Geophys. Res.-Atmos., 117, D16305, https://doi.org/10.1029/2012JD017751, 2012.

Righi, M., Hendricks, J., Lohmann, U., Beer, C. G., Hahn, V., Heinold, B., Heller, R., Krämer, M., Ponater, M., Rolf, C., Tegen, I., and Voigt, C.: Coupling aerosols to (cirrus) clouds in the global EMAC-MADE3 aerosol-climate model, Geosci. Model Dev., 13, 1635-1661, https://doi.org/10.5194/gmd-131635-2020, 2020.

Rolf, C., Vogel, B., Hoor, P., Afchine, A., Günther, G., Krämer, M., Müller, R., Müller, S., Spelten, N., and Riese, M.: Water vapor increase in the lower stratosphere of the Northern Hemisphere due to the Asian monsoon anticyclone observed during the TACTS/ESMVal campaigns, Atmos. Chem. Phys., 18, $2973-$ 2983, https://doi.org/10.5194/acp-18-2973-2018, 2018

Rollins, A. W., Thornberry, T. D., Gao, R. S., Smith, J. B., Sayres, D. S., Sargent, M. R., Schiller, C., Krämer, M., Spelten, N., Hurst, D. F., Jordan, A. F., Hall, E. G., Vömel, H., Diskin, G. S., Podolske, J. R., Christensen, L. E., Rosenlof, K. H., Jensen, E. J., and Fahey, D. W.: Evaluation of UT/LS hygrometer accuracy by intercomparison during the NASA MACPEX mission, J. Geophys. Res., 119, 1915-1935, https://doi.org/10.1002/2013JD020817, 2014.

Rollins, A. W., Thornberry, T. D., Gao, R. S., Woods, S., Lawson, R. P., Bui, T. P., Jensen, E. J., and Fahey, D. W.: Observational constraints on the efficiency of dehydration mechanisms in the tropical tropopause layer, Geophys. Res. Lett., 43, 2912-2918, https://doi.org/10.1002/2016GL067972, 2016.

Sassen, K., Wang, Z., and Liu, D.: Global distribution of cirrus clouds from CloudSat/Cloud-Aerosol Lidar and Infrared Pathfinder Satellite Observations (CALIPSO) measurements, J. Geophys. Res.-Atmos., 113, D00A12, https://doi.org/10.1029/2008JD009972, 2008.

Schiller, C., Krämer, M., Afchine, A., Spelten, N., and Sitnikov, N.: Ice water content in Arctic, midlatitude and tropical cirrus, J. Geophys. Res., 113, D24208, https://doi.org/10.1029/2008JD010342, 2008.
Schiller, C., Grooß, J.-U., Konopka, P., Plöger, F., Silva dos Santos, F. H., and Spelten, N.: Hydration and dehydration at the tropical tropopause, Atmos. Chem. Phys., 9, 9647-9660, https://doi.org/10.5194/acp-9-9647-2009, 2009.

Schoeberl, M., Jensen, E., Pfister, L., Ueyama, R., Wang, T., Selkirk, H., Thornberry, T., Dessler, A., and Avery, M.: Water Vapor, Clouds, and Saturation in the Tropical Tropopause Layer, J. Geophys. Res.-Atmos., 124, 3985-4003, https://doi.org/10.1029/2018JD029849, 2019.

Schoeberl, M. R., Jensen, E. J., Pfister, L., Ueyama, R., Avery, M., and Dessler, A. E.: Convective Hydration of the Upper Troposphere and Lower Stratosphere, J. Geophys. Res.-Atmos., 123, 4583-4593, https://doi.org/10.1029/2018JD028286, 2018.

Sitnikov, N., Yushkov, V., Afchine, A., Korshunov, L., Astakhov, V., Ulanovskii, A., Krämer, M., Mangold, A., Schiller, C., and Ravegnani, F.: The FLASH Instrument for Water Vapor Measurements on Board the High-Altitude Airplane, Instrum. Exp. Tech., 50, 113-121, 2007.

Smith, J. B., Hintsa, E. J., Allen, N. T., Stimpfle, R. M., and Anderson, J. G.: Mechanisms for midlatitude ozone loss: Heterogeneous chemistry in the lowermost stratosphere?, J. Geophys. Res.-Atmos., 106, 1297-1309, https://doi.org/10.1029/2000JD900464, 2001.

Solomon, S., Rosenlof, K. H., Portmann, R. W., Daniel, J. S., Davis, S. M., Sanford, T. J., and Plattner, G.-K.: Contributions of Stratospheric Water Vapor to Decadal Changes in the Rate of Global Warming, Science, 327, 1219-1223, https://doi.org/10.1126/science.1182488, 2010.

Sourdeval, O., Gryspeerdt, E., Krämer, M., Goren, T., Delanoë, J., Afchine, A., Hemmer, F., and Quaas, J.: Ice crystal number concentration estimates from lidar-radar satellite remote sensing Part 1: Method and evaluation, Atmos. Chem. Phys., 18, 1432714350, https://doi.org/10.5194/acp-18-14327-2018, 2018a.

Sourdeval, O., Gryspeerdt, E., Krämer, M., Goren, T., Delanoë, J., Afchine, A., Hemmer, F., and Quaas, J.: Ice crystal number concentration from satellite lidar-radar observations (DARDARNice), Data set, AERIS, https://doi.org/10.25326/09, 2018b.

Spichtinger, P. and Cziczo, D. J.: Impact of heterogeneous ice nuclei on homogeneous freezing events, J. Geophys. Res., 115, D14208, https://doi.org/10.1029/2009JD012168, 2010.

Spichtinger, P. and Krämer, M.: Tropical tropopause ice clouds: a dynamic approach to the mystery of low crystal numbers, Atmos. Chem. Phys., 13, 9801-9818, https://doi.org/10.5194/acp13-9801-2013, 2013.

Spreitzer, E. J., Marschalik, M. P., and Spichtinger, P.: Subvisible cirrus clouds - a dynamical system approach, Nonlin. Processes Geophys., 24, 307-328, https://doi.org/10.5194/npg-24307-2017, 2017

Thornberry, T., Rollins, A., Avery, M., Woods, S., Lawson, R., Bui, T., and Gao, R.-S.: Ice water content-extinction relationships and effective diameter for TTL cirrus derived from in situ measurements during ATTREX 2014, J. Geophys. Res., 122, 4494-4507, https://doi.org/10.1002/2016JD025948, 2017.

Thornberry, T. D., Rollins, A. W., Gao, R. S., Watts, L. A., Ciciora, S. J., McLaughlin, R. J., and Fahey, D. W.: A two-channel, tunable diode laser-based hygrometer for measurement of water vapor and cirrus cloud ice water content in the upper troposphere and lower stratosphere, Atmos. Meas. Tech., 8, 211-224, https://doi.org/10.5194/amt-8-211-2015, 2015. 
Ueyama, R., Jensen, E. J., and Pfister, L.: Convective Influence on the Humidity and Clouds in the Tropical Tropopause Layer During Boreal Summer, J. Geophys. Res.-Atmos., 123, 7576-7593, https://doi.org/10.1029/2018JD028674, 2018.

Urbanek, B., Groß, S., Schäfler, A., and Wirth, M.: Determining stages of cirrus evolution: a cloud classification scheme, Atmos. Meas. Tech., 10, 1653-1664, https://doi.org/10.5194/amt10-1653-2017, 2017.

Urbanek, B., Groß, S., Wirth, M., Rolf, C., Krämer, M., and Voigt, C.: High Depolarization Ratios of Naturally Occurring Cirrus Clouds Near Air Traffic Regions Over Europe, Geophys. Res. Lett., 45, 13166-13172, https://doi.org/10.1029/2018GL079345, 2018.

Vali, G., DeMott, P. J., Möhler, O., and Whale, T. F.: Technical Note: A proposal for ice nucleation terminology, Atmos. Chem. Phys., 15, 10263-10270, https://doi.org/10.5194/acp-15-102632015, 2015.

Vogel, B., Günther, G., Müller, R., Grooß, J.-U., Afchine, A., Bozem, H., Hoor, P., Krämer, M., Müller, S., Riese, M., Rolf, C., Spelten, N., Stiller, G. P., Ungermann, J., and Zahn, A.: Longrange transport pathways of tropospheric source gases originating in Asia into the northern lower stratosphere during the Asian monsoon season 2012, Atmos. Chem. Phys., 16, 15301-15325, https://doi.org/10.5194/acp-16-15301-2016, 2016.

Voigt, C., Schumann, U., Minikin, A., Abdelmonem, A., Afchine, A., Borrmann, S., Boettcher, M., Bucuchholz, B., Bugliaro, L., Costa, A., Curtius, J., Dollner, M., Doernbrack, A., Dreiling, V., Ebert, V., Ehrlich, A., Fix, A., Forster, L., Frank, F., Fuetterer, D., Giez, A., Graf, K., Grooss, J.-U., Gross, S., Heimerl, K., Heinold, B., Hueneke, T., Jaervinen, E., Jurkat, T., Kaufmann, S., Kenntner, M., Klingebiel, M., Klimach, T., Kohl, R., Krämer, M., Krisna, T. C., Luebke, A., Mayer, B., Mertes, S., Molleker, S., Petzold, A., Pfeilsticker, K., Port, M., Rapp, M., Reutter, P., Rolf, C., Rose, D., Sauer, D., Schaefer, A., Schlage, R., Schnaiter, M., Schneider, J., Spelten, N., Spichtinger, P., Stock, P., Walser, A., Weigel, R., Weinzierl, B., Wendisch, M., Werner, F., Wernli, H., Wirth, M., Zahn, A., Ziereis, H., and Zöger, M.: ML-Cirrus the airborne experiment on natural cirrus and contrail cirrus with the high-altitude long-range research aircraft HALO, B. Am. Meteorol. Soc., 98, 271-288, https://doi.org/10.1175/BAMS-D-15$00213.1,2017$.

Wall, C. J., Norris, J. R., Gasparini, B., Smith, W. L., J., Thieman, M. M., and Sourdeval, O.: Observational Evidence that Radiative Heating Modifies the Life Cycle of Tropical Anvil Clouds, J. Climate, 33, 1-68, https://doi.org/10.1175/JCLI-D-20-0204.1, 2020.

Wendisch, M., Yang, P., and Pilewskie, P.: Effects of ice crystal habit on thermal infrared radiative properties and forcing of cirrus, J. Geophys. Res., 112, D8201, https://doi.org/10.1029/2006JD007899, 2007.
Wendisch, M., Poeschl, U., Andreae, M. O., Machado, L. A. T., Albrecht, R., Schlager, H., Rosenfeld, D., Martin, S. T., Abdelmomonem, A., Afchine, A., Araujo, A. C., Artaxo, P., Aufmhoff, H., Barbosa, H. M. J., Borrmann, S., Braga, R., Buchholz, B., Cecchini, M. A., Costa, A., Curtius, J., Dollner, M., Dorf, M., Dreiling, V., Ebert, V., Ehrlich, A., Ewald, F., Fisch, G., Fix, A., Frank, F., Futterer, D., Heckl, C., Heidelberg, F., Hueneke, T., Jakel, E., Jarvinen, E., Jurkat, T., Kanter, S., Kaestner, U., Kenntner, M., Kesselmeier, J., Klimach, T., Knecht, M., Kohl, R., Koelling, T., Krämer, M., Krueger, M., Krisna, T. C., Lavric, J. V., Longo, K., Mahnke, C., Manzi, A. O., Mayer, B., Mertes, S., Minikin, A., Molleker, S., Munch, S., Nillius, B., Pfeilsticker, K., Pohlker, C., Roiger, A., Rose, D., Rosenowow, D., Sauer, D., Schnaiter, M., Schneider, J., Schulz, C., de Souza, R. A. F., Spanu, A., Stock, P., Vila, D., Voigt, C., Walser, A., Walter, D., Weigel, R., Weinzierl, B., Werner, F., Yamasoe, M. A., Ziereis, H., Zinner, T., and Zoeger, M.: ACRIDICON-CHUVA CAMPAIGN Studying Tropical Deep Convective Clouds and Precipitation over Amazonia Using the New German Research Aircraft HALO, B. Am. Meteorol. Soc., 97, 1885-1908, https://doi.org/10.1175/BAMS-D-14$00255.1,2016$.

Wernli, H., Boettcher, M., Joos, H., Miltenberger, A. K., and Spichtinger, P.: A trajectory-based classification of ERA-Interim ice clouds in the region of the North Atlantic storm track, Geophys. Res. Lett., 43, 6657-6664, https://doi.org/10.1002/2016GL068922, 2016.

Wolf, V., Kuhn, T., Milz, M., Voelger, P., Krämer, M., and Rolf, C.: Arctic ice clouds over northern Sweden: microphysical properties studied with the Balloon-borne Ice Cloud particle Imager B-ICI, Atmos. Chem. Phys., 18, 17371-17386, https://doi.org/10.5194/acp-18-17371-2018, 2018.

Wolf, V., Kuhn, T., and Krämer, M.: On the dependence of cirrus parametrizations on the cloud origin, Geophys. Res. Lett., 46, 12565-12571, https://doi.org/10.1029/2019GL083841, 2019.

Woods, S., Lawson, R. P., Jensen, E., Bui, T. P., Thornberry, T., Rollins, A., Pfister, L., and Avery, M.: Microphysical Properties of Tropical Tropopause Layer Cirrus, J. Geophys. Res.-Atmos., 123, 6053-6069, https://doi.org/10.1029/2017JD028068, 2018.

Yang, Q., Fu, Q., and Hu, Y.: Radiative impacts of clouds in the tropical tropopause layer, J. Geophys. Res.-Atmos., 115, D00H12, https://doi.org/10.1029/2009JD012393, 2010.

Zondlo, M. A., Paige, M. E., Massick, S. M., and Silver, J. A.: Vertical cavity laser hygrometer for the National Science Foundation Gulfstream-V aircraft, J. Geophys. Res., 115, D02309, https://doi.org/10.1029/2010JD014445, 2010. 